THE ROLE OF SOIL STIFFNESS IN REVERSE FAULT RUPTURE PROPAGATION

\author{
A Thesis \\ presented to \\ the Faculty of California Polytechnic State University, \\ San Luis Obispo
}

In Partial Fulfillment
of the Requirements for the Degree
Master of Science in Civil and Environmental Engineering

by

Moises Ivan Buelna

December 2017 
(C) 2017

Moises Ivan Buelna ALL RIGHTS RESERVED 
COMMITTEE MEMBERSHIP

TITLE: $\quad$ The Role of Soil Stiffness in Reverse Fault Rupture Propagation

AUTHOR: $\quad$ Moises Ivan Buelna

DATE SUBMITTED: $\quad$ December 2017

COMMITTEE CHAIR: Robb Eric S. Moss, Ph.D., P.E.

Professor of Civil and Environmental Engineering

COMMITTEE MEMBER: $\quad$ Garrett Hall, Ph.D., P.E.

Professor of Civil and Environmental Engineering

COMMITTEE MEMBER: Stephen Klisch, Ph.D.

Professor of Mechanical Engineering 


\title{
ABSTRACT \\ The Role of Soil Stiffness in Reverse Fault Rupture Propagation \\ Moises Buelna
}

\begin{abstract}
A nonlinear Mohr-Coulomb constitutive model with a strain dependent yield surface and nonassociated flow was employed to study the plastic soil properties which affect the rate of surface fault rupture propagation in reverse events. These numerical simulations show a trend for soils with higher stiffness to have a higher rate of rupture propagation. Additionally the study shows the effects of strain softening and hardening on the rate of rupture propagation. Soils which strain harden exhibiting ductile behavior typically require more basal offset to rupture to the surface than soils which strain soften exhibiting brittle behavior. These results agree with our previous fault box studies, which showed that soils with higher near surface shear wave velocity were more likely to propagate rupture to the surface for a given reverse event. The numerical modeling allowed for a more comprehensive evaluation of material types and fault angles than the fault box, and provided confidence in these findings.
\end{abstract}

Keywords: Fault Rupture, Mohr-Coulomb Failure, Soil Plasticity 


\section{ACKNOWLEDGMENTS}

I would like to thank Professor Moss for all of his help and continual encouragement throughout the life of this project. He placed a lot of trust in me in allowing me to work independently for so long.

I would also like to thank my committee members Professors Hall and Klisch for their patience with me in delivering a completed draft.

Finally, and most importantly, I would like to thank my friends and family for continually motivating and supporting me. I may never practice as a Civil Engineer, but it is only because of path that I took through Cal Poly that I am able to produce the work I do right now. 


\section{TABLE OF CONTENTS}

LIST OF TABLES. viii

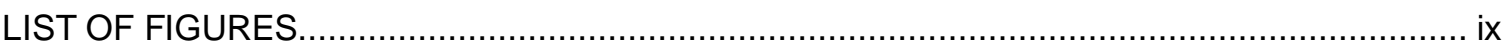

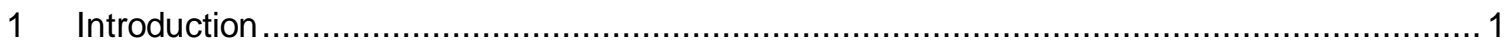

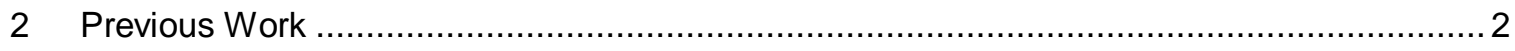

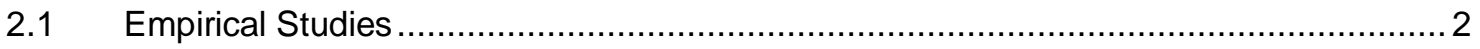

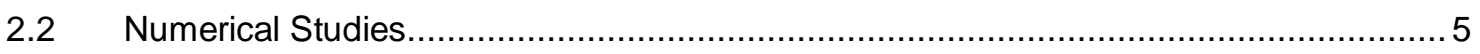

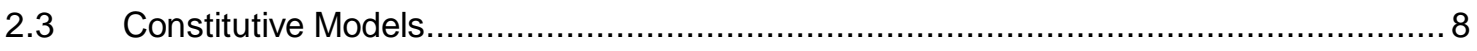

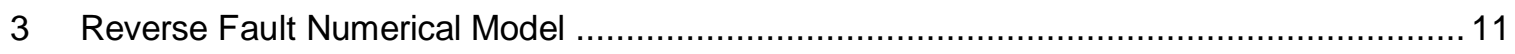

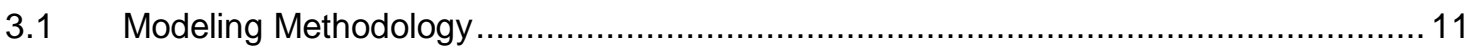

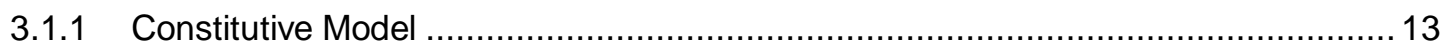

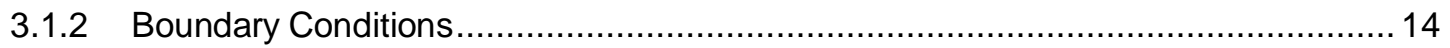

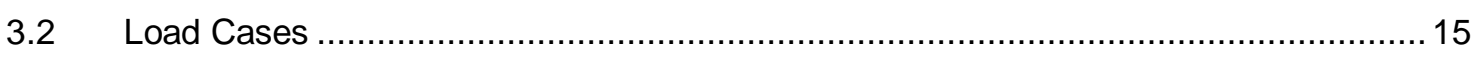

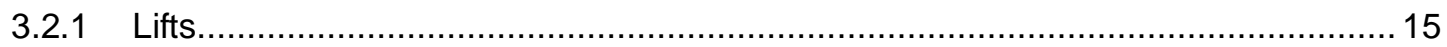

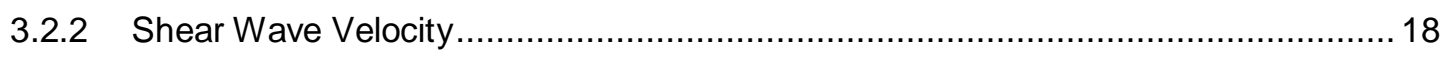

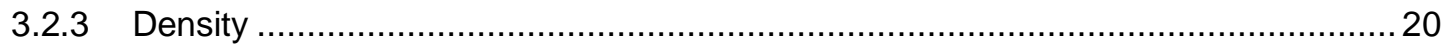

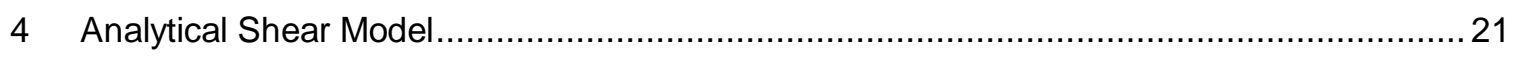

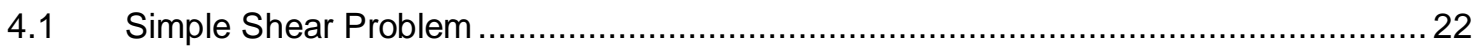

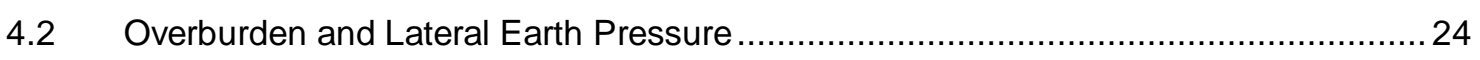

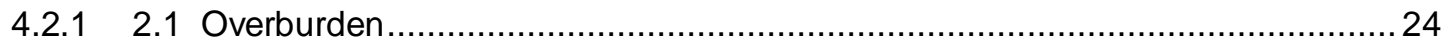

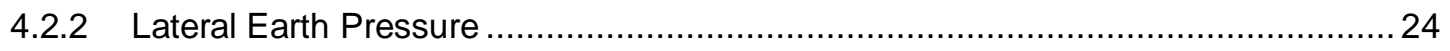

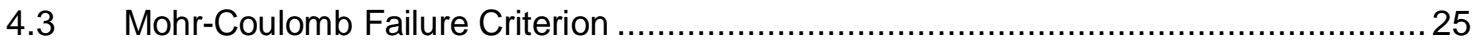

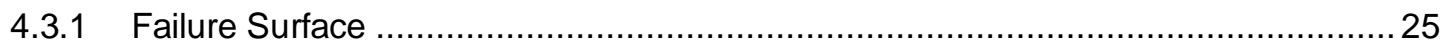




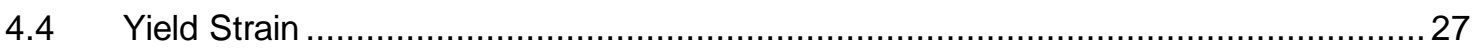

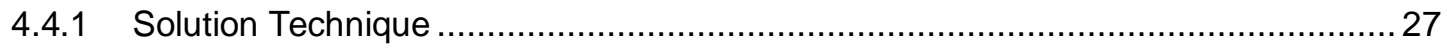

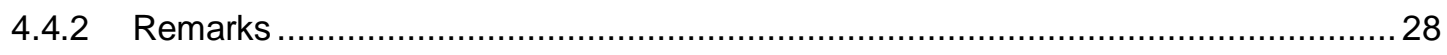

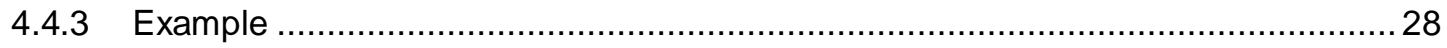

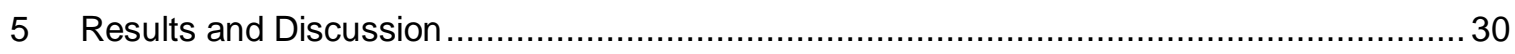

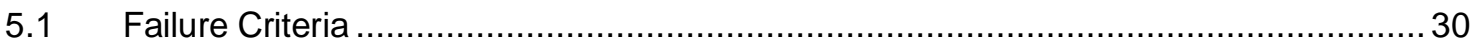

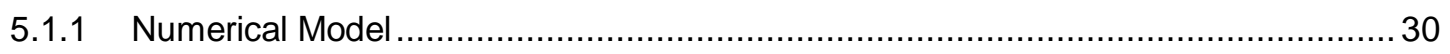

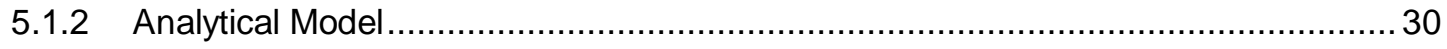

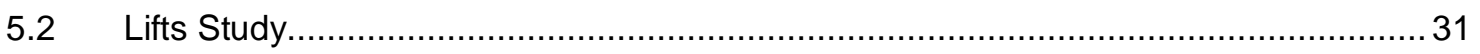

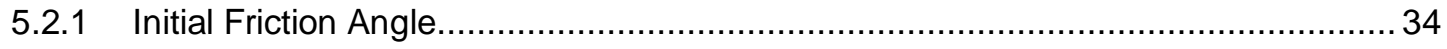

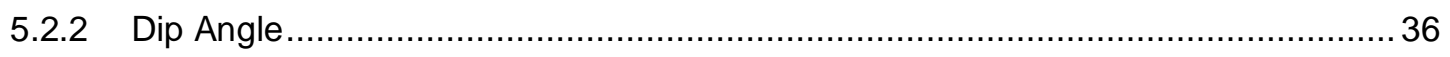

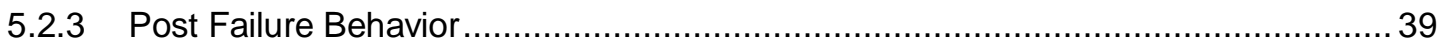

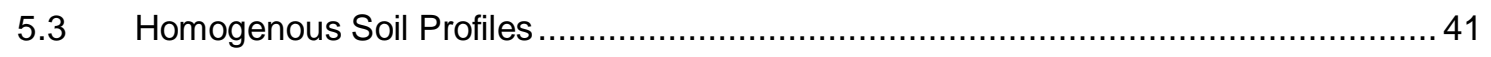

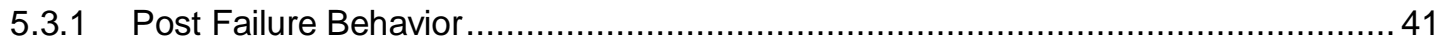

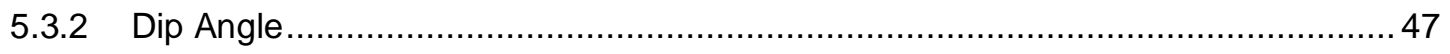

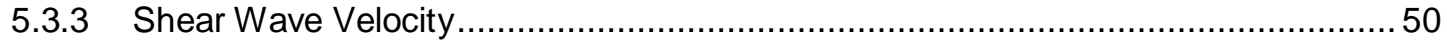

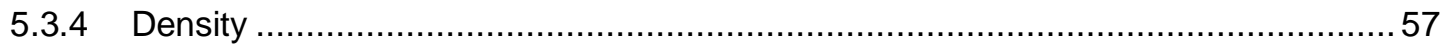

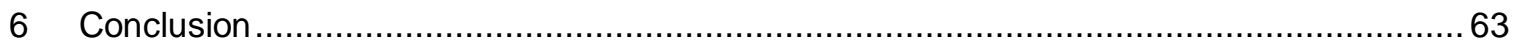

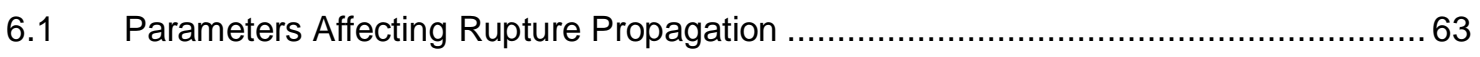

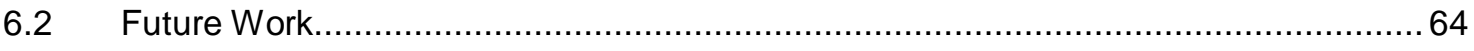

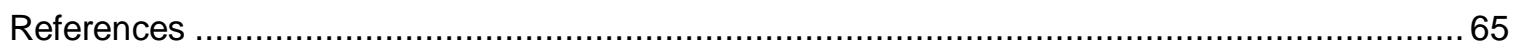




\section{LIST OF TABLES}

Page

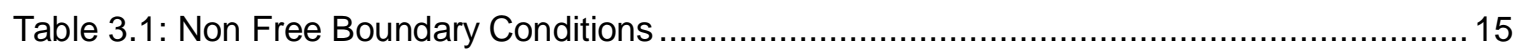

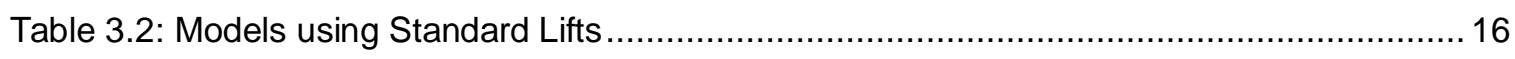

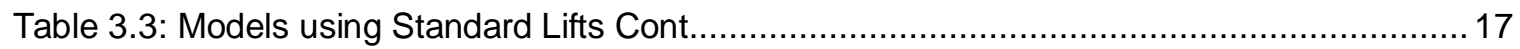

Table 3.4: Models with Homogeneous Lifts, Using Alternate $V s$.......................................... 19

Table 3.5: Models with Homogeneous Lifts, Using Alternate Density with $V s=100 \mathrm{~ms} \ldots \ldots \ldots \ldots . . .20$ 


\section{LIST OF FIGURES}

Page

Figure 2.1: Path of Reverse Fault Rupture through Stiff Earth Materials [6] ............................ 2

Figure 2.2: Path of Reverse Fault Rupture through Ductile Earth Materials [6] ........................ 3

Figure 2.3: Brittle Material under Reverse Fault Movement [7] .......................................... 3

Figure 2.4: Ductile Material under Reverse Fault Movement [7] ........................................... 4

Figure 2.5: FEA Model of a Direct Shear Test [12] ........................................................ 5

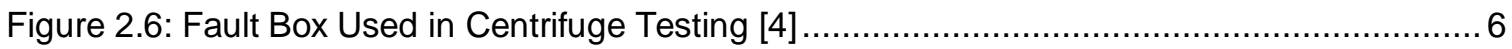

Figure 2.7: Normalized Bedrock Fault Displacement Required for Surface Fault Rupture [14] ..... 7

Figure 2.8: Yield Contour for Hardening Soil Model in Principal Stress Space [15] ..................... 8

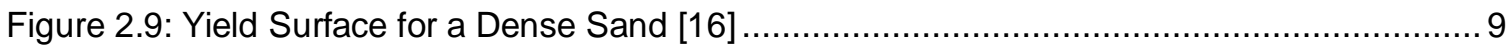

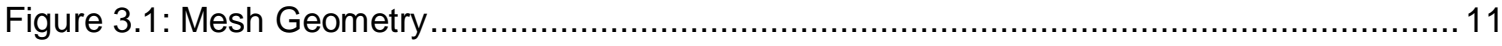

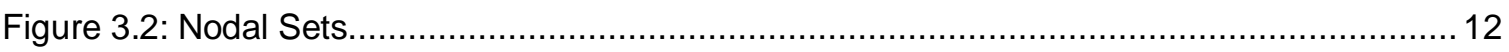

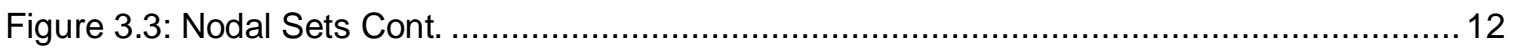

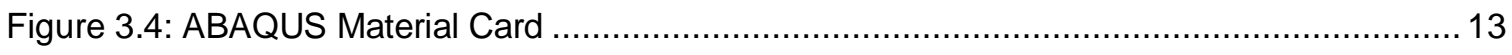

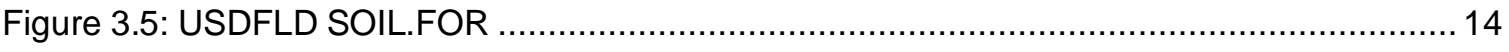

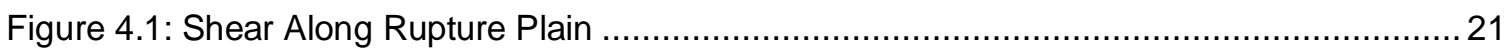

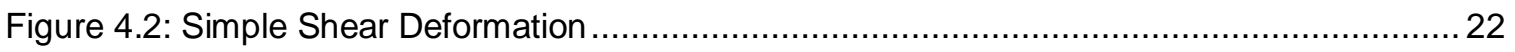

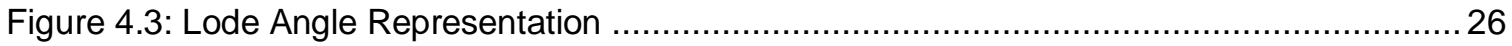

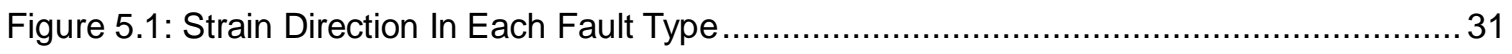

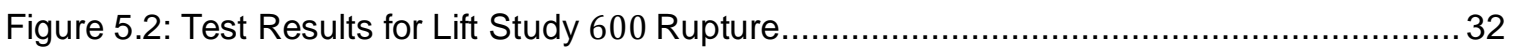

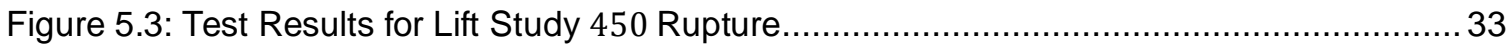

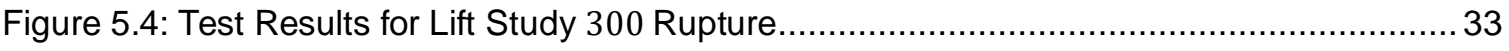

Figure 5.5: Dip 60o, Friction Angle 30o, Perfectly Plastic ................................................... 34

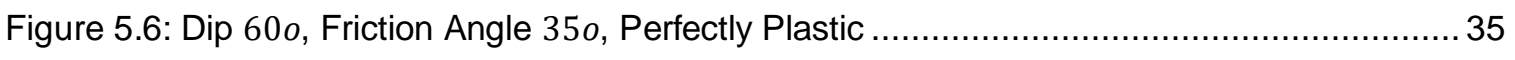

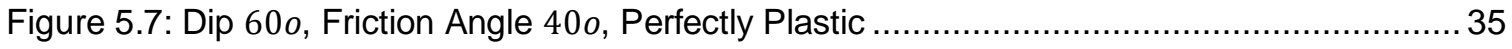

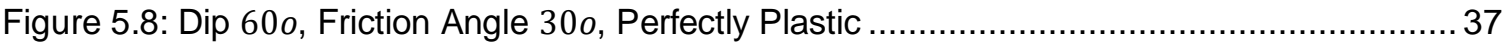

Figure 5.9: Dip 45o, Friction Angle 30o, Perfectly Plastic ................................................. 37 
Figure 5.10: Dip 30o, Friction Angle 30o, Perfectly Plastic

Figure 5.11: Dip 60o, Friction Angle 35o, Softening ..... 39

Figure 5.12: Dip 60o, Friction Angle 35o, Perfectly Plastic ............................................... 40

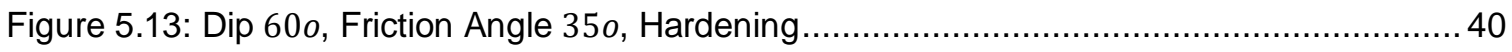

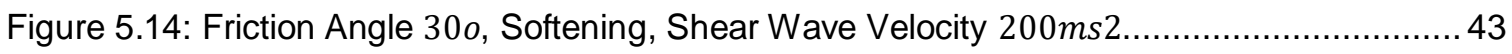

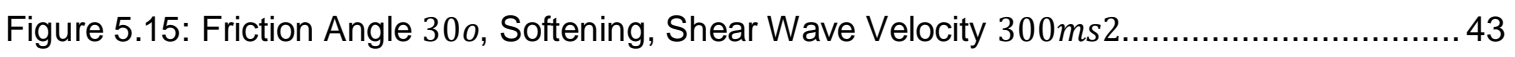

Figure 5.16: Friction Angle 30o, Perfectly Plastic, Shear Wave Velocity $200 \mathrm{~ms} 2 \ldots \ldots \ldots \ldots \ldots \ldots \ldots . . . . . . . . . . .44$

Figure 5.17: Friction Angle 30o, Perfectly Plastic, Shear Wave Velocity $300 \mathrm{~ms} 2 \ldots \ldots \ldots \ldots \ldots \ldots \ldots . . . . . . . . . . .44$

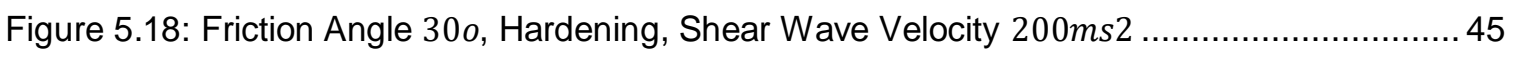

Figure 5.19: Friction Angle 30o, Hardening, Shear Wave Velocity $300 \mathrm{~ms} 2$............................ 45

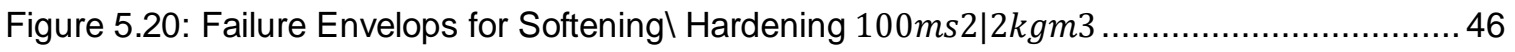

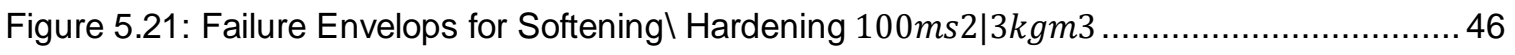

Figure 5.22: Failure Envelops for Softening $\backslash$ Hardening $100 \mathrm{~ms} 2 \mid 4 \mathrm{kgm} 3$................................ 47

Figure 5.23: Failure Envelops for 35o PP 100 ms 2|2kgm3| Dip 60o, 45o, 30o .......................... 48

Figure 5.24: Failure Envelops for 35o PP 100 ms 2|3kgm3| Dip 60o, 45o, 30o .......................... 48

Figure 5.25: Failure Envelops for 35o PP 100ms2|4kgm3| Dip 60o, 45o, 30o ......................... 49

Figure 5.26: Failure Envelops for 35o PP $100-200 m s 2|4 k g m 3|$ Dip $60 o, 45 o, 30 o \ldots \ldots \ldots \ldots \ldots . . . .49$

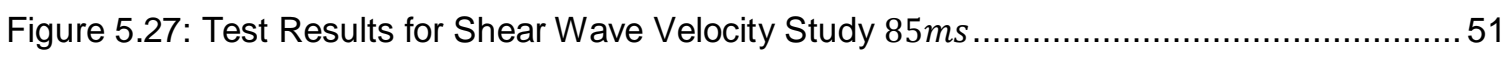

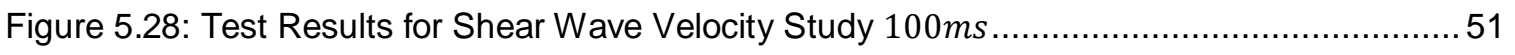

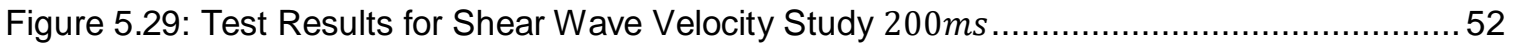

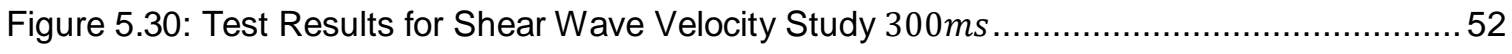

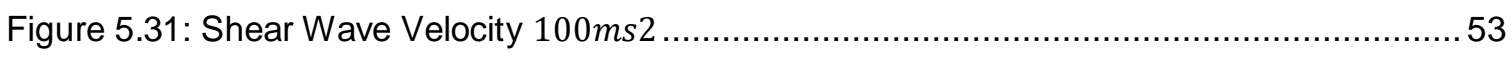

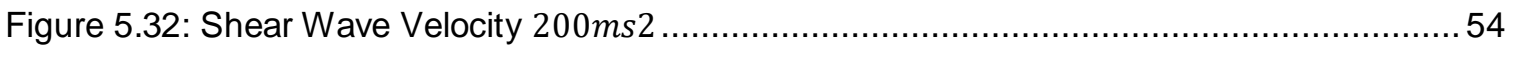

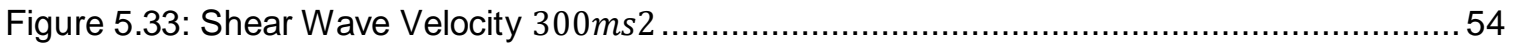

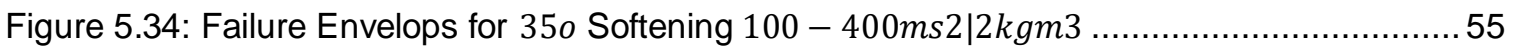

Figure 5.35: Failure Envelops for 350 Perfectly Plastic $100-400 \mathrm{~ms} 2 \mid 2 \mathrm{kgm} 3$......................... 56

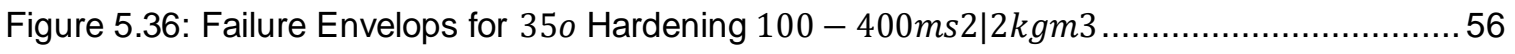

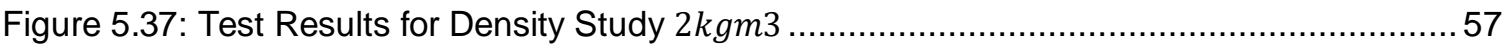




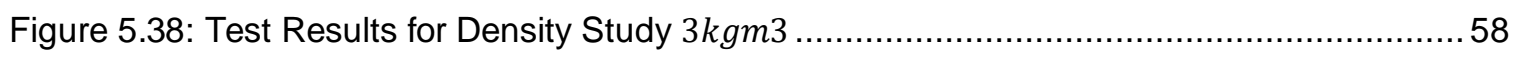

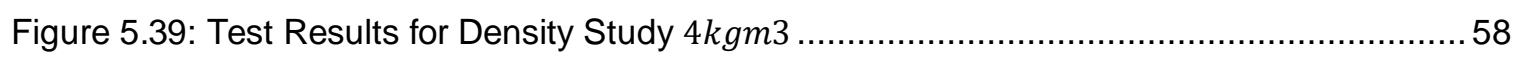

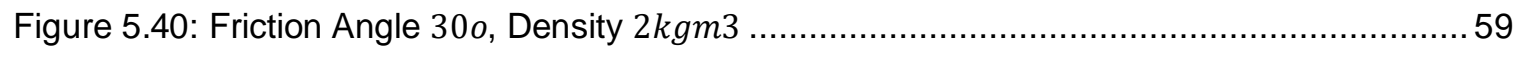

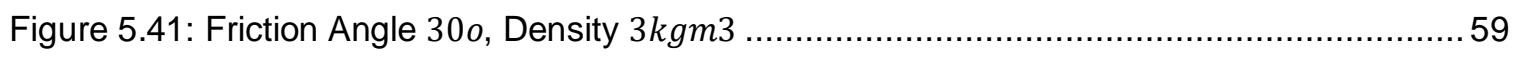

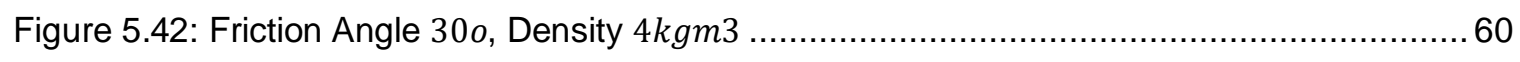

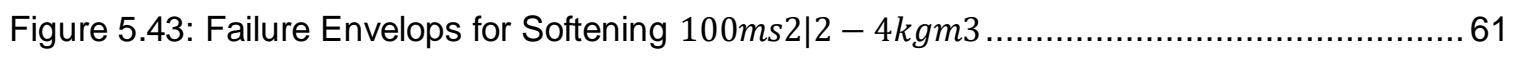

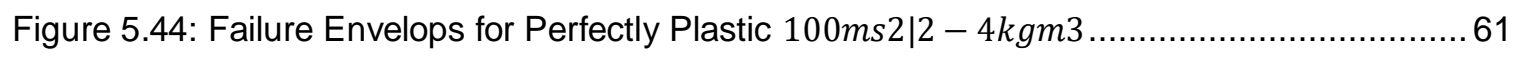

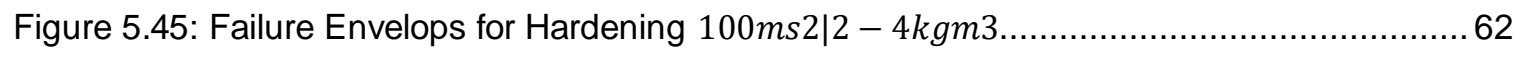




\section{INTRODUCTION}

Fault rupture can pose a threat to engineering structures if the rupture propagates to the ground surface and creates excessive ground deformation. While legislation like the Alquist Priolo Fault Zoning Act [1] attempts to mitigate this risk by prohibiting construction of buildings intended for human occupancy over active faults zones, construction across active faults is not always avoidable for infrastructure such as bridges, roads, and utilities. Current research has detailed the

process of earthquake fault rupture in an attempt to better quantify the risks associated with building across active faults and to establish a methods for practicing engineers to mitigate the risks when engineering structures which may be at risk.

The likelihood of occurrence of surface fault rupture in reverse events given the shear wave velocity of the upper $30 \mathrm{~m}$ of soil is presented in [2]. The researchers found a bifurcation in the soil response to rupture propagation between soils with low or high shear wave velocities. This was attributed to soil stiffness; soils with low shear wave velocities were assumed to be soft and have ductile behavior while soils with higher shear wave velocities were assumed to be stiff with brittle behavior. This ductile v. brittle behavior would explain the difference in the rate of rupture propagation. Further experimental work by [3] supported this by showing an increase in the normalized basal displacement necessary to achieve rupture in both loose $\mathrm{v}$. dense sand and soft v. stiff clay.

The study herein, Chapters $3-6$, aims to identify the mechanisms within the non-linear behavior of soil that affect the rate of surface fault rupture propagation in reverse events through numerical analysis of various soil profiles. A constitutive model adopted from [4], detailed below, is used to conduct a parametric study perturbing soil properties to identify the impact each has on the rate of rupture propagation. This work was conducted in an effort to support the empirical case studies of [2]. 


\section{PREVIOUS WORK}

\subsection{Empirical Studies}

Several field and fault box studies have been performed by others in an attempt to understand rupture behavior in dip slip faults.

Bray [5] surveyed indicative reverse fault rupture field studies and the path of fault rupture, noting its tendency to curve concave to the downthrown block and form secondary faults at steep angles, see Figure 2.1-2. The study concludes that the fault rupture occurs in a narrow shear band and less fault movement is required to rupture through brittle v. ductile material.

\section{LESS OFFSET AT GROUND SURFACE}

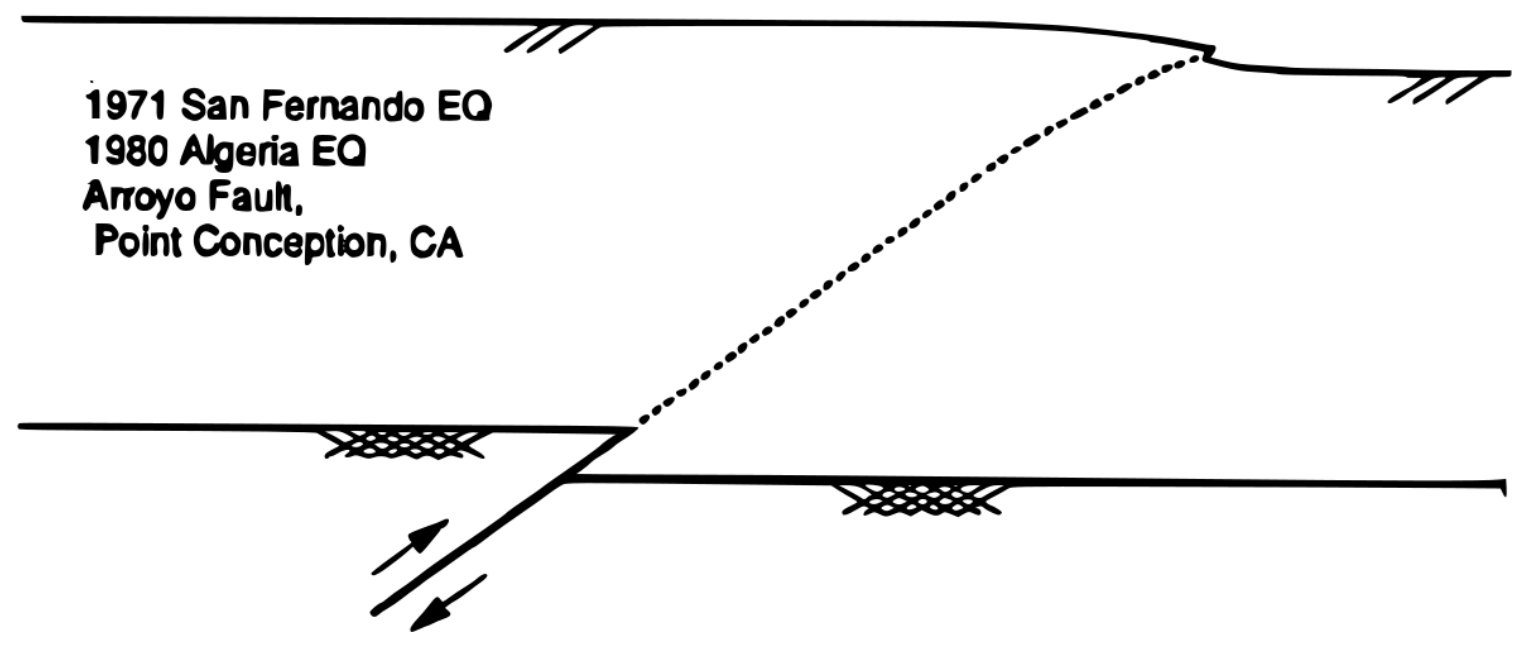

Figure 2.1: Path of Reverse Fault Rupture through Stiff Earth Materials [6] 


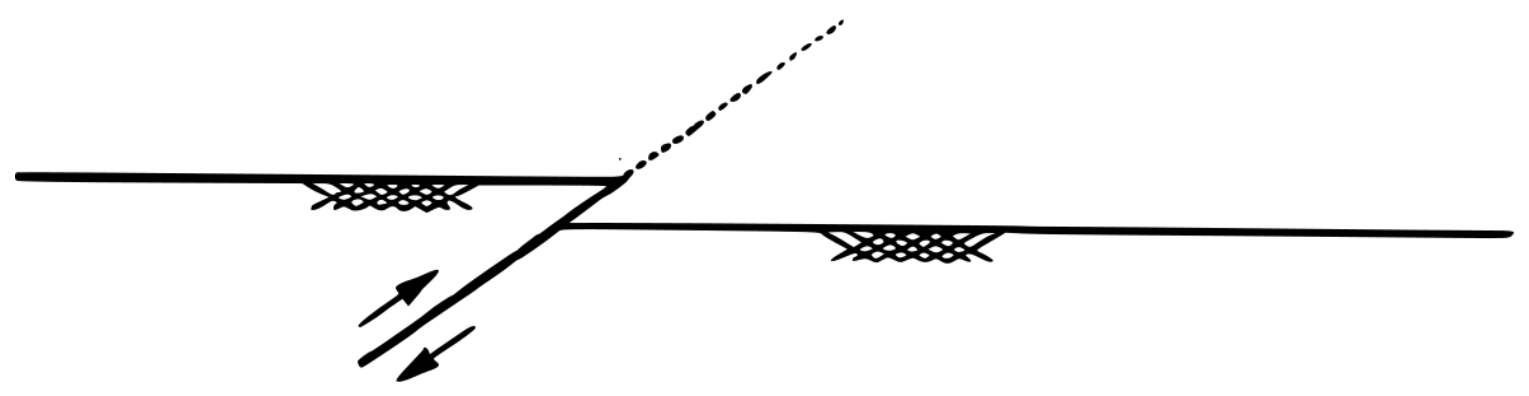

Figure 2.2: Path of Reverse Fault Rupture through Ductile Earth Materials [6]

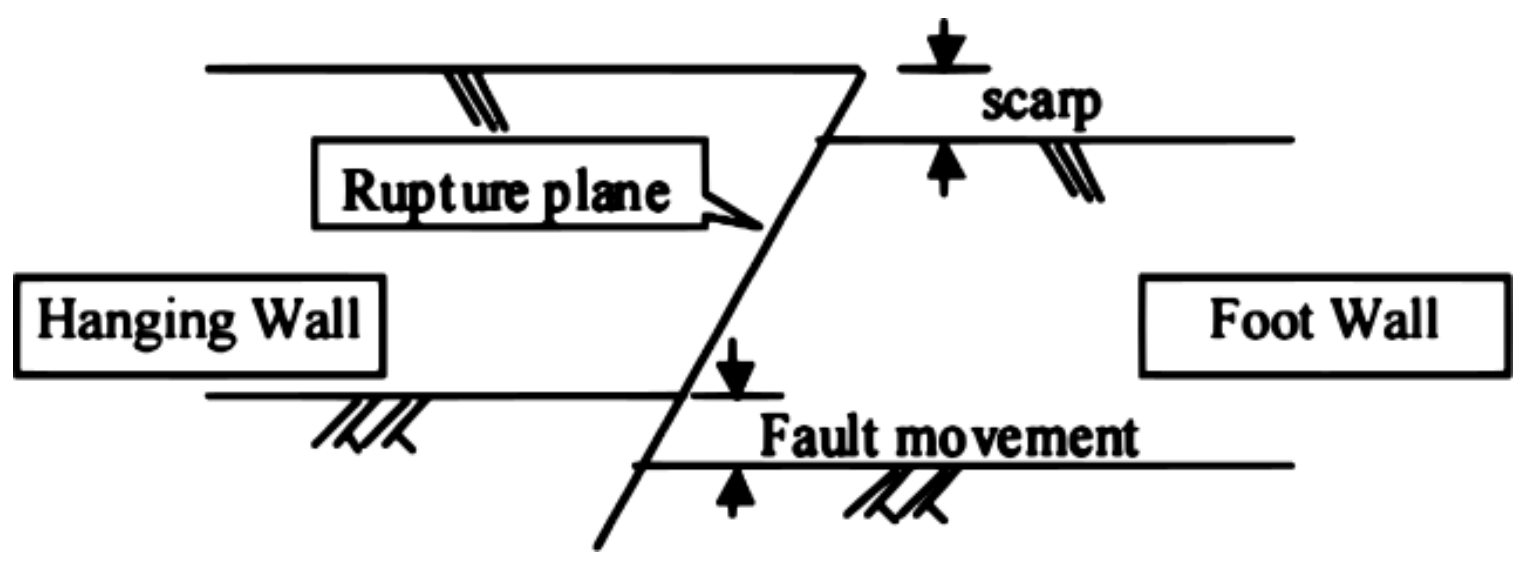

Figure 2.3: Brittle Material under Reverse Fault Movement [7] 


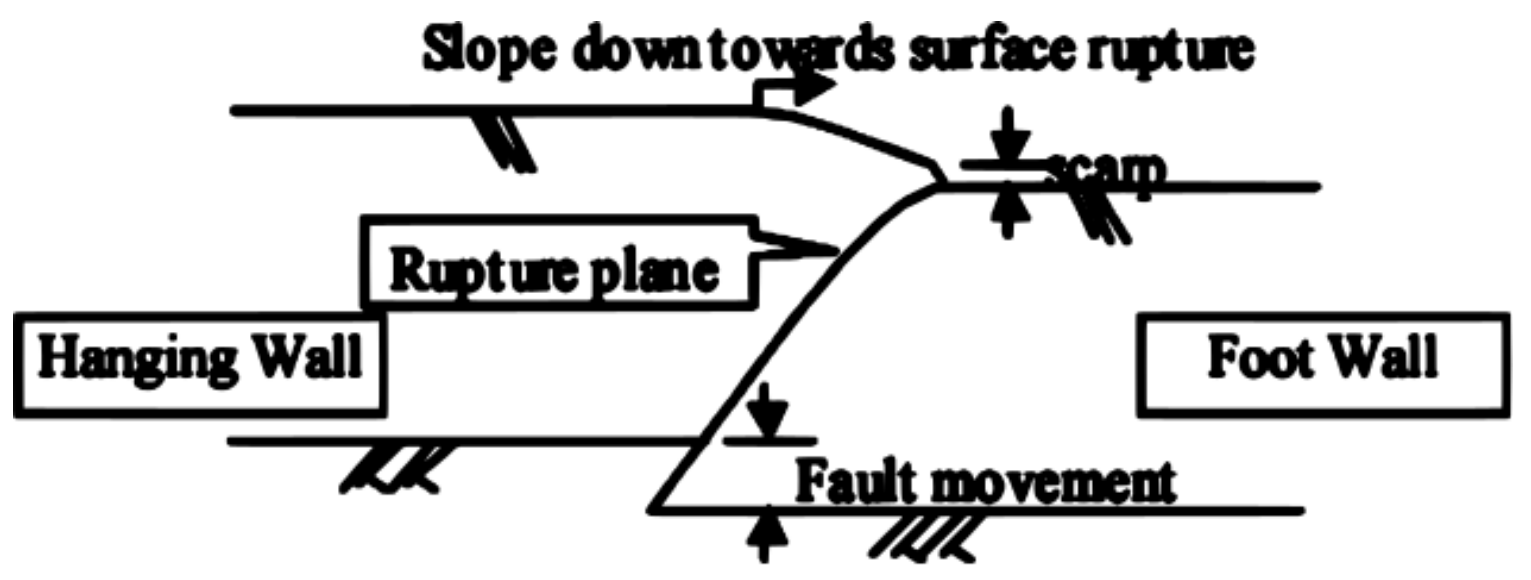

Figure 2.4: Ductile Material under Reverse Fault Movement [7]

Cole and Lade in [8] and [9] respectively performed independent $1 \mathrm{~g}$ fault box studies on sandy soils to evaluate the location of the rupture influence zone through the soil deposit. They were interested in determining whether the stress or velocity characteristics played major roles in determining the location of the surface fault trace. They looked at the effects of the inclination angle on the location of the surface trace and pattern of surface soil deformation. Both studies found that reverse events required more normalized basal displacement.

Roth in [10] conducted centrifuge tests using a scale fault box to study reverse strike events. A centrifuge was used in order to increase the gravity of the sand sample replicating field stress conditions at depth. This method overcomes the effective stress distribution problem present in $1 \mathrm{~g}$ fault studies. The results are similar behavior to $1 \mathrm{~g}$ box studies and show that the inertial effects of fault shearing do not heavily affect surface fault rupture propagation. The shear bands present in the cohesionless materials match the profiles shown in the free field case of the Bransby [11] centrifuge studies done in order to evaluate reverse fault-foundation interaction. 


\subsection{Numerical Studies}

Researchers have employed numerical analysis techniques to validate soil models from lab data to use in studying fault rupture through idealized soil profiles.

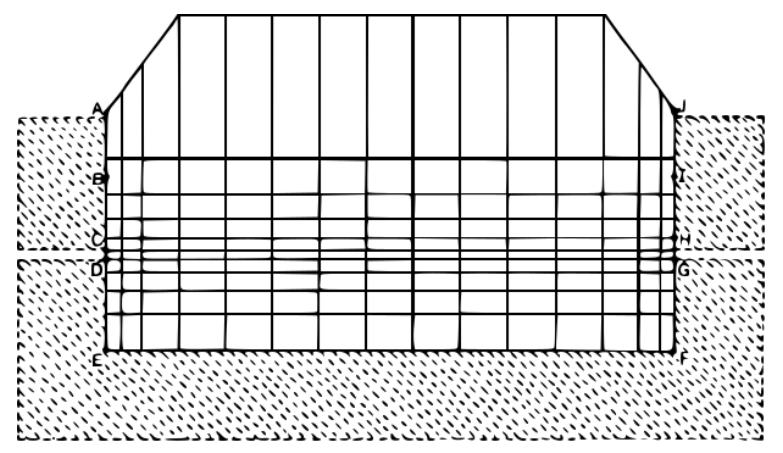

Figure 2.5: FEA Model of a Direct Shear Test [12]

Potts et al. in [13] and [12] studied fault rupture by modeling direct shear tests and conducted 2 case studies using Finite Element Analysis (FEA) to model failure of embankments. They utilized a non-associative elastic plastic strain softening Cam Clay model with a Mohr Coulomb yield surface, with (8) node plane strain elements. They found that direct shear tests mimic simple shear, and soils with brittle behavior had more uniform stress profiles. Their embankment studies used a nonlinear elastic plastic Mohr Coulomb constitutive model in the FEA code ICFEP, also employing (8) node plane strain elements. They modeled the elastic modulus (E) as a hyperbolic function of fitting parameters and Poisson's ratio $(v)$ as a log function of the stress level. They found that the strain softening behavior of soil influenced the progressive collapse of the embankments.

Bray et al. in [5] used FEA and empirical studies to conclude that the soil failure strain impacts rupture propagation to the surface. They found the amount of base deflection required to propagate rupture to the surface was inversely proportional to the failure strain of the soil. They noted that other surface parameters, lateral earth pressure coefficient, cohesion, Poisson's ratio, 
and initial elastic modulus $\left(K, c, v\right.$, and $\left.E_{\mathrm{i}}\right)$, affect surface fault rupture but not to the extent of failure strain. They employed Duncan hyperbolic strain hardening to model the post yield behavior of cohesive soil and defined failure at $95 \%$ of the residual shear strength. The Duncan model provided good estimates for the drained behavior of clays when compared to lab tests, but assumes the pore pressures mimic lab studies for the undrained response.

Yilmaz and Paolucci [3] looked at the fault-foundation interaction of shallow foundation in undrained soils. They employed the FEA code PLAXIS with an elastic perfectly plastic soil model with a Tresca yield surface using cubic constant strain triangle elements. They defined soil failure at $1 \%$ shear strain, and verified their model by developing an upper bound limit analysis approach using a set of admissible kinematic mechanisms. They found the minimum bearing load required to divert fault rupture around shallow foundations.

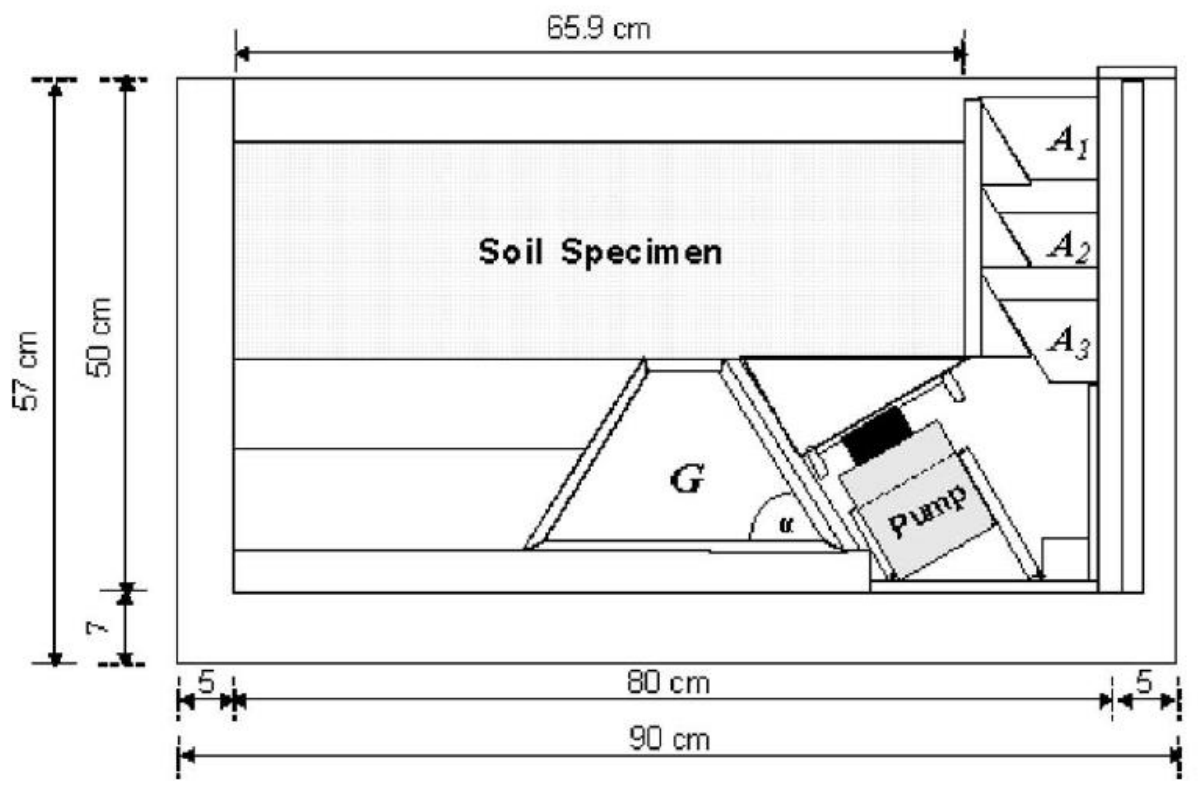

Figure 2.6: Fault Box Used in Centrifuge Testing [4]

Anastasopoulos et al. in [4] studied fault rupture propagation through sand. They utilized FEA with a modified Mohr-Coulomb elastic plastic constitutive model. The model interpolates 
between the initial and residual friction angle $\phi_{m}$ and dilation angle $v$. The results of the numerical models are validated against centrifugal fault box tests with good correlation. The study found $0.75 \%-1 \%$ normalized basal displacement required to rupture dense v. loose sand respectively in normal events but $2 \%-4 \%$ for strike slip events. The researchers concluded that soil ductility influences the rupture propagation rate in loose v. dense sand while active v passive states explains the difference in normal v. reverse events.

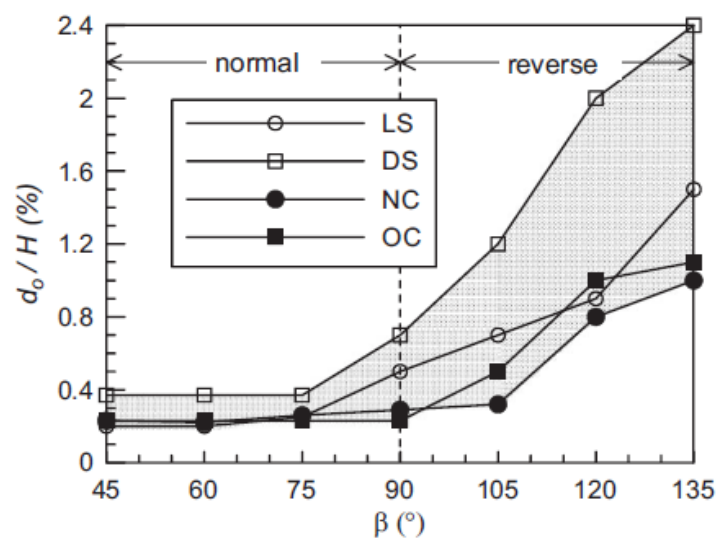

Figure 2.7: Normalized Bedrock Fault Displacement Required for Surface Fault Rupture [14]

In [14] Loukidis et al. studied fault rupture through uniform soil profiles. They employed a similar Modified Mohr Coulomb model as described in [4] but used the Finite Difference code FLAC to perform the analyses. They looked at a loose and dense sand, and a normally and over consolidated clay across several inclination angles for both normal and reverse faults. They found little difference in the normalized basal displacement required to achieve rupture between all the soils in normal events. Surprisingly they found slightly more displacement required for an over consolidated clay v. a normally consolidated clay and much greater displacement required for dense v. loose sands for most angles in reverse strike events, contrary to the results of previous works, see Figure 2.7. 


\subsection{Constitutive Models}

Several advanced constitutive models have been developed for soils using fitting parameters derived from standard Geotechnical lab tests.

Lade developed an elasto-plastic constitutive model for cohesionless soils in [9] for use in general 3D stress conditions. The model employs cap plasticity with non-associated plastic flow. The yield cap, which closes the open end of the conical failure surface is a function defined by the first and second stress invariants $I_{1}$ and $I_{2}$. The conical failure surface on the other hand is a function defined by the first and third invariants $I_{1}$ and $I_{3}$. There are however several deficiencies with the model. It does not predict plastic stresses during proportional loading or account for the transition between a loose and dense state, and it predicts straight line failure curves for sands, while testing shows the curves to be slightly curved.

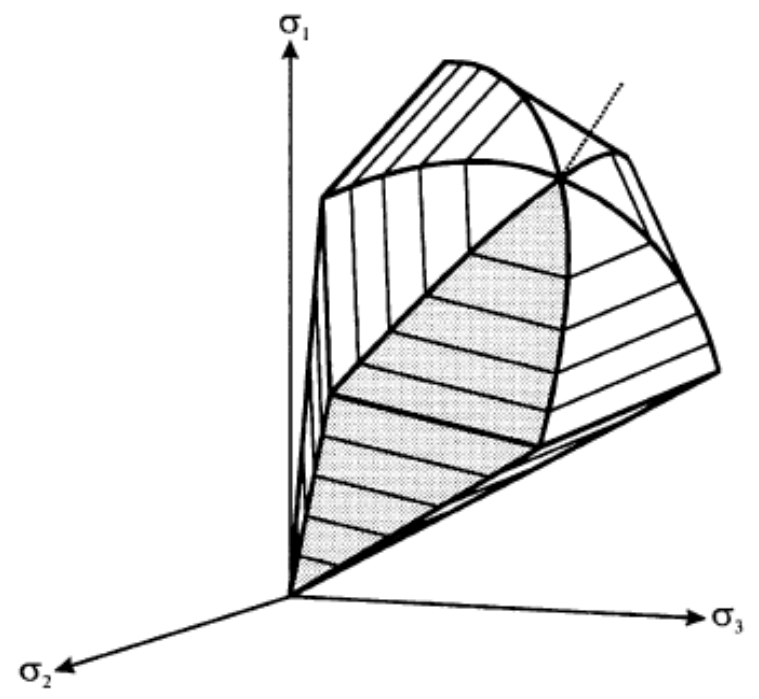

Figure 2.8: Yield Contour for Hardening Soil Model in Principal Stress Space [15]

In [15] Schanz et al., develop the hardening soil model deployed in the FEA code PLAXIS. The model is an elasto-plastic model with mutiple curved yield surfaces employing cap plasticity. The non-associative flow rule is a function of the critical state friction angle $\left(\phi_{C S}\right)$ and mobilized 
friction angle $\left(\phi_{m}\right)$. The secant Young's modulus $\left(E_{50}\right)$ is used as the reference with $E_{\text {oed }}$, the primary loading Young's modulus, a hyperbolic function of stress and friction angle. The model is calibrated with compressive triaxial tests and implemented in PLAXIS.

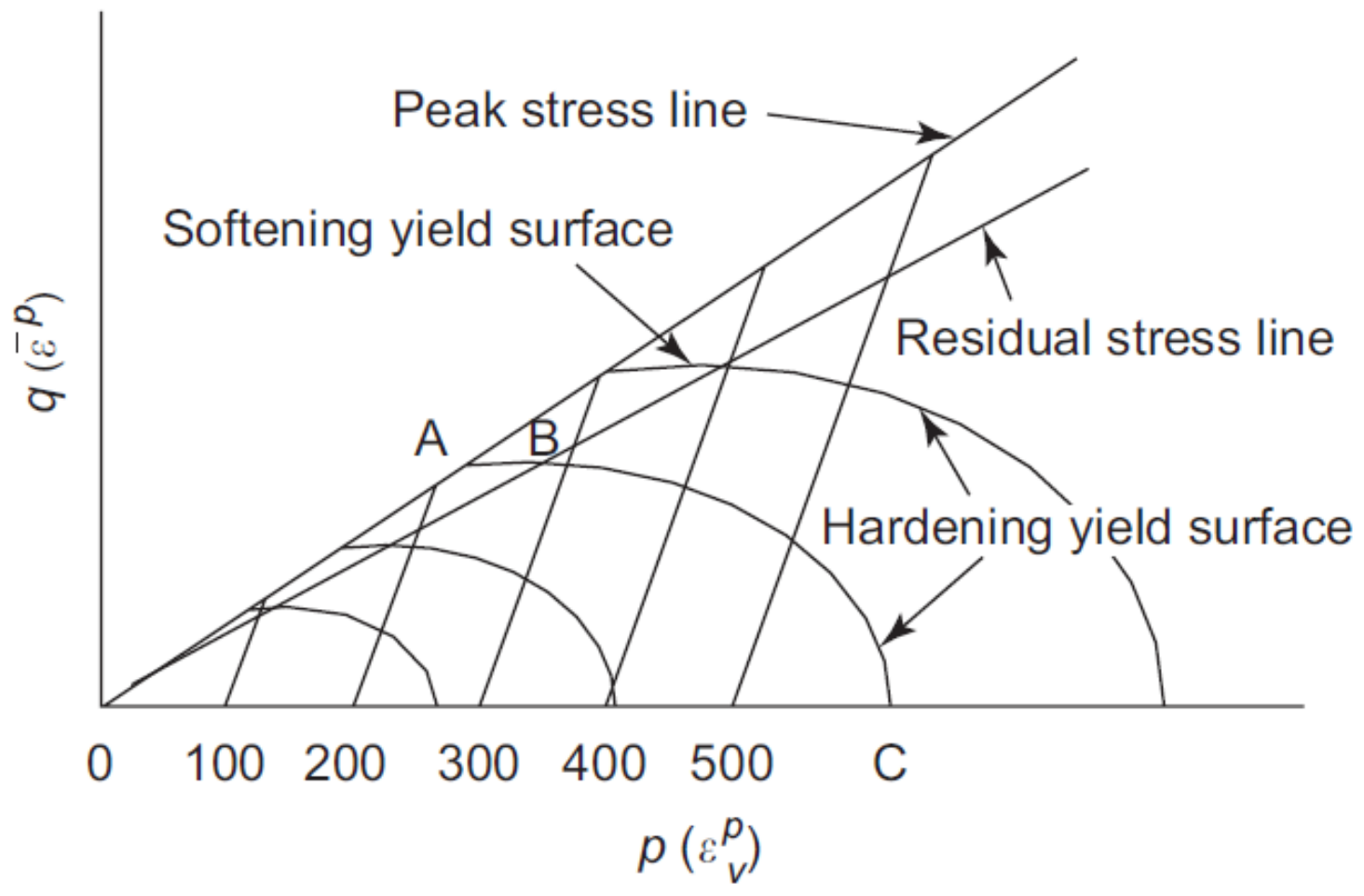

Figure 2.9: Yield Surface for a Dense Sand [16]

Guo and Li develop an elasto-plastic strain softening model for geotechnical materials in [16]. The model modifies the Tsinghua Elastic Plastic model with strain softening behavior. The 12 model parameters can be developed from triaxial shearing and isotropic compression tests. The model is able to capture dilatancy behaviors during shear loading. Validation tests showed good correlation between experimental settlement tests.

Desai et al. present a methodology in [17] for developing and verifying general soil constitutive models within the framework of general plasticity theory. The Hierarchical approach uses a basic model, isotropic, isotropic hardening, with associative flow $\delta_{0}$ which can be modified 
into more advanced models, such as adding non associative flow $\delta_{1}$, by perturbing the model with the addition of a function increasing the complexity. The nomenclature $\delta_{0+R}$ describes the degree of complexity where $\mathrm{R}$ is the number of perturbations. Wang et al. [18] and Liu et al. [19] develop $\delta_{1}$ hierarchical single surface models for geotechnical materials with parameters developed from triaxial tests. Liu defines the model so it can be presented in p'-q space and calibrates it using Eastern Scheldt sand, while Wang implements the standard $\delta_{1}$ model in ABAQUS as a 3D user defined material (UMAT) subroutine and calibrates the model with Leighton Buzzard sand. Both Wang and Liu add non-associative flow to the basic $\delta_{0}$ model by perturbing the yield function. Both models show good correlation with lab tests. 


\section{REVERSE FAULT NUMERICAL MODEL}

\subsection{Modeling Methodology}

The non-linear implicit models used for this investigation are based on those created and validated by Anastasopoulos in [4] [20] to study fault rupture propagation through sand. The only modifications made were to the constitutive model parameters and enforced displacement boundary conditions. Figure 3.1 shows an illustration of the model mesh. The solver used was ABAQUS 6.13 [21].

The soil profile is $40 \mathrm{~m}$ deep and $160 \mathrm{~m}$ wide with the model origin located at the top center. For elements $E,\{E \mid-80 \leq X \geq-40,40 \leq X \geq 80\}$ the mesh is $2 m$ long by $1 m$ deep, for $\{E \mid-$ $40 \leq X \geq 40$ \} the mesh is $1 \mathrm{~m}$ long by $1 \mathrm{~m}$ deep. This mesh geometry is identical to what was previously used and validated and so no further convergence study was performed.

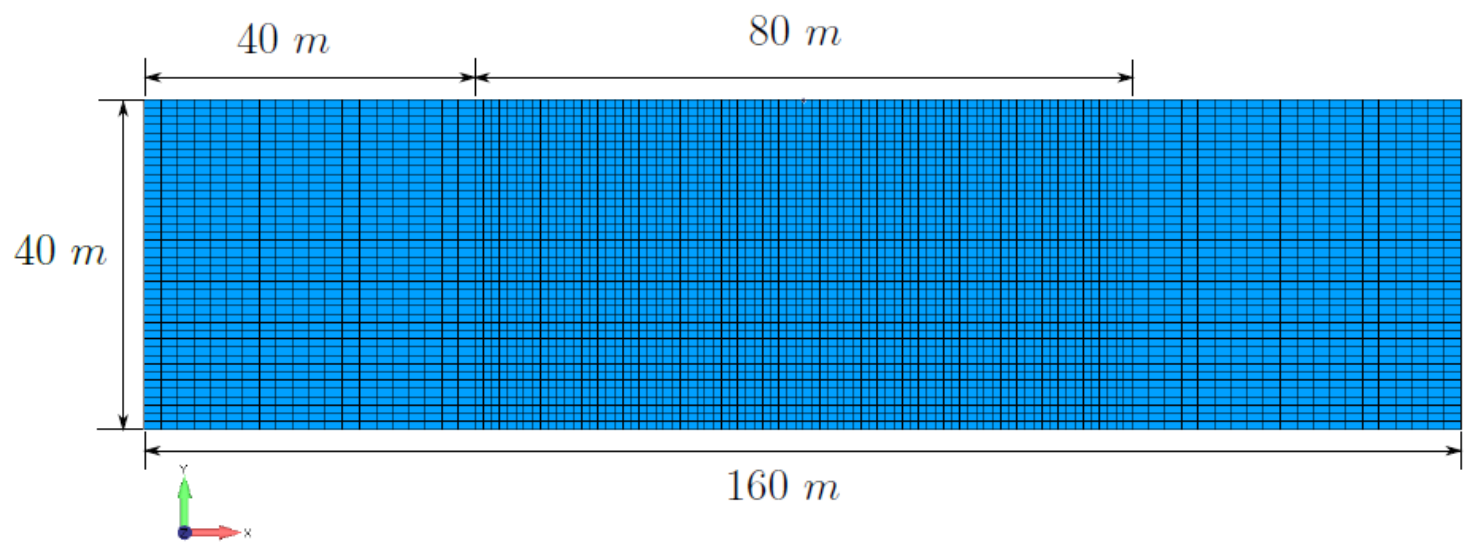

Figure 3.1: Mesh Geometry

The soil profile is separated into 8 lifts labeled "MSOIL1" - "MSOIL8", each $4 m$ deep, with MSOIL1 as the top lift and MSOIL8 as the bottom lift. The model is setup with 2 configurations of these lifts, "Lifts" which assigns an increasing elastic modulus with depth, and "Homogeneous" which uses the same elastic modulus for all 8 lifts. The lifts configuration is what was previously validated in the literature. 
The model defines (5) nodal sets labeled "NBASEL", "NBASER", "NSIDEL", "NSIDER", and "NOUT", and (1) element set, "ELSOUT". NBASEL are the nodes along the bottom left of the model, for nodes $\mathrm{N},\{N \mid Y=-40,-80 \leq X \geq-21\}$; NBASER are the nodes along the bottom right of the model, $\{N \mid Y=-40,-22 \leq X \geq 80\}$; NSIDEL are the nodes along the left side of the profile, $\{N \mid X=-80,-40 \leq Y \geq 0\} ;$ NSIDER are the nodes along the right side of the profile, $\{N \mid X=$ $80,-40 \leq Y \geq 0\} ;$ and NOUT are the nodes along the top surface of the model, $\{N \mid Y=0,-80 \leq$ $X \geq 80\}$. These sets are used to define boundary conditions as well as well as for output sets.

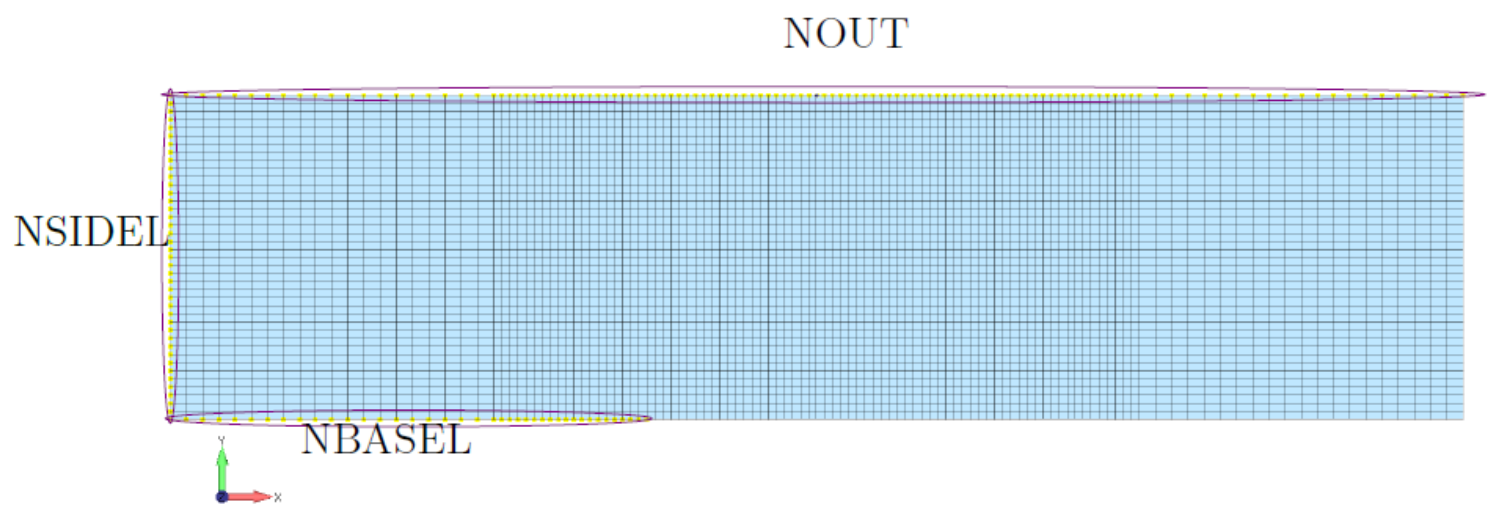

Figure 3.2: Nodal Sets

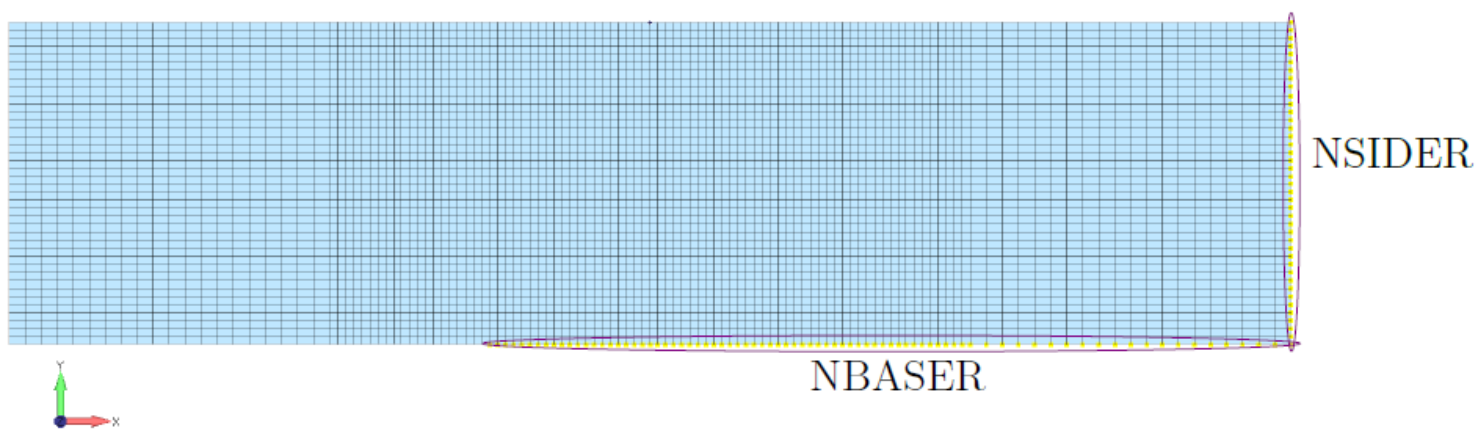

Figure 3.3: Nodal Sets Cont. 


\subsubsection{Constitutive Model}

The constitutive model used is non-linear elastic plastic, with a Mohr-Coulomb yield surface, and a function dependent softening/hardening scheme. The elastic properties are defined by density $(\rho)$, Young's Modulus ( $E$ ), and Poisson's Ratio $(v)$. The Mohr-Coulomb yield surface is defined using Friction Angle $(\theta)$, Dilation Angle $(\phi)$, a Cohesion Yield Stress, and Field Variables. The Field Variables define $(\theta)$ and $(\phi)$ for initial and residual conditions. Figure 3.4 shows a sample of material card as written in the ABAQUS input file.

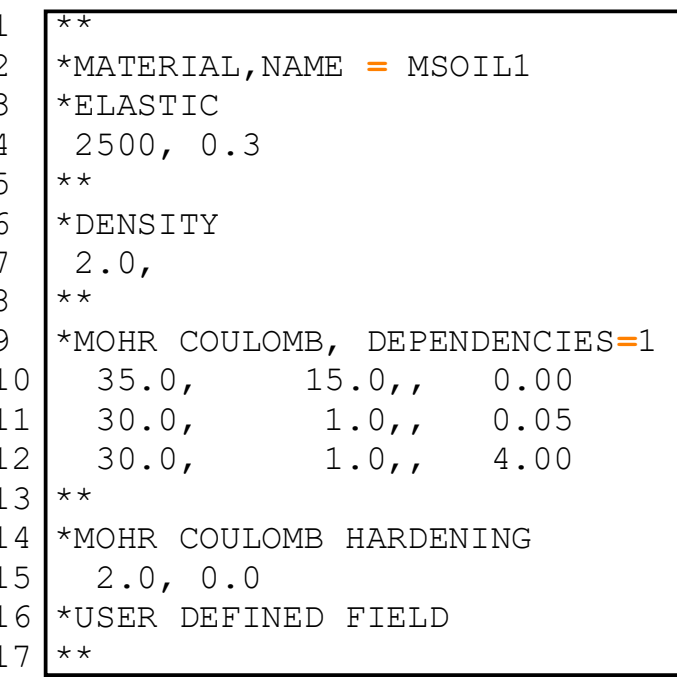

Figure 3.4: ABAQUS Material Card

The hardening scheme is defined by a user defined field subroutine, USDFLD programmed in FORTRAN which uses the principle shear stress $S 12$ from the current analysis step to interpolate $(\theta)$ and $(\phi)$ based on the Field Variables. This USDFLD subroutine, code in Figure 3.5, was provided by Anastasopoulos for use in this study. 


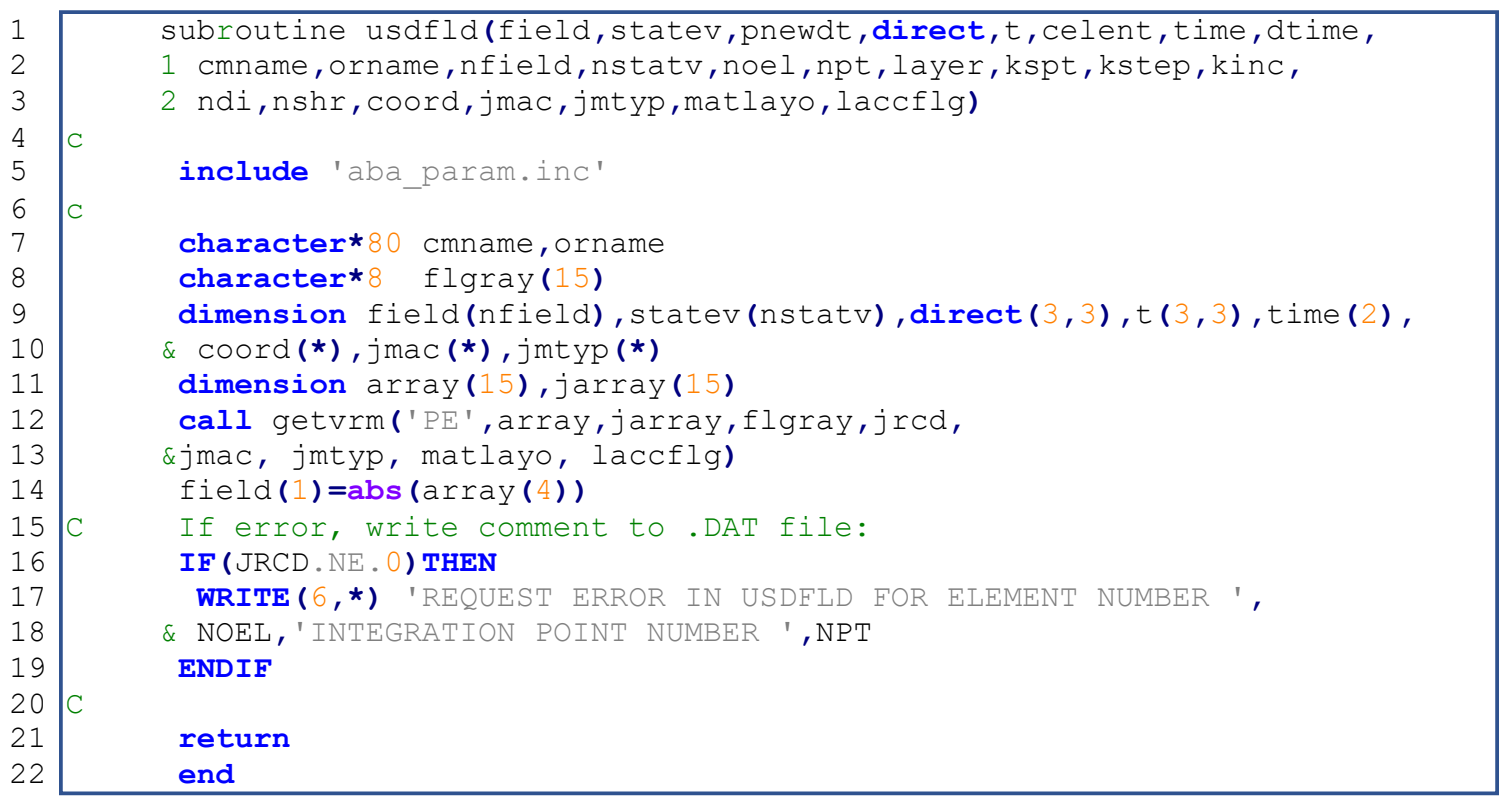

Figure 3.5: USDFLD SOIL.FOR

\subsubsection{Boundary Conditions}

The Boundary conditions are applied to nodal sets NBASER, NBASEL, NSIDER, and NSIDEL. There are 2 phases to loading steps, an initial Geostatic step, and $\left(N_{s}-1\right)$ enforced displacement load sets, where $N_{s}$ is the total number of steps in the analysis; the boundary conditions vary between the Geostatic step and the load steps. The non free Degrees of Freedom (DOFs) for NBASER and NSIDER remain as zero displacement constraint sets for all steps, the non zero DOFS for NBASEL and NSIDEL are non zero during the load steps, but vary depending on the dip angle being modeled. Table 1 shows the nonzero DOFS for the nodal sets. The loading phase either increased the normalized basal displacement by $1 \%$ or $0.2 \%$ depending on the type of analysis and convergence issues encountered. 
Table 3.1: Non Free Boundary Conditions

\begin{tabular}{ccccc}
\hline STEP & NBASE & NBASEL & NSIDER & NSIDEL \\
\hline 1 & DOF2 & DOF2 & DOF1 & DOF1 \\
$2-N_{s}$ & DOF12 & DOF2 & DOF1 & DOF2 \\
\hline
\end{tabular}

\subsection{Load Cases}

Several parametric studies were performed using a Fontainebleau sand as a base with a constitutive model and mesh provided by Anastasopoulos.

The material properties of the Fontainebleau sand were perturbed for use in parametric studies. These new synthetic soils have properties consistent with the constitutive theory, but may have elastic parameters atypical for terrestrial soils. The goal of these studies is to discover trends for materials which behave in accordance to the above theory. Expanding the range of typical parameters simplified the identification of trends as they are less likely to be the result of numerical error in analysis of soils with only slightly varying properties.

\subsubsection{Lifts}

The first set of models were developed to study the effect that the post failure behavior had on the rate of rupture propagation. The elastic properties, $(E),(v)$, and $(\rho)$ were left unchanged for each lift. Models where created for 3 dip angles $60^{\circ}, 45^{\circ}$, and $30^{\circ}$; various values of initial $(\theta)$; and varying degrees of softening/hardening, difference between initial and residual $(\theta)$. Tables 2 and 3 list the complete list of models studied.

This set of models isolates the changes to those directly impacting the size and shape of the failure surface, by keeping the same elastic properties for each model the stress states should be identical up to the point of initial failure. 
Table 3.2: Models using Standard Lifts

\begin{tabular}{ccccc}
\hline Number & Dip & Initial $\theta$ & Residual $\theta$ & Soil Profile \\
\hline 1 & 60 & 30 & 20 & Lifts \\
2 & 60 & 30 & 25 & Lifts \\
3 & 60 & 30 & 30 & Lifts \\
4 & 60 & 30 & 35 & Lifts \\
5 & 60 & 30 & 40 & Lifts \\
6 & 60 & 35 & 30 & Lifts \\
7 & 60 & 35 & 35 & Lifts \\
8 & 60 & 35 & 40 & Lifts \\
9 & 60 & 40 & 35 & Lifts \\
10 & 60 & 40 & 40 & Lifts \\
11 & 60 & 40 & 45 & Lifts \\
12 & 60 & 45 & 40 & Lifts \\
13 & 60 & 45 & 45 & Lifts \\
14 & 60 & 45 & 50 & Lifts \\
\hline \hline
\end{tabular}


Table 3.3: Models using Standard Lifts Cont.

\begin{tabular}{ccccc}
\hline Number & Dip & Initial $\theta$ & Residual $\theta$ & Soil Profile \\
\hline 15 & 45 & 30 & 25 & Lifts \\
16 & 45 & 30 & 30 & Lifts \\
17 & 45 & 30 & 35 & Lifts \\
18 & 45 & 35 & 30 & Lifts \\
19 & 45 & 35 & 35 & Lifts \\
20 & 45 & 35 & 40 & Lifts \\
21 & 30 & 30 & 25 & Lifts \\
22 & 30 & 30 & 30 & Lifts \\
23 & 30 & 30 & 35 & Lifts \\
24 & 30 & 35 & 30 & Lifts \\
25 & 30 & 35 & 35 & Lifts \\
26 & 30 & 35 & 40 & Lifts \\
\hline \hline
\end{tabular}




\subsubsection{Shear Wave Velocity}

The next set of models looked to evaluate the rate of rupture propagation given various shear wave velocities, a parameter used in [2] to determine the likelihood of surface rupture.

Given the equation 1 for $(G)$ in terms of $\left(V_{s}\right)$ and $(\rho)$,

$$
G=\rho V_{s}^{2}
$$

and the relationship between $(G),(E)$, and $(v)$,

$$
G=\frac{E}{2(1+v)}
$$

quick substitution of 2 in 1 yields 3

$$
V_{s}=\sqrt{\frac{E}{2 \rho(1+v)}}
$$

allowing the values of $E$ to be calculated for given values of $\rho$ and $V_{S}$.

These models used the same elastic parameters for all (8) lifts, effectively creating one homogeneous soil profile. Using the same $\rho$ and $v$ from the previous set, $E$ was then calculated to generate a profile with a shear wave velocity equal to the upper and lower $5 \mathrm{~m}$ lifts of the previous

models, as well as profiles with shear wave velocities of $100 \frac{\mathrm{m}}{\mathrm{s}}, 200 \frac{\mathrm{m}}{\mathrm{s}}$, and $300 \frac{\mathrm{m}}{\mathrm{s}}$. Table 4 lists the complete list of models studied. Only a dip angle of $60^{\circ}$ was studied with various initial $(\theta)$ and varying degrees of softening/hardening. 
Table 3.4: Models with Homogeneous Lifts, Using Alternate $V_{s}$

\begin{tabular}{|c|c|c|c|c|}
\hline Number & Dip & Initial $\theta$ & Residual $\theta$ & Soil Profile \\
\hline 27 & 60 & 30 & 25 & $E \mid V_{s}=85$ \\
\hline 28 & 60 & 30 & 30 & $E \mid V_{s}=85$ \\
\hline 29 & 60 & 30 & 35 & $E \mid V_{s}=85$ \\
\hline 30 & 60 & 35 & 30 & $E \mid V_{s}=85$ \\
\hline 31 & 60 & 35 & 35 & $E \mid V_{s}=85$ \\
\hline 32 & 60 & 35 & 40 & $E \mid V_{s}=85$ \\
\hline 33 & 60 & 30 & 25 & $E \mid V_{s}=100$ \\
\hline 34 & 60 & 30 & 30 & $E \mid V_{s}=100$ \\
\hline 35 & 60 & 30 & 35 & $E \mid V_{s}=100$ \\
\hline 36 & 60 & 35 & 30 & $E \mid V_{s}=100$ \\
\hline 37 & 60 & 35 & 35 & $E \mid V_{s}=100$ \\
\hline 38 & 60 & 35 & 40 & $E \mid V_{s}=100$ \\
\hline 39 & 60 & 30 & 25 & $E \mid V_{s}=200$ \\
\hline 40 & 60 & 30 & 30 & $E \mid V_{s}=200$ \\
\hline 41 & 60 & 30 & 35 & $E \mid V_{s}=200$ \\
\hline 42 & 60 & 35 & 30 & $E \mid V_{s}=200$ \\
\hline 43 & 60 & 35 & 35 & $E \mid V_{s}=200$ \\
\hline 44 & 60 & 35 & 40 & $E \mid V_{s}=200$ \\
\hline 45 & 60 & 30 & 25 & $E \mid V_{s}=300$ \\
\hline 46 & 60 & 30 & 30 & $E \mid V_{s}=300$ \\
\hline 47 & 60 & 30 & 35 & $E \mid V_{s}=300$ \\
\hline 48 & 60 & 35 & 30 & $E \mid V_{s}=300$ \\
\hline 49 & 60 & 35 & 35 & $E \mid V_{s}=300$ \\
\hline 50 & 60 & 35 & 40 & $E \mid V_{s}=300$ \\
\hline
\end{tabular}




\subsubsection{Density}

The final set of models was generated to look at the effect of the elastic parameters of a soil profile with a given $\left(V_{s}\right)$. Using 3 the appropriate value of $(E)$ can be calculated with $V_{S}=100 \frac{\mathrm{m}}{\mathrm{s}}$ and varying values of $\rho$. Table 5 lists the complete list of models studied. Only a dip angle of $60^{\circ}$ was studied with various initial $(\theta)$ and varying degrees of softening/hardening; densities varied between $2 \frac{\mathrm{kg}}{\mathrm{m}^{3}}, 3 \frac{\mathrm{kg}}{\mathrm{m}^{3}}$, and $4 \frac{\mathrm{kg}}{\mathrm{m}^{3}}$.

Table 3.5: Models with Homogeneous Lifts, Using Alternate Density with $V_{s}=100 \frac{\mathrm{m}}{\mathrm{s}}$

\begin{tabular}{ccccc}
\hline Number & Dip & Initial $\theta$ & Residual $\theta$ & Soil Profile \\
\hline 51 & 60 & 30 & 25 & $E \mid \rho=3$ \\
52 & 60 & 30 & 30 & $E \mid \rho=3$ \\
53 & 60 & 30 & 35 & $E \mid \rho=3$ \\
54 & 60 & 35 & 30 & $E \mid \rho=3$ \\
55 & 60 & 35 & 35 & $E \mid \rho=3$ \\
56 & 60 & 35 & 40 & $E \mid \rho=3$ \\
57 & 60 & 30 & 25 & $E \mid \rho=4$ \\
58 & 60 & 30 & 30 & $E \mid \rho=4$ \\
59 & 60 & 30 & 35 & $E \mid \rho=4$ \\
60 & 60 & 35 & 30 & $E \mid \rho=4$ \\
61 & 60 & 35 & 35 & $E \mid \rho=4$ \\
62 & 60 & 35 & 40 & $E \mid \rho=4$ \\
\hline
\end{tabular}




\section{ANALYTICAL SHEAR MODEL}

In addition to studying the rupture propagation through numerical fault models, the various states of stress and strain along the rupture plane were evaluated.

If the loading during a reverse rupture event is idealized as entirely displacement driven and the material is treated as perfectly ductile we can assume that a majority of the soil profile remains in an elastic state. It is only the regions along the fault plane that would undergo any deformation. This deformation, if restricted to a very thin shear band would be equivalent to 2 elastic blocks sliding along each other yielding a rupture zone between them. Figure 4.1 illustrates this idealization.

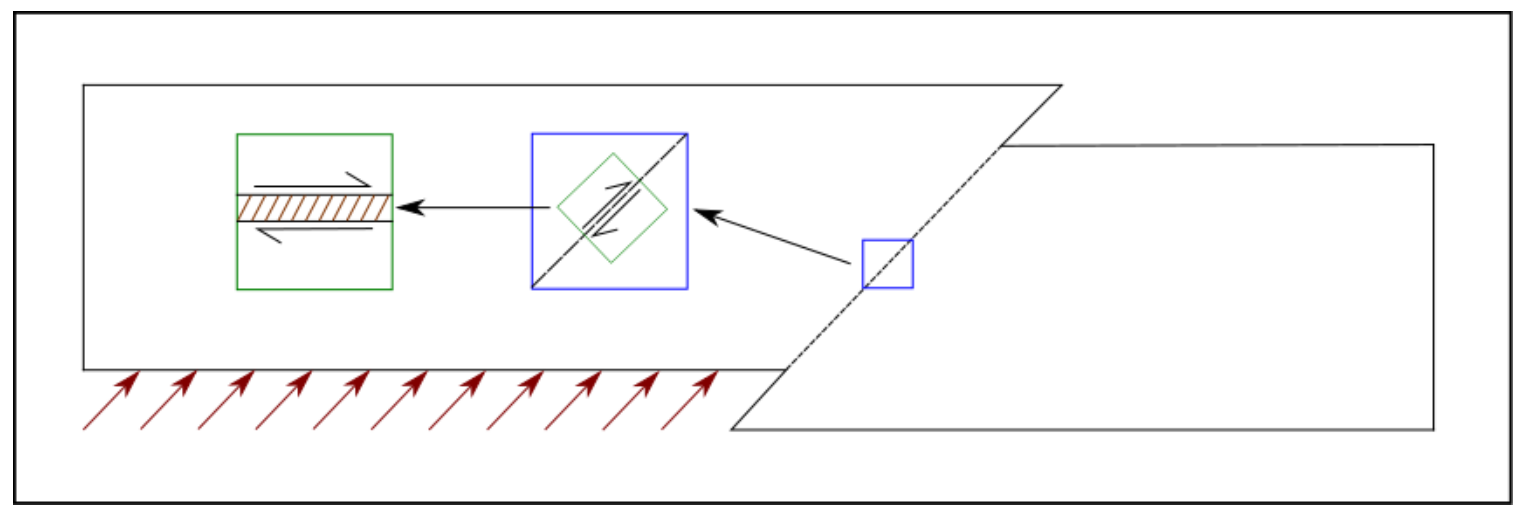

Figure 4.1: Shear Along Rupture Plain

The shear band in granular materials can be approximated as $16 \times d_{50 \%}$ [22] or 16 times the diameter of the $50 \%$ passing soil grain, which for a coarse sand would be limited to $16 \mathrm{~mm}$. The thickness of the soil profile of interest is several orders of magnitude greater than the shear band, supporting the assumption that the fault rupture zone can be idealized as 2 elastic sliding blocks with a shear zone undergoing simple shear deformation. 


\subsection{Simple Shear Problem}

Simple shear is defined as an isochoric plane deformation where a set of line elements do not change length or orientation [23]. Figure 4.2 illustrates this deformation.

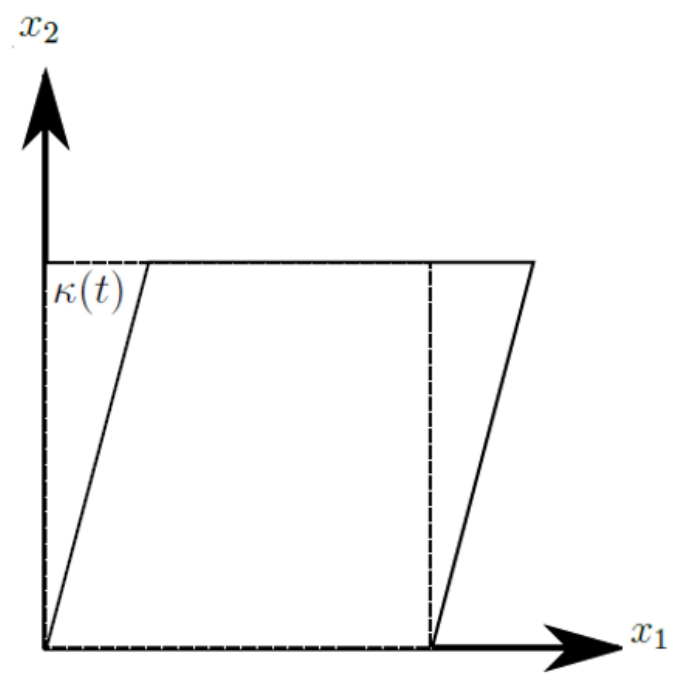

Figure 4.2: Simple Shear Deformation

This deformation can be described by the components of (4). The deformation gradient tensor is then defined by (5) resulting in (6).

$$
\begin{gathered}
x=<X_{1}+\kappa(t) X_{2}, X_{2}, X_{3}> \\
F_{i j}=x_{i, j} \\
F=\left[\begin{array}{lll}
1 & \kappa(t) & 0 \\
0 & 1 & 0 \\
0 & 0 & 1
\end{array}\right]
\end{gathered}
$$

The right Cauchy-Green deformation tensor (7) can be used to calculate the Finite Strain given (9) resulting in (10). 


$$
\begin{aligned}
C_{I J} & =F_{k I} F_{k J} \\
& =\left[\begin{array}{lll}
1 & \kappa(t) & 0 \\
\kappa(t) & 1+\kappa(t)^{2} & 0 \\
0 & 0 & 1
\end{array}\right] \\
E_{I J} & =\frac{1}{2}\left(C_{I J}-\delta_{I J}\right) \\
& =\frac{1}{2}\left[\begin{array}{lll}
0 & \kappa(t) & 0 \\
\kappa(t) & \kappa(t)^{2} & 0 \\
0 & 0 & 0
\end{array}\right]
\end{aligned}
$$

The stress state due to applied shear $T_{\tau}$ can then calculated using generalized Hooke's law by (11). Although a lagrangian strain measure is used implying that $\mathrm{T}$ is a 2 nd Piola-Kirchhoff stress tensor, for small strains this material model can be treated as an isotropic linear elastic model given that $2^{\text {nd }}$ Piola-Kirchhoff and Cauchy stress are identical at small strains.

$$
\left[\begin{array}{l}
T_{11} \\
T_{22} \\
T_{33} \\
T_{23} \\
T_{13} \\
T_{12}
\end{array}\right]=\frac{E}{(1+v)(1-2 v)}\left[\begin{array}{llllll}
(1-v) & v & v & 0 & 0 & 0 \\
v & (1-v) & v & 0 & 0 & 0 \\
v & v & (1-v) & 0 & 0 & 0 \\
0 & 0 & 0 & 2 G & 0 & 0 \\
0 & 0 & 0 & 0 & 2 G & 0 \\
0 & 0 & 0 & 0 & 0 & 2 G
\end{array}\right]\left[\begin{array}{l}
E_{11} \\
E_{22} \\
E_{33} \\
E_{23} \\
E_{13} \\
E_{12}
\end{array}\right]
$$

The angle at which the simple shear can be applied can be modified by rotating the basis vectors. This is done with the application of a Rotation Tensor $Q$. For rotations about $X_{3}, Q$ is defined by (12) and the rotated stress state $T^{\prime}$ can be defined by (13)

$$
\begin{aligned}
Q & =\left[\begin{array}{lll}
\cos (\phi) & -\sin (\phi) & 0 \\
\sin (\phi) & \cos (\phi) & 0 \\
0 & 0 & 1
\end{array}\right] \\
T^{\prime} & =Q T Q^{T}
\end{aligned}
$$




\subsection{Overburden and Lateral Earth Pressure}

\subsection{Overburden}

The overburden stress $\sigma_{v}$ at any given point is equal to the weight of the soil above, or neglecting pore pressure (14),

$$
\sigma_{V}=\int_{0}^{h} \rho(h) d h
$$

and the stress state due to overburden $T_{v}$ can be calculated as (15).

$$
T_{v}=\left[\begin{array}{lll}
\sigma_{v} & 0 & 0 \\
0 & 0 & 0 \\
0 & 0 & 0
\end{array}\right]
$$

\subsubsection{Lateral Earth Pressure}

The sliding rigid block assumption prevents the soil from deforming, allowing the use of an at rest lateral earth pressure coefficient $K_{0}$ both in plane and out of plane to calculate the lateral stresses induced by overburden. As the soil model assumes a clean sand, $K_{0}$ can be directly calculated using (16). The horizontal stress due to overburden is then defined by (17), and the stress state due to horizontal stresses by (18).

$$
\begin{aligned}
& K_{0}=1-\sin (\theta) \\
& \sigma_{h}=K_{0} \sigma_{v} \\
& T_{h}=\left[\begin{array}{lll}
0 & 0 & 0 \\
0 & \sigma_{h} & 0 \\
0 & 0 & \sigma_{h}
\end{array}\right]
\end{aligned}
$$




\subsection{Mohr-Coulomb Failure Criterion}

Mohr-Coulomb failure theory is a model used to describe the shear strength of soils as a function of effective stresses, cohesion, and internal friction angle. It can be expressed as a function of the Lode angle $\theta_{L}$, the first invariant of the stress tensor $I_{1}$, and the 2nd and 3rd invariants of the deviatoric stress tensor $J_{2}$ and $J_{3}$.

\subsubsection{Failure Surface}

The deviatoric stress tensor is derived by subtracting the hydrostatic stresses from the stress tensor $T i j$, where the hydrostatic stress is equal to $1 / 3$ of the trace, resulting in (19).

$$
S_{i j}=T_{i j}-\frac{1}{3} T_{i i} \delta_{i j}
$$

The invariants are defined by (20), (21), and (22), and $\theta_{L}$ as (23) and 24).

$$
\begin{aligned}
& I_{1}=T_{k k} \\
& J_{2}=\frac{1}{2}\left(S_{i i} S_{j j}-S_{i j} S_{j i}\right) \\
& J_{3}=e_{i j k} S_{i 1} S_{j 2} S_{k 3} \\
& \theta_{L}=-\frac{1}{3} \sin ^{-1}\left(-\frac{3 \sqrt{3}}{2} \frac{J_{3}}{J_{2}^{3 / 2}}\right)
\end{aligned}
$$

where

$$
-\frac{\pi}{6} \leq 0 \leq \frac{\pi}{6}
$$


The Mohr-Coulomb criteria can then be expressed as:

$$
f=I_{1} \sin \theta+\sqrt{J_{2}} \cos \theta_{L}-\frac{\sqrt{J_{2}}}{3} \sin \theta \sin \theta_{L}-c \cos \phi
$$

when

$$
f<0
$$

the material is in an elastic stress state, when

$$
f=0
$$

$f$ is defining the failure surface, and the stress state is at a yield point. For the purposes of this exercise we will assume that there is no hardening and the yield surface does not change with additional strain loading.

The Lode angle $\theta_{L}$ can be interpreted as the geometrical representation of the angle between the deviatoric stress and the state of pure shear projected onto the deviatoric stress plane. Figure 4.3 shows the Lode angle being measured off the line of pure shear. A lode angle of 0 would imply loading in pure shear where, $\frac{\pi}{6}$ Triaxial Extension, and $-\frac{\pi}{6}$ Triaxial Compression.

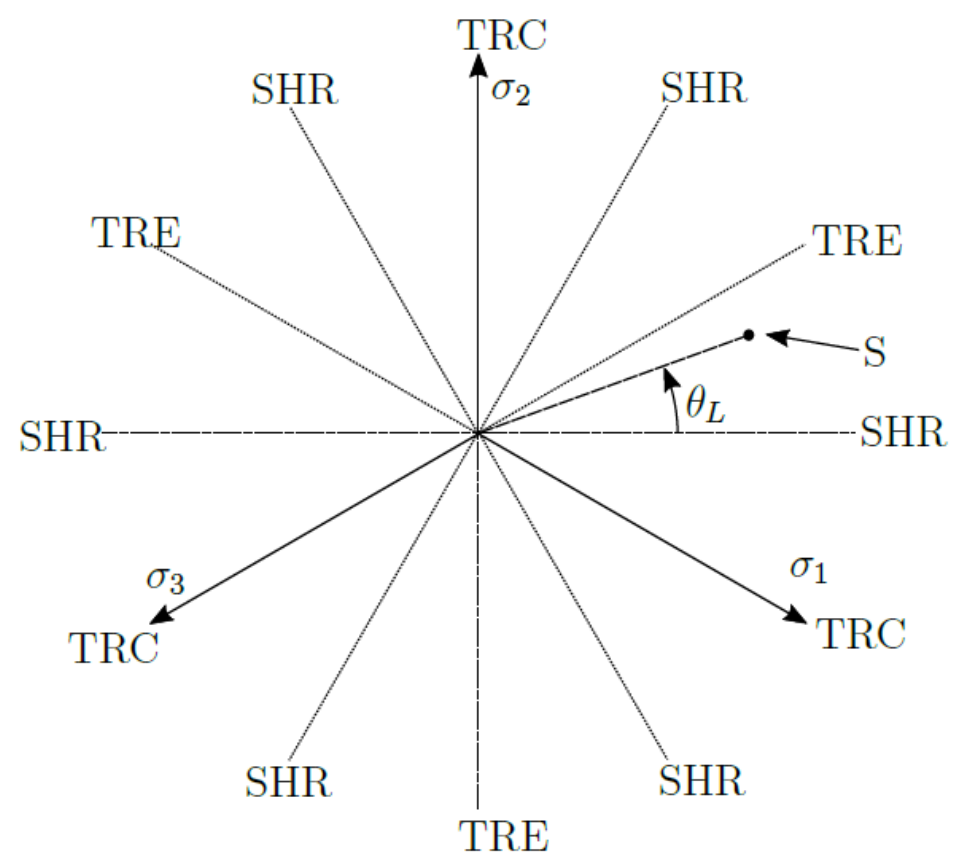

Figure 4.3: Lode Angle Representation 


\section{$4.4 \quad$ Yield Strain}

Given the results of the previous 2 sections it is possible to determine the required strain to yield a point given it's material properties and applied overburden.

\subsubsection{Solution Technique}

The stress state $T_{o v b}$ due to overburden and lateral earth pressures can be determined by combining $T_{v}$ and $T_{h}$ as in (26) and 27).

$$
\begin{aligned}
& T_{o v b}=T_{v}+T_{h} \\
& T_{o v b}=\left[\begin{array}{lll}
\sigma_{v} & 0 & 0 \\
0 & \sigma_{h} & 0 \\
0 & 0 & \sigma_{h}
\end{array}\right]
\end{aligned}
$$

To make it easier to apply the strain component, $T_{\text {ovb }}$ can be rotated using (13) to yield $T_{\text {ovb }}{ }^{\prime}$ where $Q$ is the rotation matrix for the negative value of the dip angle of interest. In this way the stress due to an applied strain $T_{\tau}$ can be directly added to $T_{o v b}$ to calculate the total stress state in the material $T$.

An initial guess for strain $\kappa(t)$ is used to calculate $T$ using (28).

$$
T=T_{\tau}+T_{o v b}{ }^{\prime}
$$

From $T$ the values of $S, I_{1}, J_{2}, J_{3}, \theta_{L}$, and finally $f$, can be calculated using (19), (20), (21), (22), (23), (25) respectively. Using any approporaite numerical iteration technique a value of $\kappa(t)$ can be found to satisfy the condition $f=0$ where the stress state is on the yield surface. 


\subsubsection{Remarks}

The solution method listed above can be used to solve for the onset of yield for cases where the material paramers themselves are dependent function, such as the user defined soil material described in Section 1.1. Special attention needs to be paid in selecting a numerical procedure to iterate which accounts for the change in value.

\subsubsection{Example}

Using the material properties defined in Figure 3.4, a dip angle of $60^{\circ}$, and defining an initial overburden of $400 \mathrm{~Pa}$, we can calculate the required strain to yield.

An initial value of 0 is used for $\kappa(t)$ setting $\theta(\kappa)=35^{\circ}$. Using the initial overburden of 400 $P a$ we can use (16), (17), and (26) to calculate $T$.

$$
T=\left[\begin{array}{lll}
-400 & 0.00 & 0.00 \\
0.00 & -170.57 & 0.00 \\
0.00 & 0.00 & -170.57
\end{array}\right]
$$

The stress tensor $\mathrm{T}$ can then under go a $60^{\circ}$ clockwise rotation to account for the dip angle using (12) and (13) yielding (30).

$$
T^{\prime}=\left[\begin{array}{lll}
-227.93 & -99.35 & 0.00 \\
-99.35 & -342.64 & 0.00 \\
0.00 & 0.00 & -170.57
\end{array}\right]
$$

Because strain is set to zero, there is no contribution from $T_{\tau}$ to the stress state, for calculations where $\kappa(t) \neq 0$ the stress due to induced shear can be calculated with (11), and (28) used to calculate the total stress. 
The deviatoric stress tensor S can be calculated using (19) yielding (31).

$$
S=\left[\begin{array}{lll}
19.12 & -99.35 & 0.00 \\
-99.35 & -95.60 & 0.00 \\
0.00 & 0.00 & 76.48
\end{array}\right]
$$

Using (30) and (31), the invariants and Lode parameter can be calculated as follows using (20), (21), (22), (23):

$$
\begin{aligned}
& I_{1}=-741.14 \\
& J_{2}=17546.13 \\
& J_{3}=-894581.9 \\
& \theta_{L}=-0.523
\end{aligned}
$$

Resulting in,

$$
f=-297.72
$$

which is much less that 0 . This is consistent with the failure theory as Mohr-Coulomb relies on deviatoric stresses for failure. These calculation steps can be repeated for various values of $\kappa(t)$ until a value is found which yields a value for $f$ sufficiently close to zero.

For the values defined in this problem, $\kappa(t)=1.04058$ is sufficient to cause failure. It is important to note that there will be 2 values of $\kappa(t)$ which can fail the material, a positive and negative strain, because we are interested in a reverse event a positive value of $\kappa(t)$ must be obtained. 


\section{RESULTS AND DISCUSSION}

The results for the Numerical and Analytical Shear models are presented in part below. Where appropriate the full list of data is presented in an accompanying appendix.

\subsection{Failure Criteria}

\subsubsection{Numerical Model}

The modeling methodology employed idealizes the granular material as a homogeneous solid making it difficult to capture a distinct yield line propagating to the surface as is common in fault box and centrifuge studies [4] [20] [11] [8] [7] [10] [24]. The stress values which are used to determine $S 12$ for the user subroutine and yield condition are calculated at element integration points and interpolated to the nodes which lay on the surface. A failure criteria defining rupture is needed to account for the limitations of the modeling techniques and numerical solver.

To be considered fully ruptured a model needed to have a line of continuously yielded elements to the surface. The yield flag marker could not be used as the constitutive model adjusted the size of the yield surface by interpolating values of $\theta$ based on $S 12$, so an element that had previously had a plastic yield state could potentially be in an elastic state in the next load step. For an element to be considered yielded the absolute value of the plastic yield strain PE12 at any integration point had to be greater than 0.0005 .

\subsubsection{Analytical Model}

The full details pertaining to the development of the failure criteria for the Analytical Shear Model is presented in Section 4. 
It is possible to achieve yield through either positive or negative shear strains. The sign convention used for the derivation, see Figure 5.1, uses the normal to the footwall as the $x_{1}$ axis with $x_{2}$ along footwall and $x_{3}$ into the page. A positive shear is equivalent to reverse faulting and a negative, normal faulting.

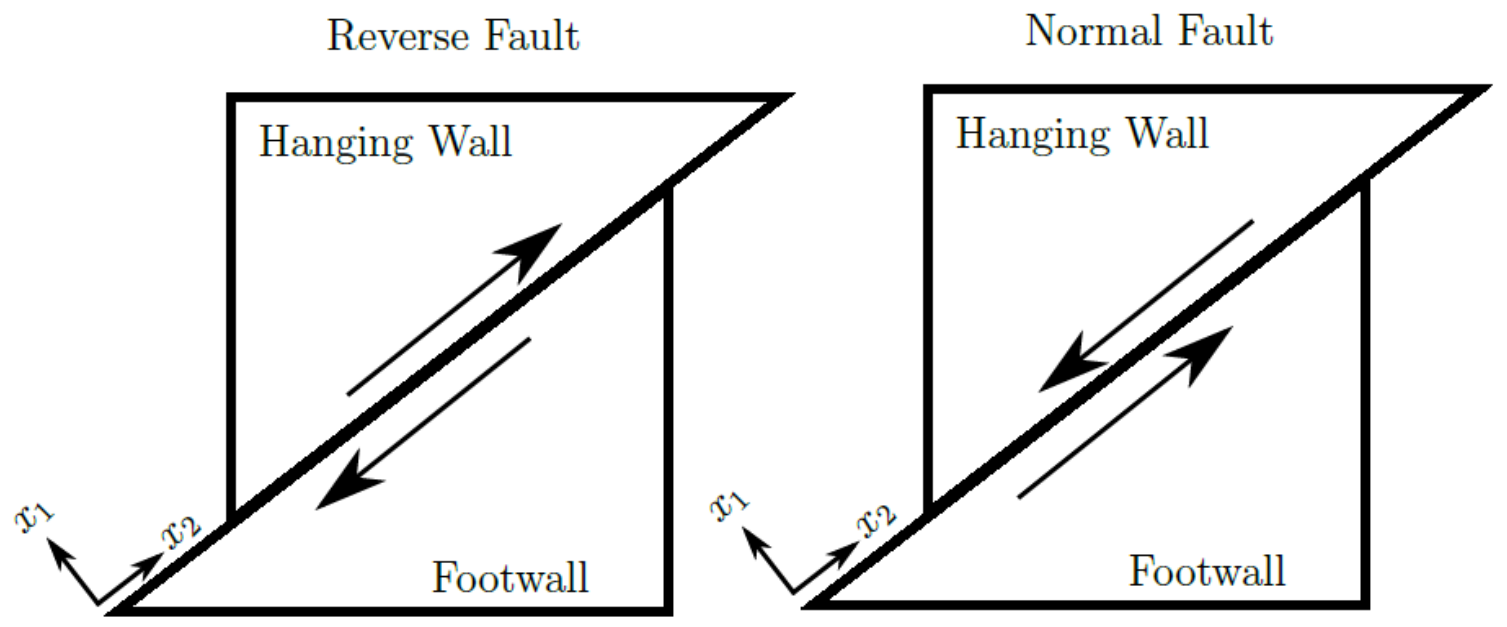

Figure 5.1: Strain Direction In Each Fault Type

\subsection{Lifts Study}

The initial lift study examined the rate of fault rupture propagation based on a soil profile comprising of several lifts with increasing elastic modulus with depth. Figure 5.2-5.4 show the results for soil profiles of given initial friction angles for fault angles of $60^{\circ}, 45^{\circ}$, and $30^{\circ}$.

For a given initial friction angle $\theta$, more normalized basal displacement was required to achieve rupture for a soil which strain softened versus a soil which strained hardened. The hardening/softening characteristic relates to a soils ductility; soils that soften exhibit brittle behavior while soils which strain harden exhibit ductile behavior.

For soils with the same elastic properties, those with higher initial friction angles required more normalized basal displacement to achieve surface rupture. With elastic parameters identical, 
the increasing friction angle increases the size of the yield surface requiring more strain to achieve yield at each point along the rupture plane.

This trend holds for all three rupture angles studied with little difference between the soils with $\theta$ values of $30^{\circ}$ and $35^{\circ}$ common across all three rupture angles.

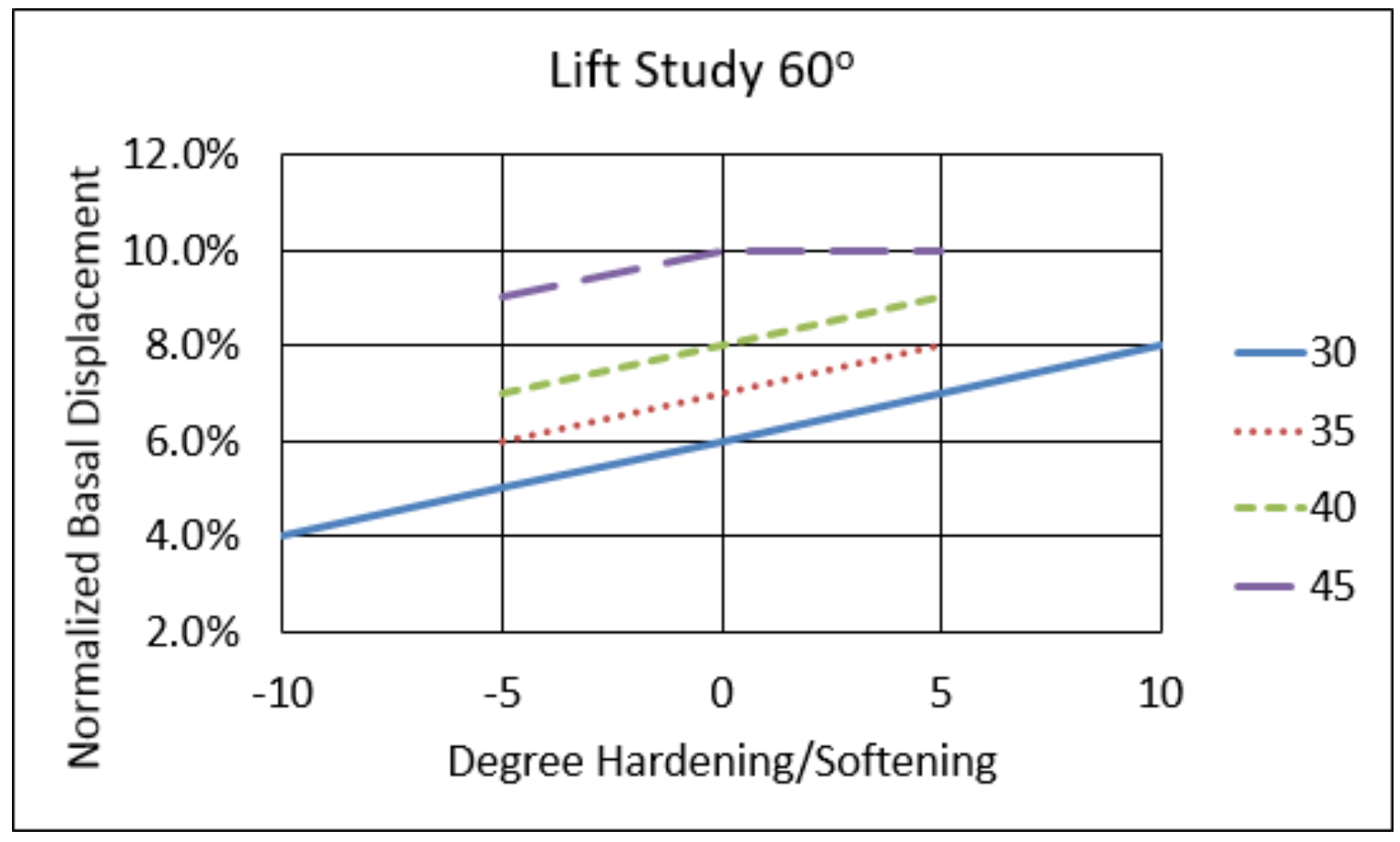

Figure 5.2: Test Results for Lift Study $60^{\circ}$ Rupture 


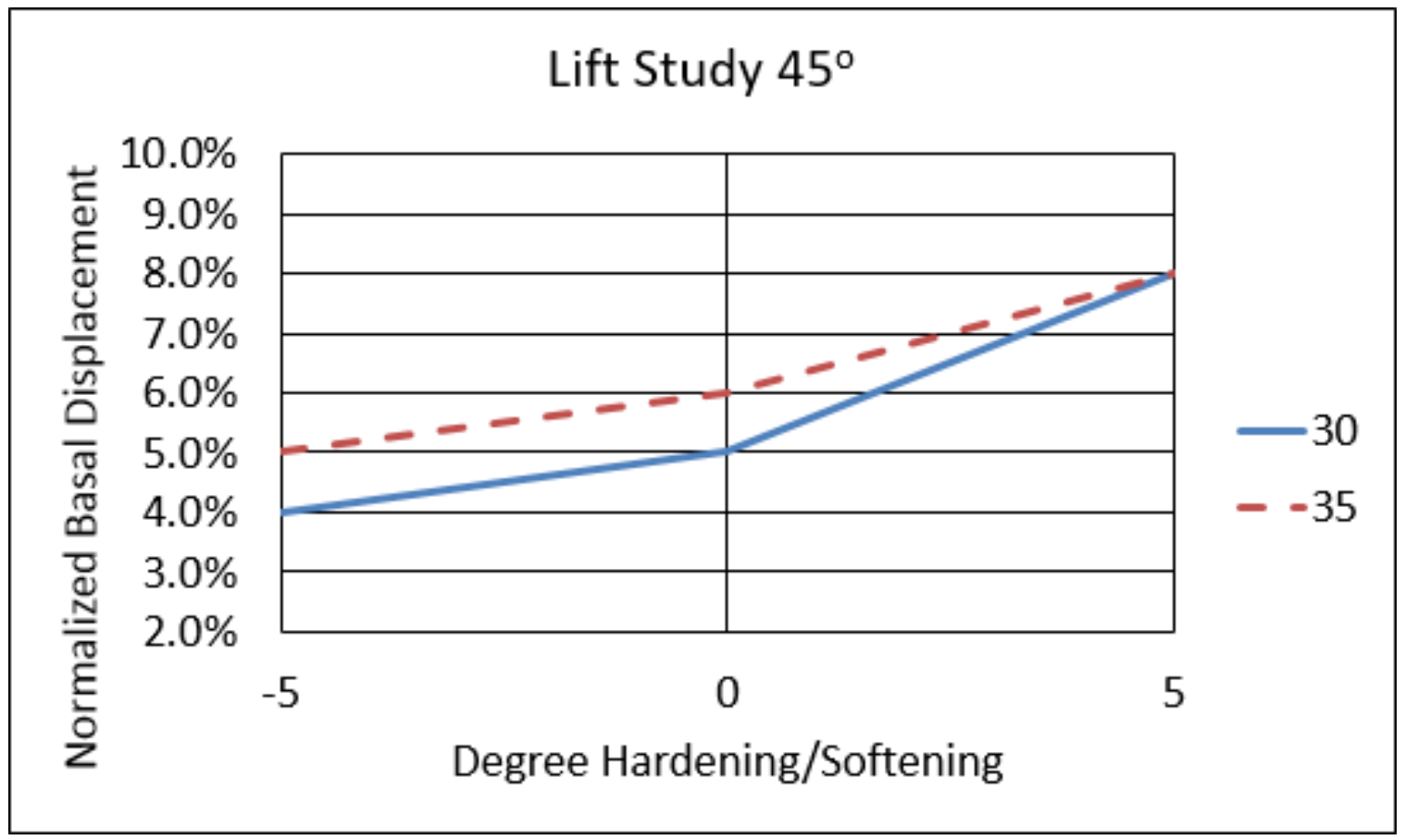

Figure 5.3: Test Results for Lift Study $45^{\circ}$ Rupture

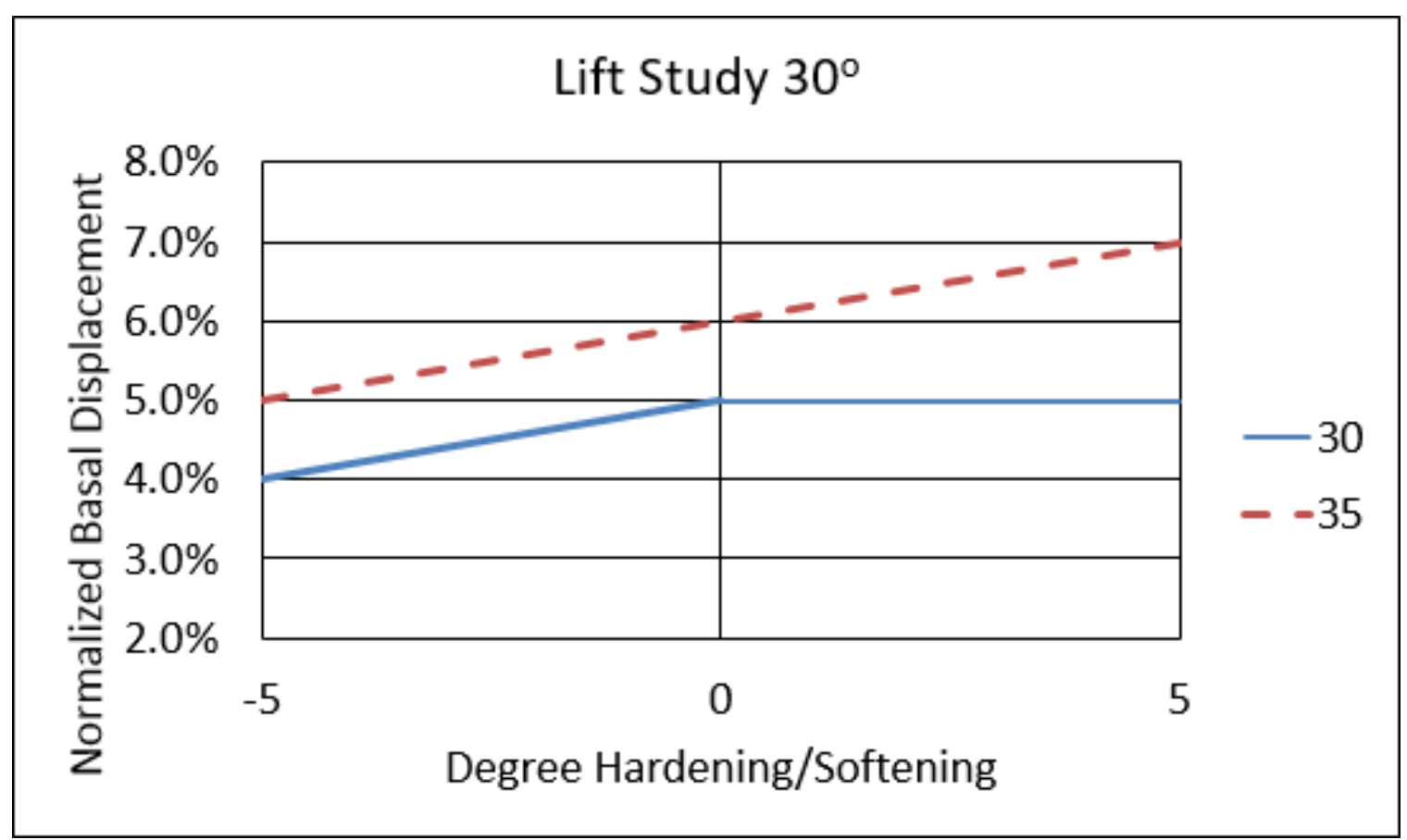

Figure 5.4: Test Results for Lift Study $30^{\circ}$ Rupture 


\subsubsection{Initial Friction Angle}

Figures 5.5-5.7 show the fully ruptured soil profiles for Increasing initial Friction Angles of a perfectly plastic soil.

The results of the Numerical models show that increasing the Initial Friction Angle increases the required Normalized Basal Displacement to achieve rupture. The profiles show narrowing bands for increasing Friction Angle, widening near the surface.

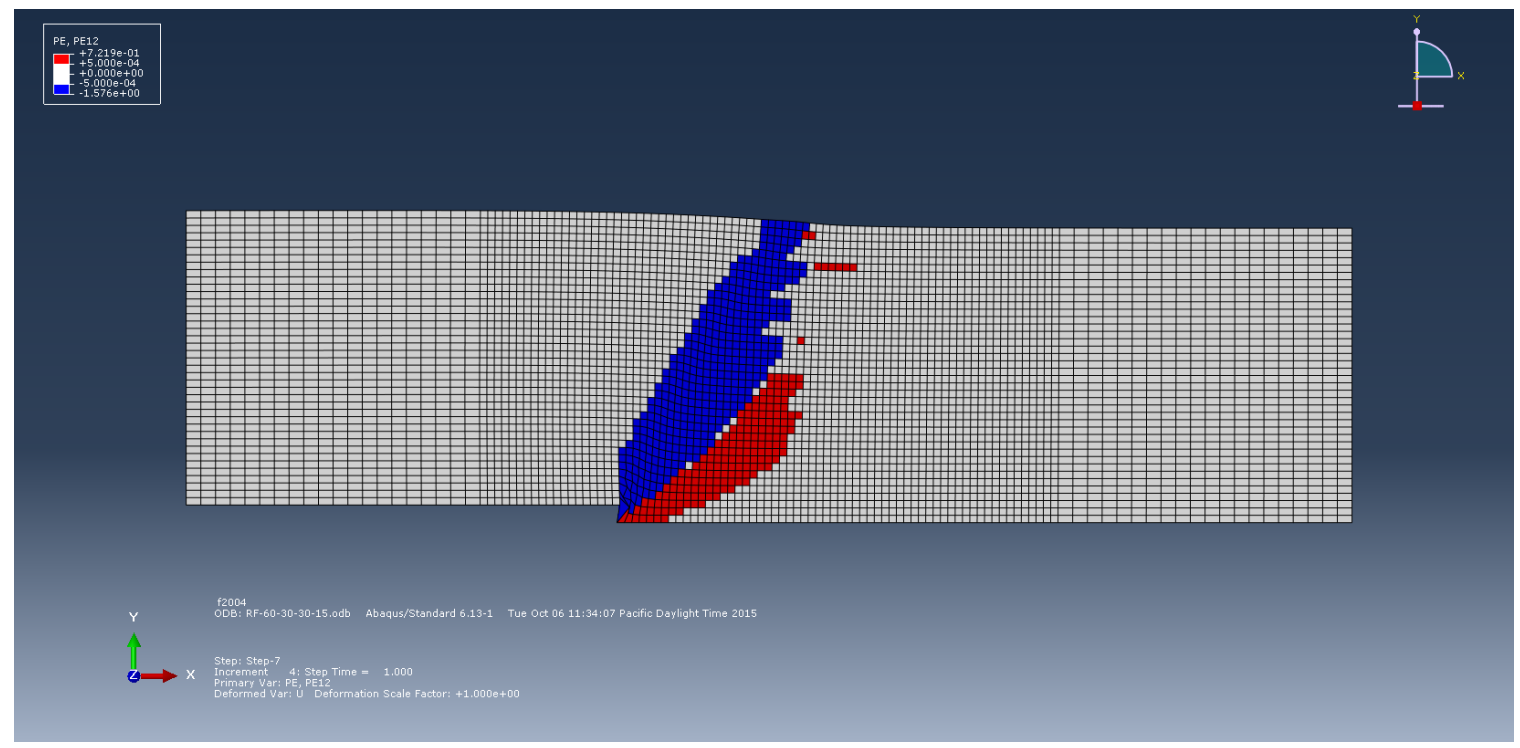

Figure 5.5: Dip $60^{\circ}$, Friction Angle $30^{\circ}$, Perfectly Plastic 


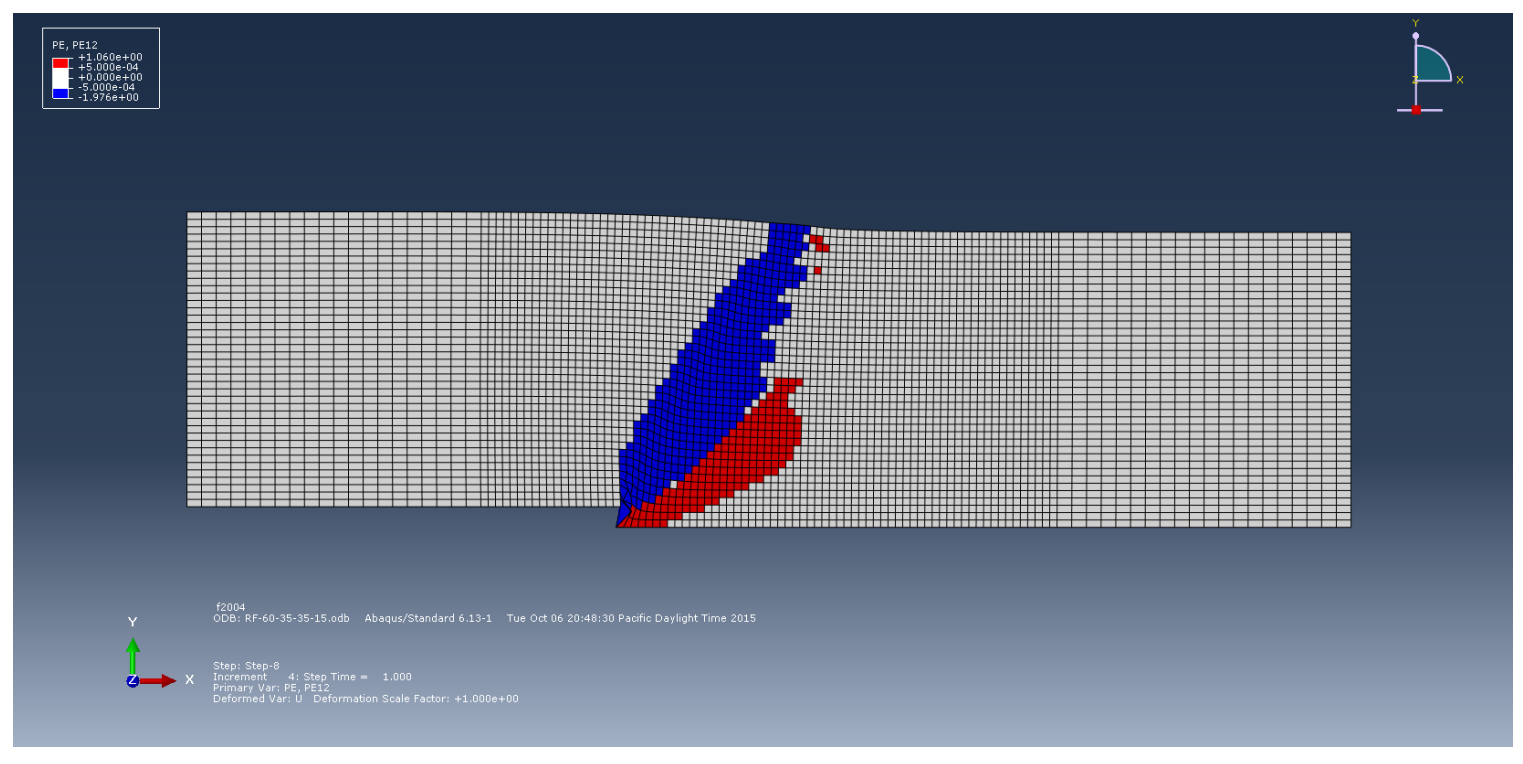

Figure 5.6: Dip $60^{\circ}$, Friction Angle $35^{\circ}$, Perfectly Plastic

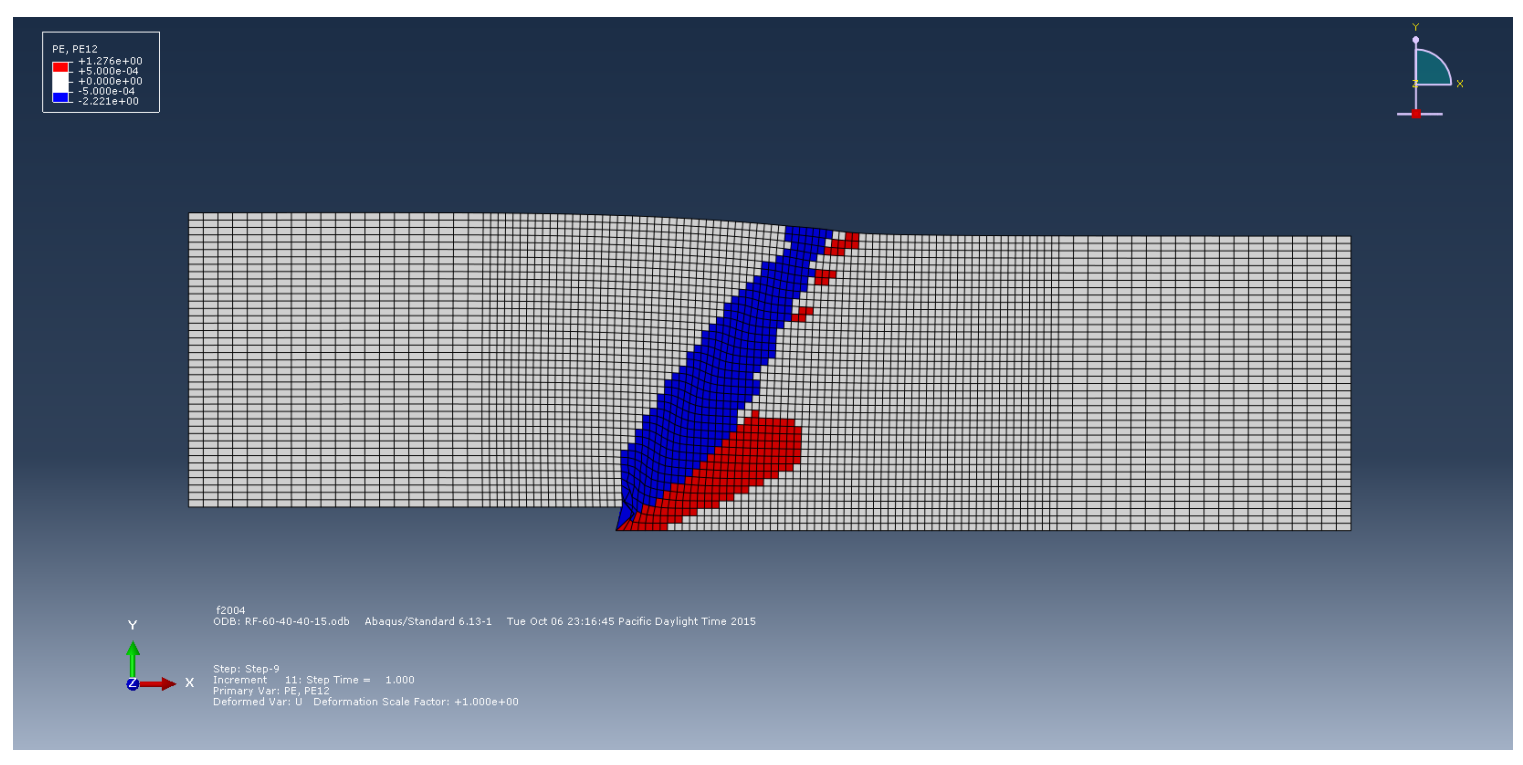

Figure 5.7: Dip $60^{\circ}$, Friction Angle $40^{\circ}$, Perfectly Plastic 


\subsubsection{Dip Angle}

The Numerical models showed that the Dip Angle had little impact on the amount of Normalized Basal Displacement required to achieve rupture.

The thickness and shape of the yield bands in Figures 5.8-5.1 appear similar with different Dip Angles. The additional strain required for the same Normalized Basal Displacement appears to be transfered to the footwall.

As the Dip Angle becomes shallower, a larger component of the applied shear is transfered as pure shear along the fault plane instead of vertical compression. When the Dip Angle increases, more of the applied shear component is resolved as compressive stress. The increased compressive stress increases the size of the Yield Surface requiring more shear strain to yield compared to a shallow Dip which does not increase the size of the yield surface as much through loading.

The resolution of applied shear as compressive strength in steeper Dip angles versus larger required total strain for a similar Normalized Basal Displacement in shallow dip angles results in little overall difference in the Required Normalized Displacement to achieve rupture for similar soils under different Dip Angles. 


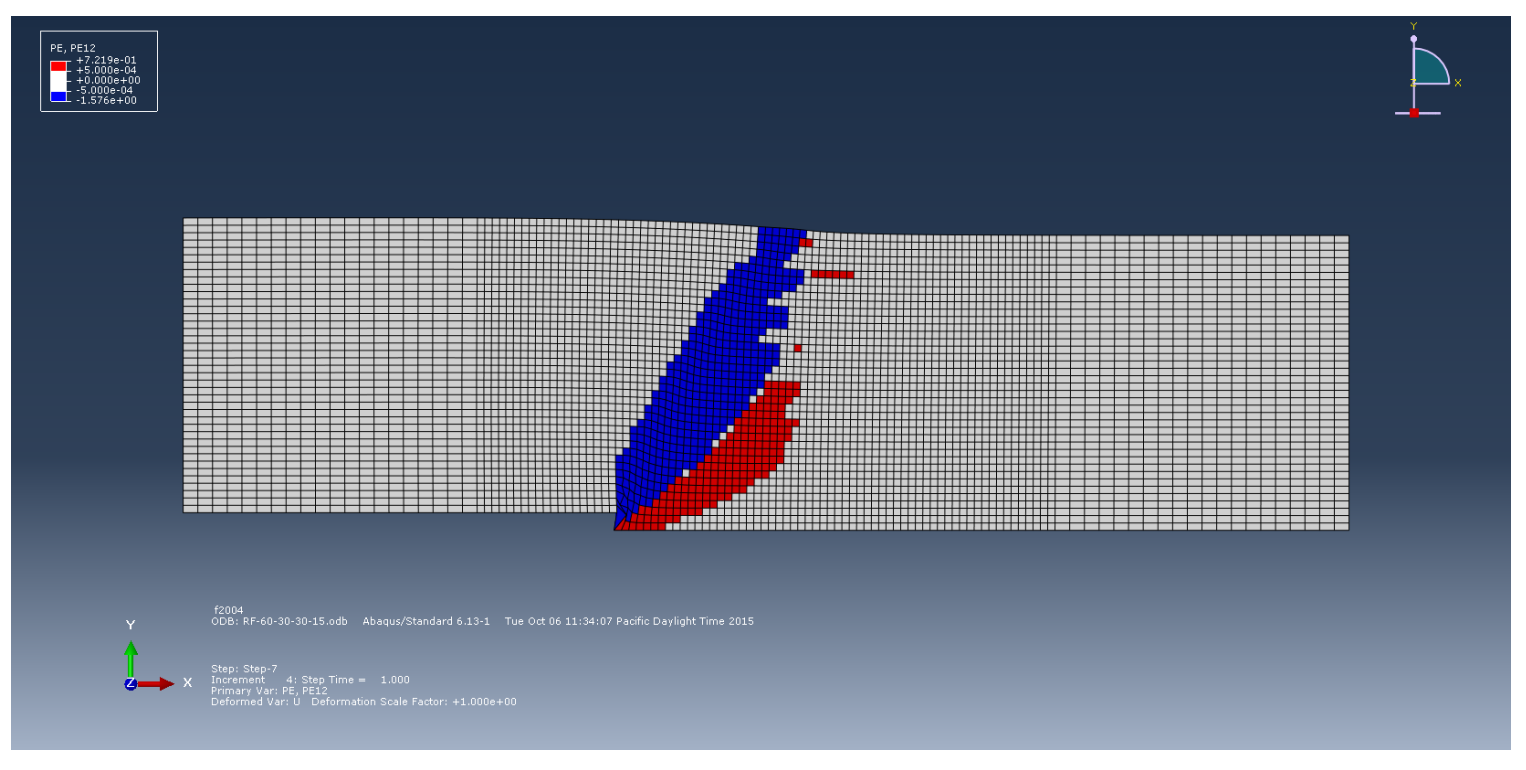

Figure 5.8: Dip $60^{\circ}$, Friction Angle $30^{\circ}$, Perfectly Plastic

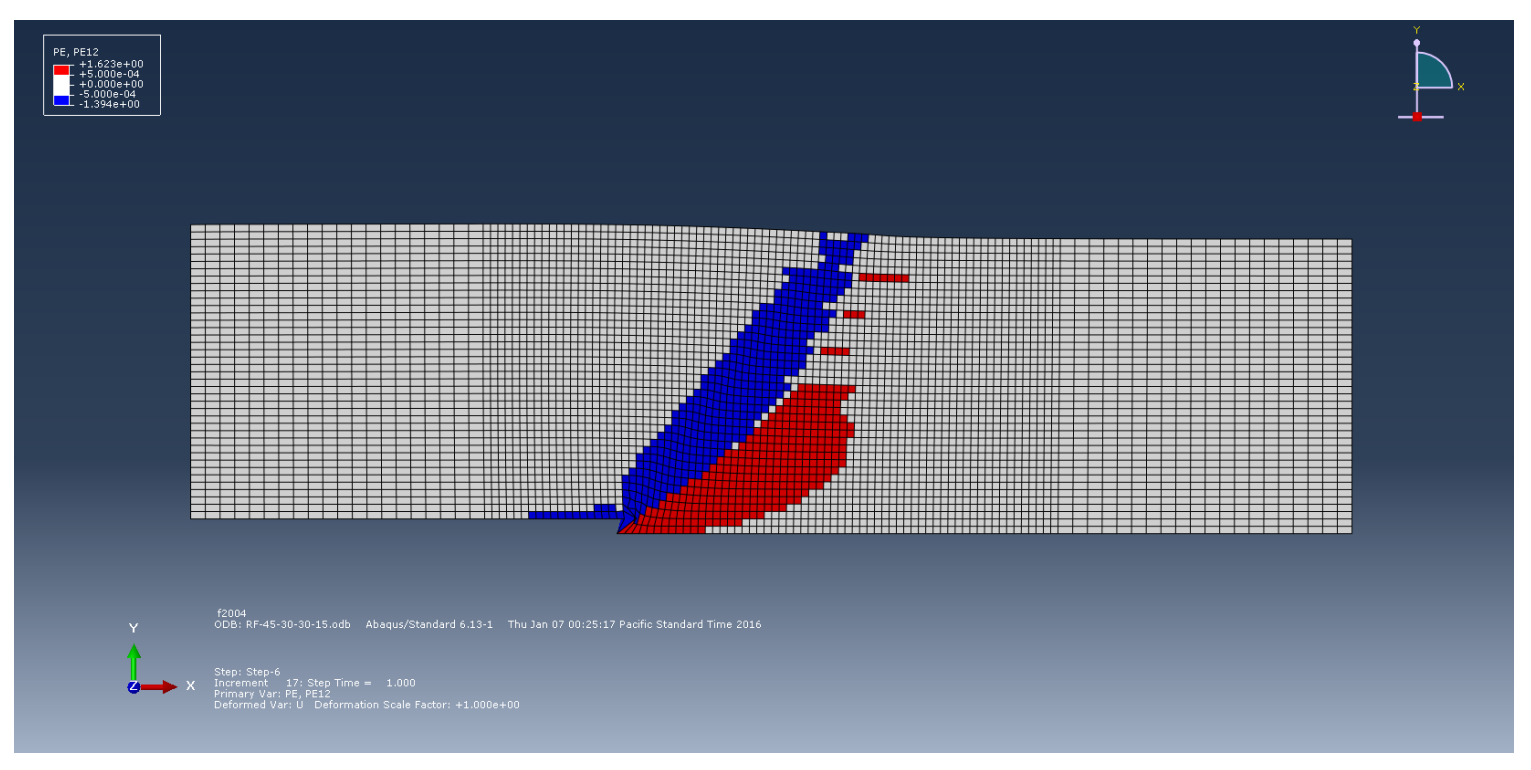

Figure 5.9: Dip $45^{\circ}$, Friction Angle $30^{\circ}$, Perfectly Plastic 


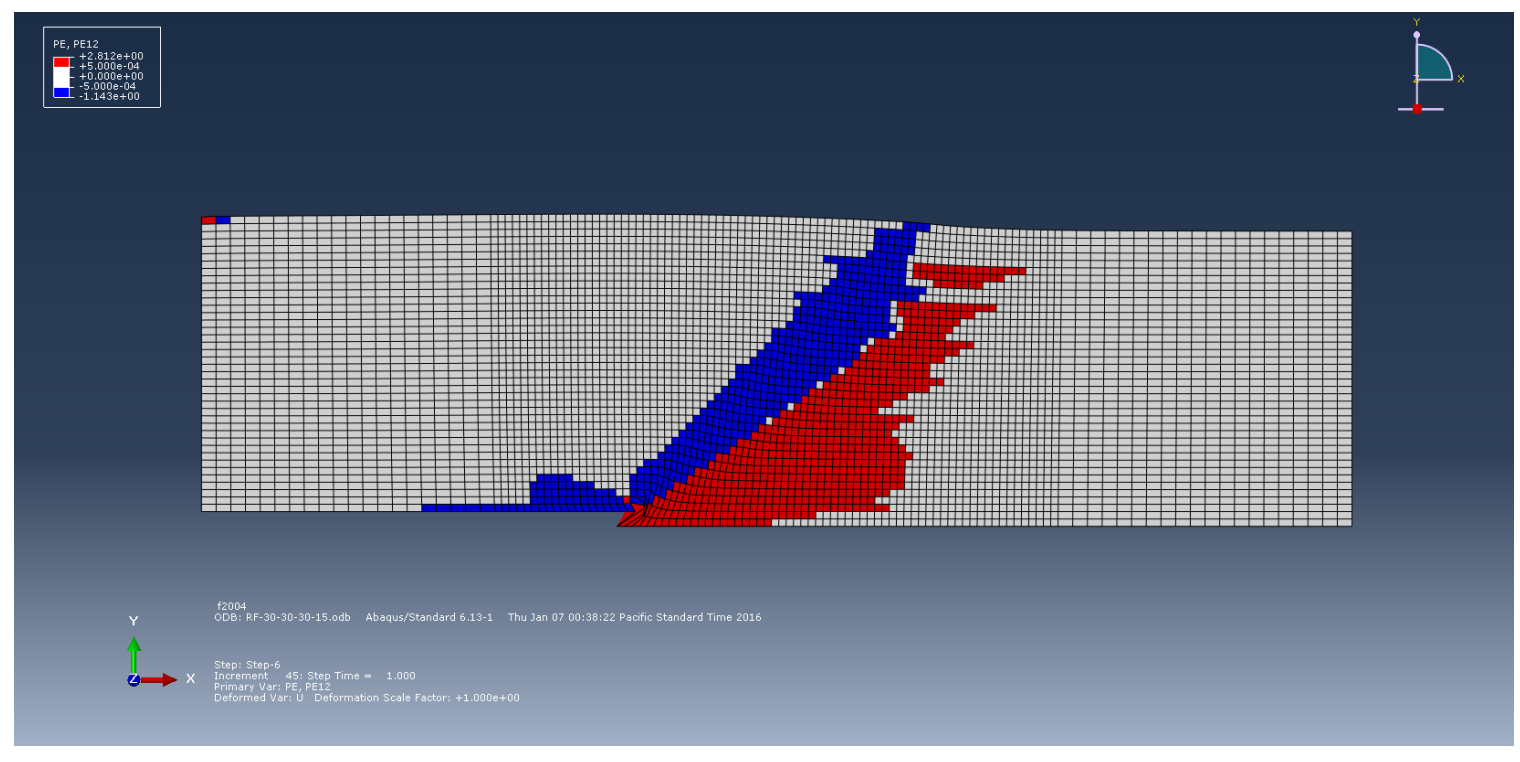

Figure 5.10: Dip $30^{\circ}$, Friction Angle $30^{\circ}$, Perfectly Plastic 


\subsubsection{Post Failure Behavior}

The Numerical models show that soils which strain harden will require more Normalized Basal Displacement to rupture than soils that strain soften.

The profiles in Figures 5.11-5.13 clearly show that the shear bands widen substantially as soils transition from strain softening to strain hardening.

A material which strain softens has a yield surface which shrinks with additional applied strain, while a soil which strain hardens grows the yield surface with additional applied strain. A shrinking yield surface creates a region which is substantially softer than the surrounding soil. As the enforced displacement increases, a larger percentage of the strain is resolved by the softer portion propagating the rupture at a faster rate than a soil profile without a soft region.

Perfectly Plastic and Hardening soils tend to resolve the additional enforced displacement laterally as the soil adjacent in the lift yields at a strain equal to or less than the the element along the rupture plane. This results in a wider shear band and more Normalized Basal Displacement because the strain energy is distributed to a larger region.

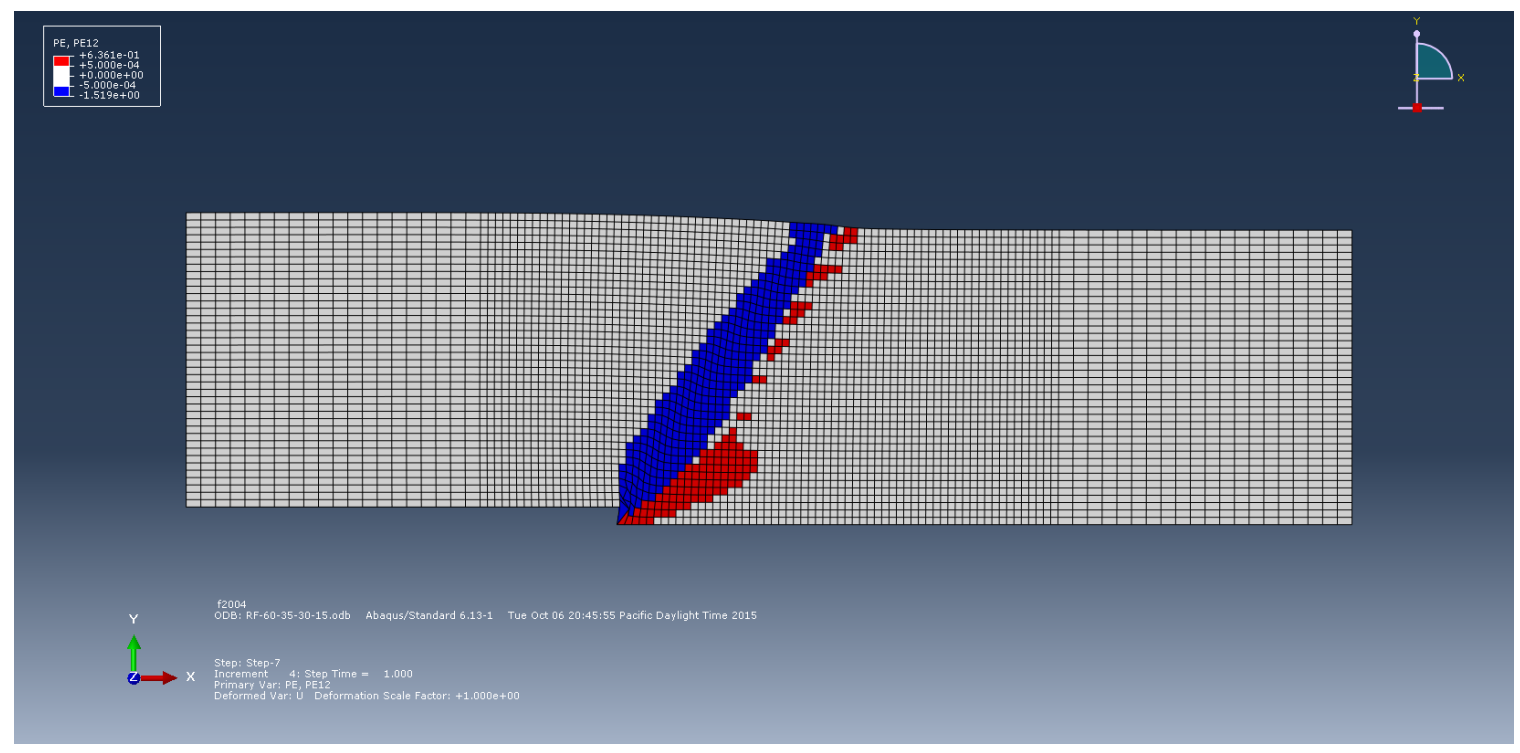

Figure 5.11: Dip $60^{\circ}$, Friction Angle $35^{\circ}$, Softening 


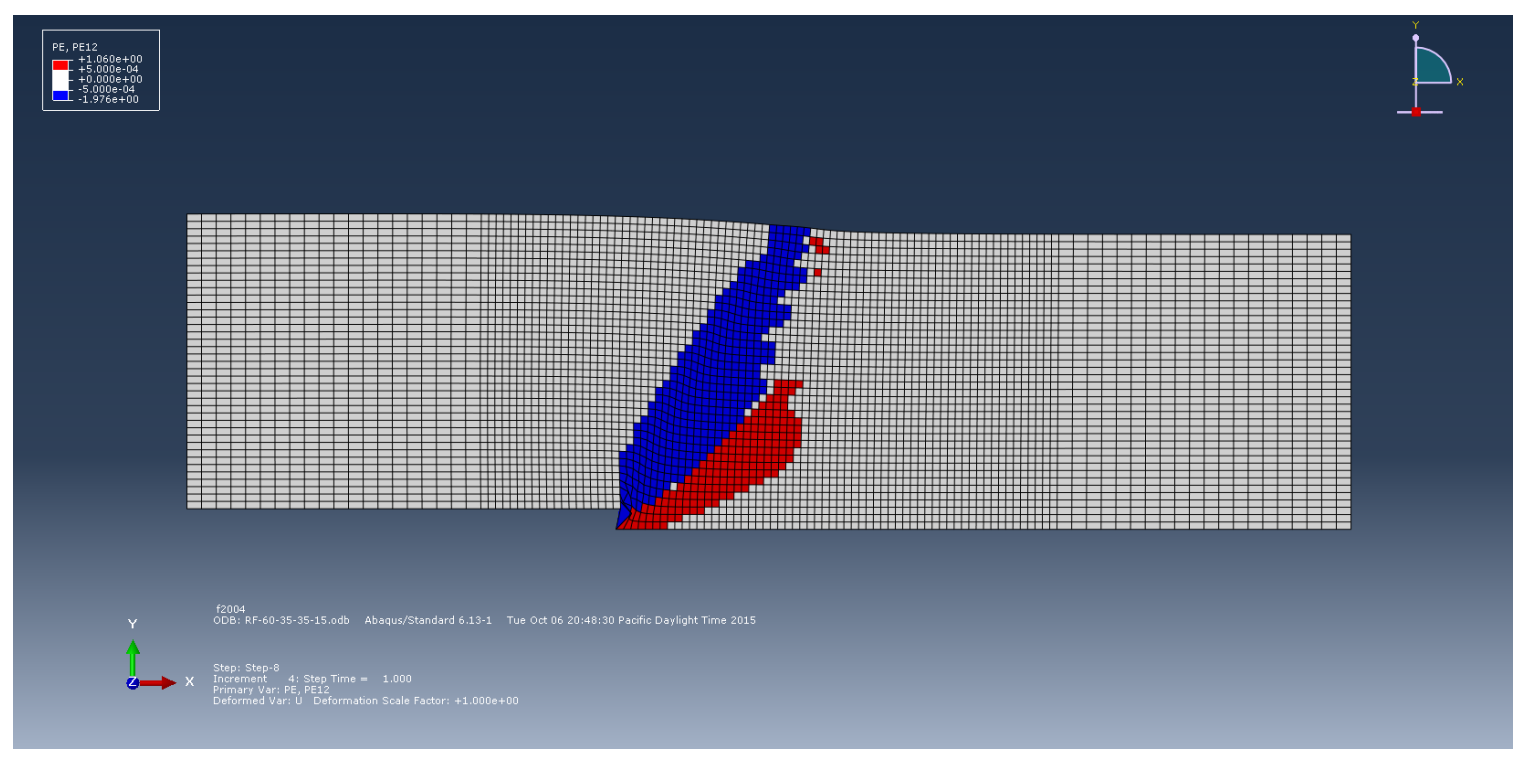

Figure 5.12: Dip $60^{\circ}$, Friction Angle $35^{\circ}$, Perfectly Plastic

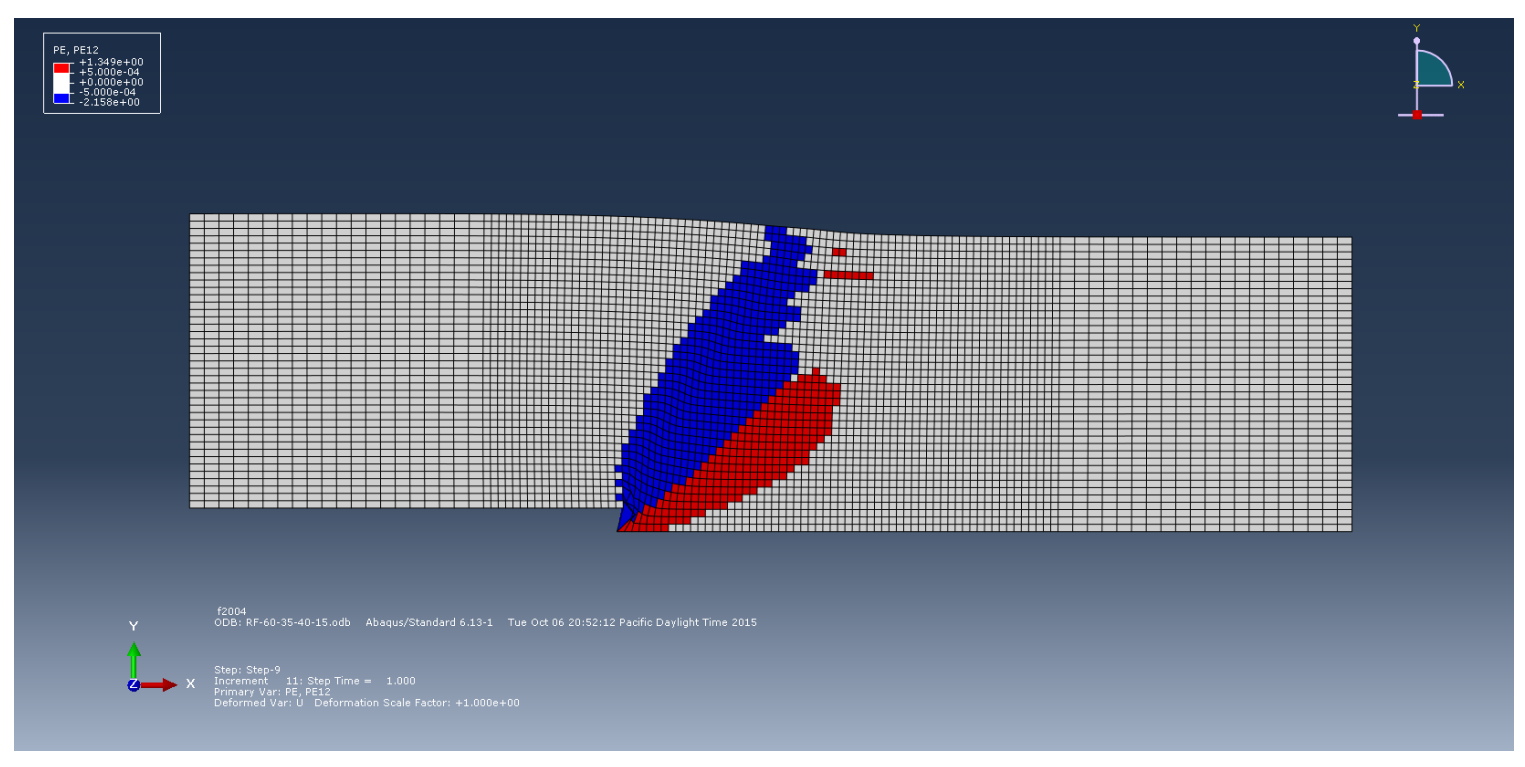

Figure 5.13: Dip $60^{\circ}$, Friction Angle $35^{\circ}$, Hardening 


\subsection{Homogenous Soil Profiles}

The homogenous soil profiles generated for the following studies are not intended to simulate terrestrial soil profiles. For a given soil composition, geological forces acting at a site produce variation in geotechnical parameters (e.g. void ratio) along the depth of the lift. These parameters in turn affect the engineering material properties that were of interest to this work.

These profile are therefore used to evaluate the rate of rupture propagation through a soil profile of uniform soil material. The only variation through the soil profile is the increasing in situ stress with depth. This increase in the stress state changes the size, but not the shape of the failure surface.

\subsubsection{Post Failure Behavior}

The study was expanded by evaluating the contribution that the Post Failure Behavior had on similar soils with varying Shear Wave Velocities. The Numerical Study results showed that the trend remained even when adjusting Shear Wave Velocity, soils which softened required less Normalized Basal Displacement then soils which strain hardened. For a soil with a given density, the Shear Wave Velocity impacted the rate of rupture the most, with the Post Failure Behavior having secondary effects.

Figures 5.14-5.19 show shear bands of 2 different shear wave velocities for a soils which

soften, are plastic, and harden. The size and shape of the shear bands between the $200 \frac{\mathrm{m}}{\mathrm{s}}$ and $300 \frac{m}{s}$ soils are fairly similar. The widening of the bands as the soils harden is identical to what was witnessed in the Lifts Study in Section 5.2.

The trend, highlighted in Figures 5.20 -5.22, show that for a soil with given set of elastic properties, the post failure behavior has minimal impact on the initial yield strain.

The analysis method does not account for the material behavior once yielded, only the amount of strain required to yield. The Anastasopolous soil model [4] changes the size of the yield 
surface given a principle shear strain, it is possible for soils with certain parameters to begin reduction of the friction angle before reaching a Mohr-Coulomb yield; the soils used in this study do not seem to exhibit this. 


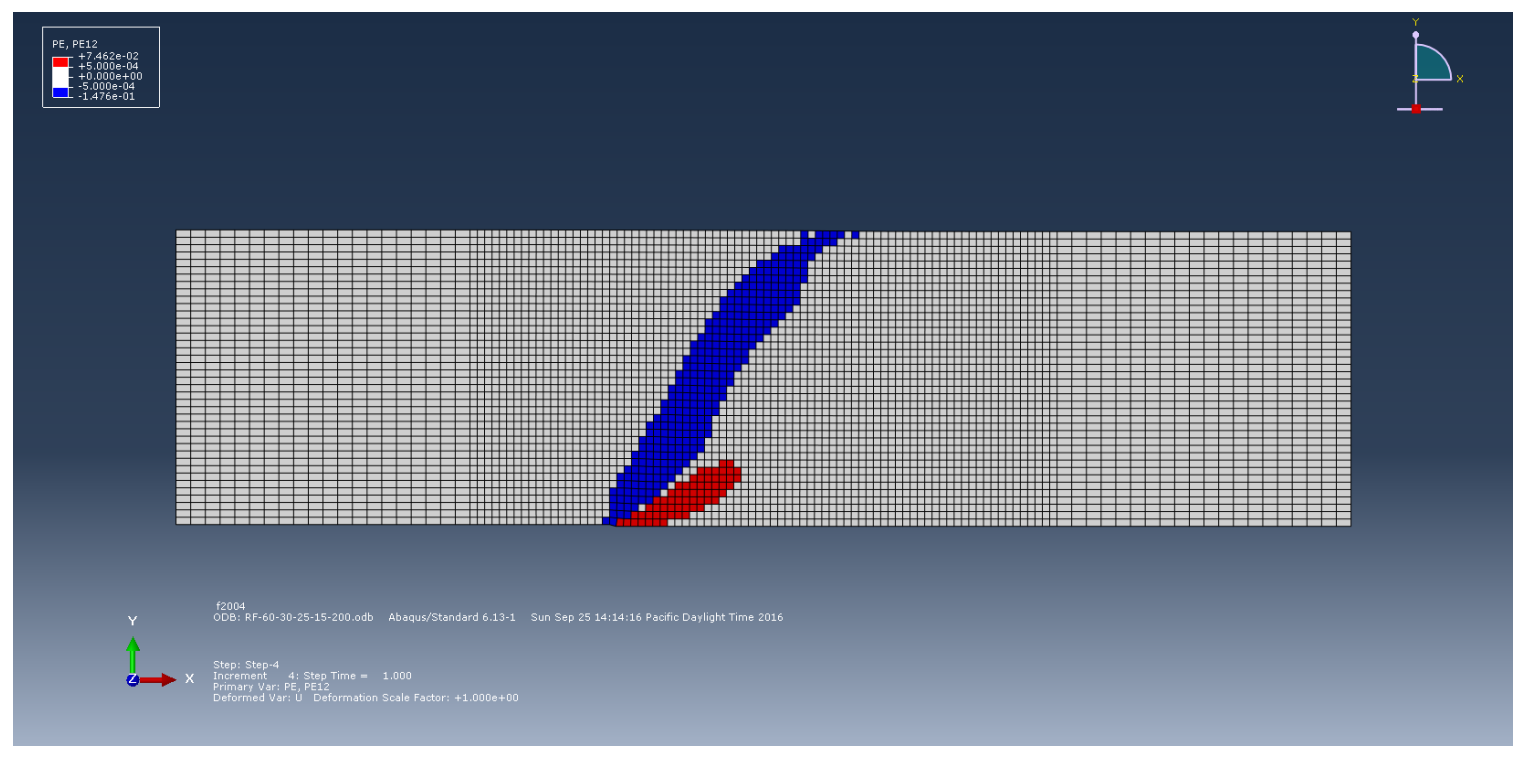

Figure 5.14: Friction Angle $30^{\circ}$, Softening, Shear Wave Velocity $200 \frac{\mathrm{m}}{\mathrm{s}^{2}}$

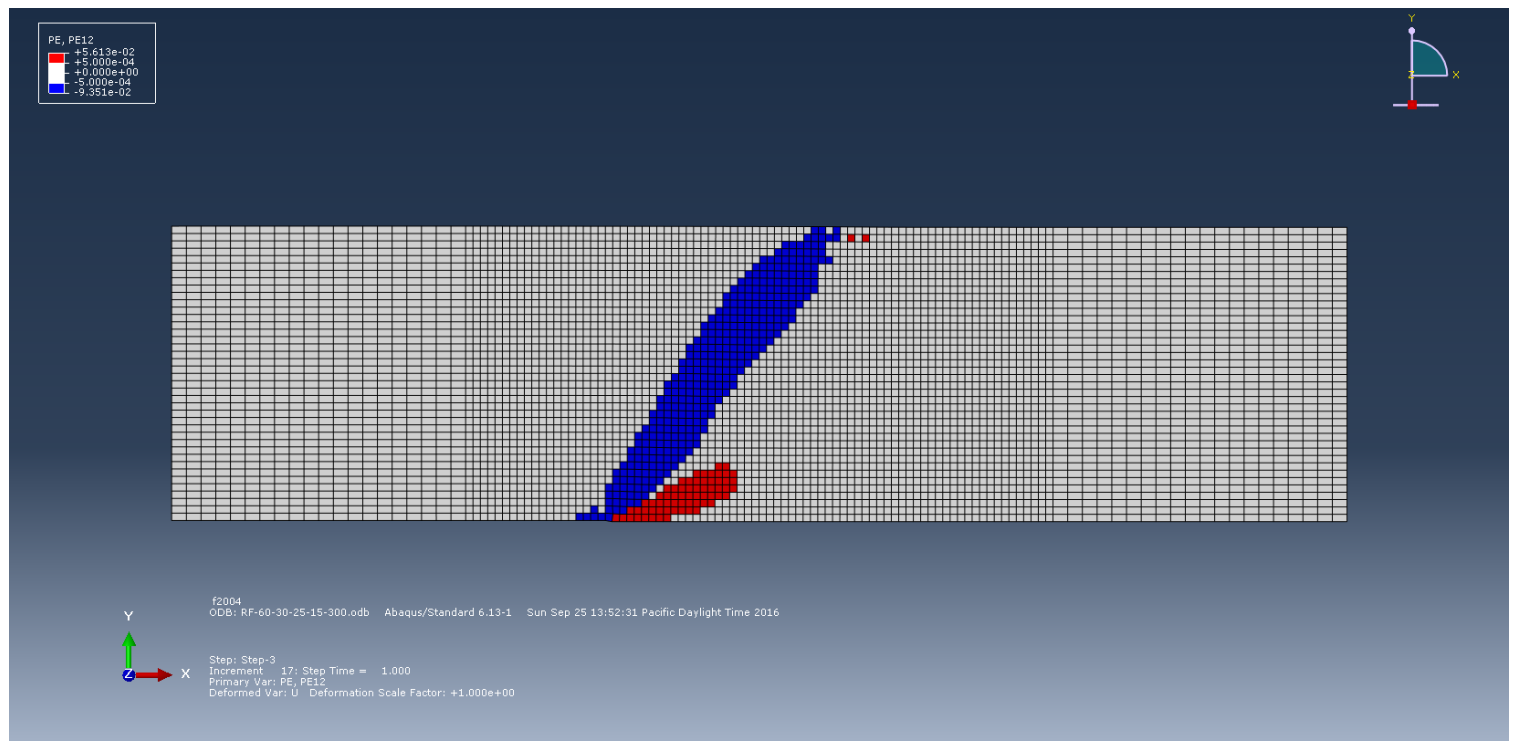

Figure 5.15: Friction Angle $30^{\circ}$, Softening, Shear Wave Velocity $300 \frac{\mathrm{m}}{\mathrm{s}^{2}}$ 


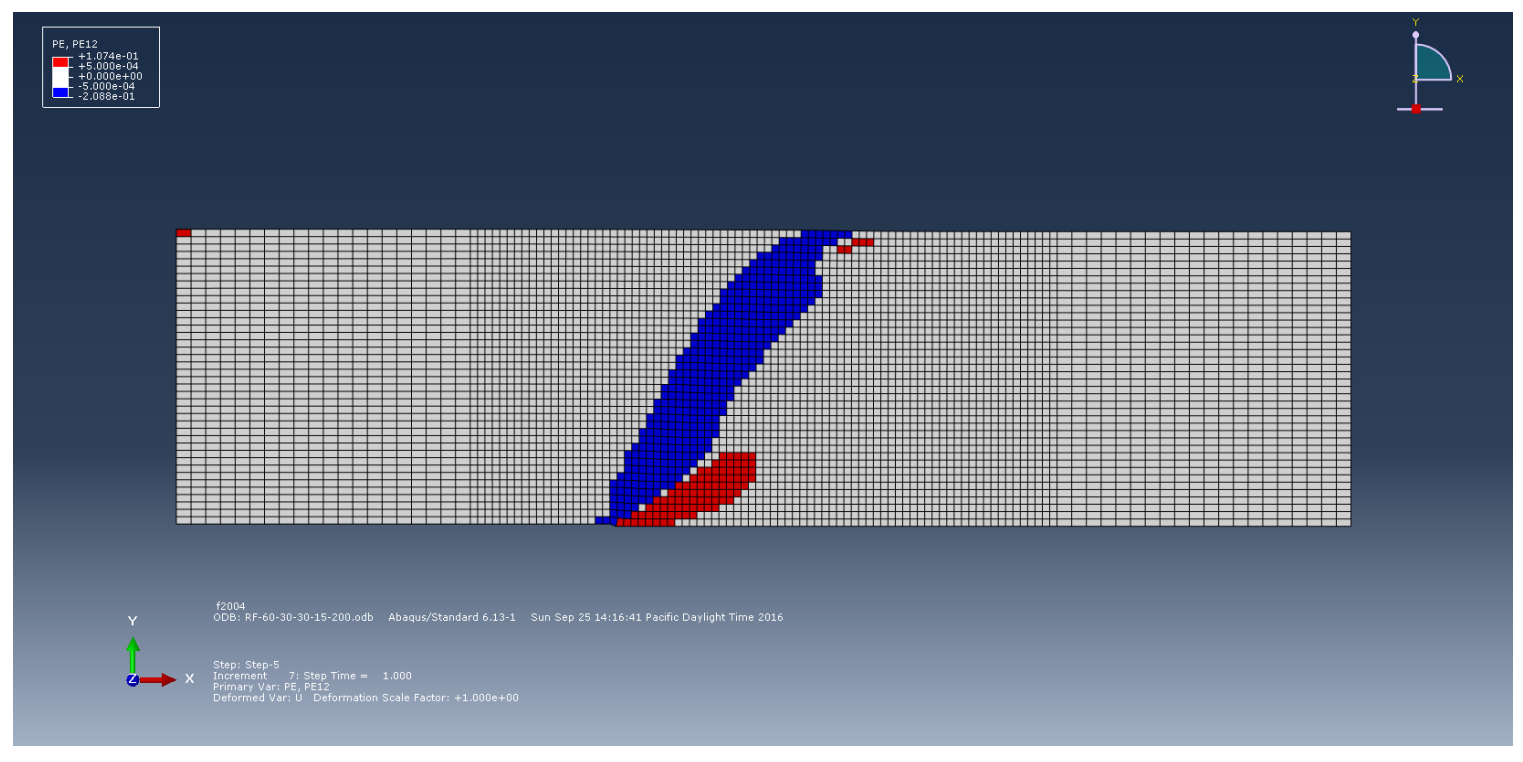

Figure 5.16: Friction Angle $30^{\circ}$, Perfectly Plastic, Shear Wave Velocity $200 \frac{\mathrm{m}}{\mathrm{s}^{2}}$

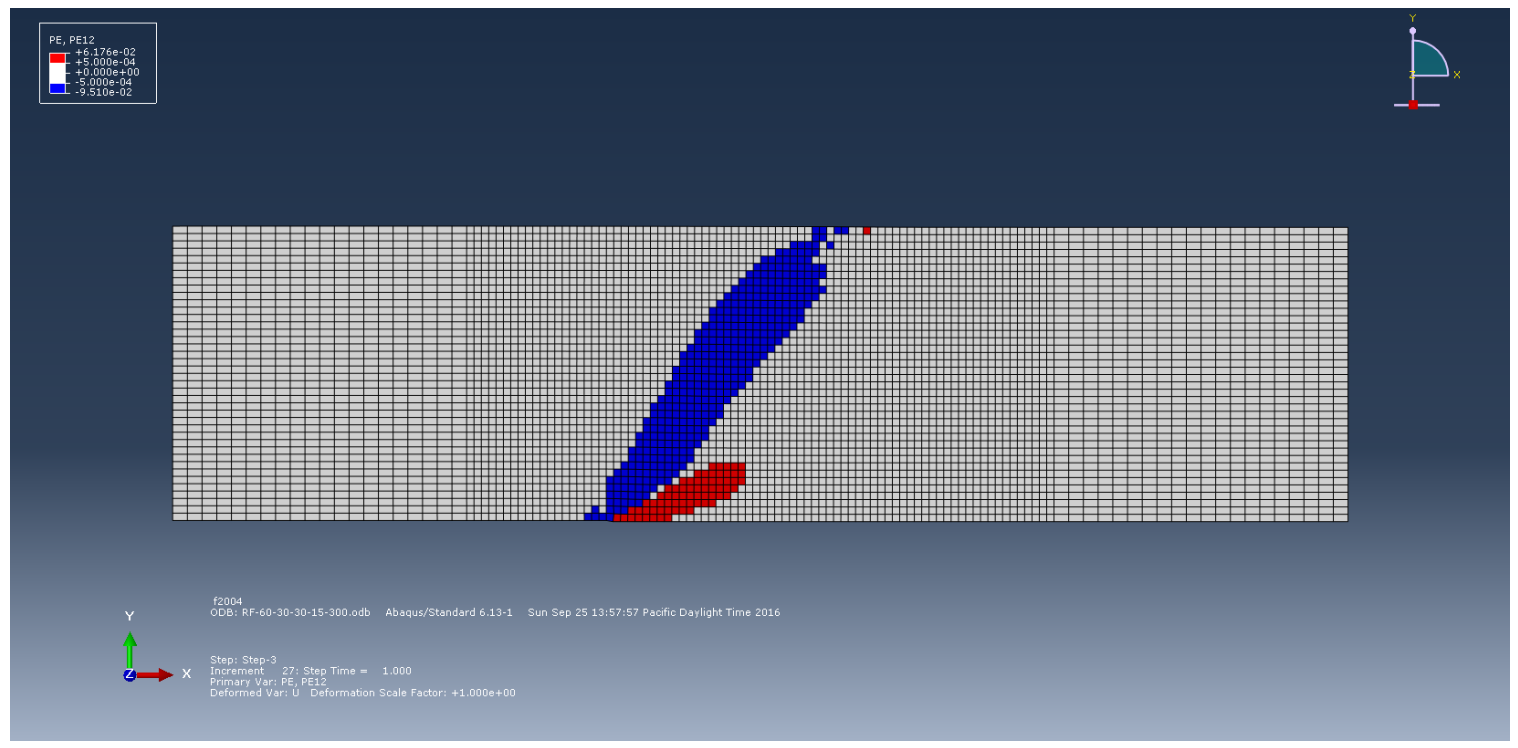

Figure 5.17: Friction Angle $30^{\circ}$, Perfectly Plastic, Shear Wave Velocity $300 \frac{\mathrm{m}}{\mathrm{s}^{2}}$ 


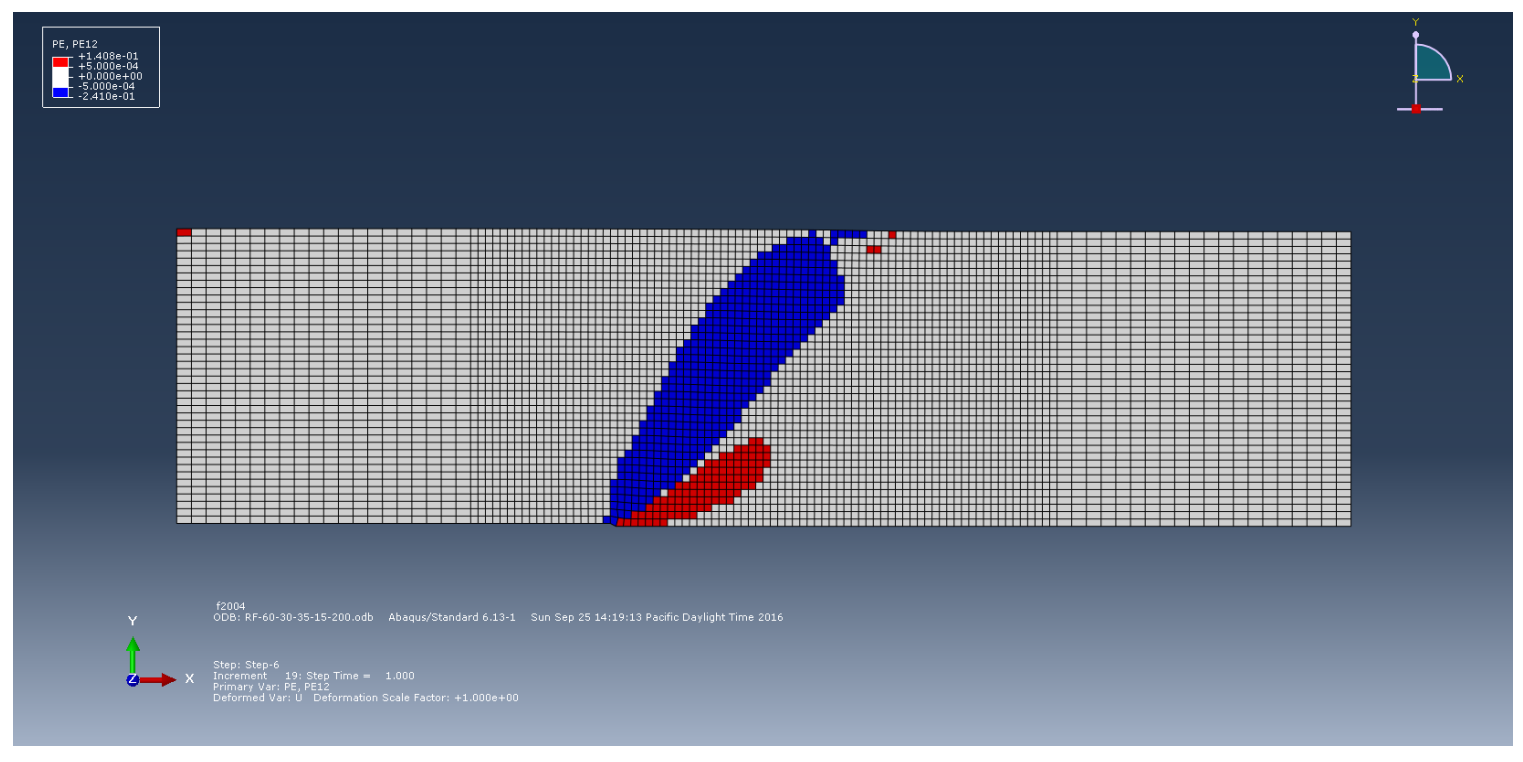

Figure 5.18: Friction Angle $30^{\circ}$, Hardening, Shear Wave Velocity $200 \frac{\mathrm{m}}{\mathrm{s}^{2}}$

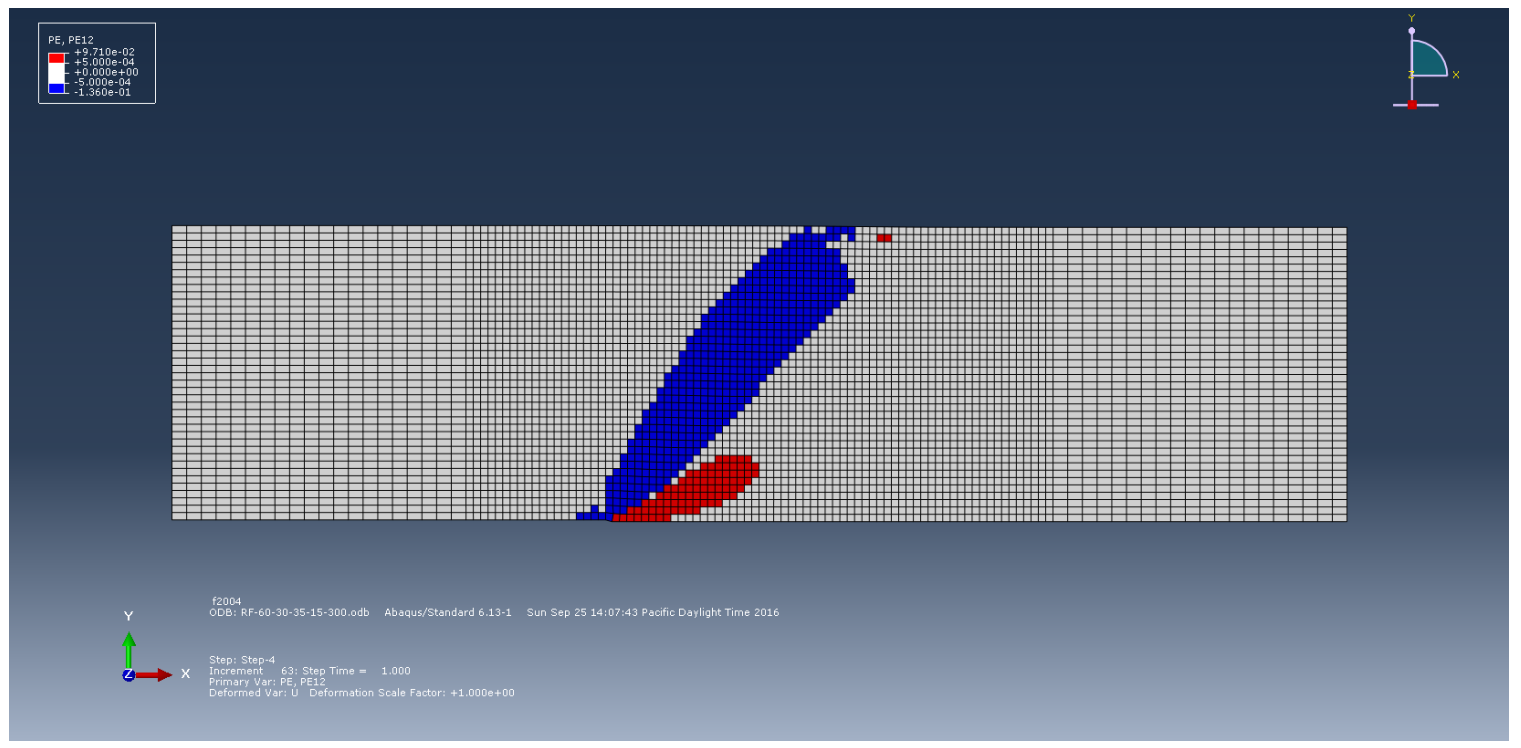

Figure 5.19: Friction Angle $30^{\circ}$, Hardening, Shear Wave Velocity $300 \frac{\mathrm{m}}{\mathrm{s}^{2}}$ 


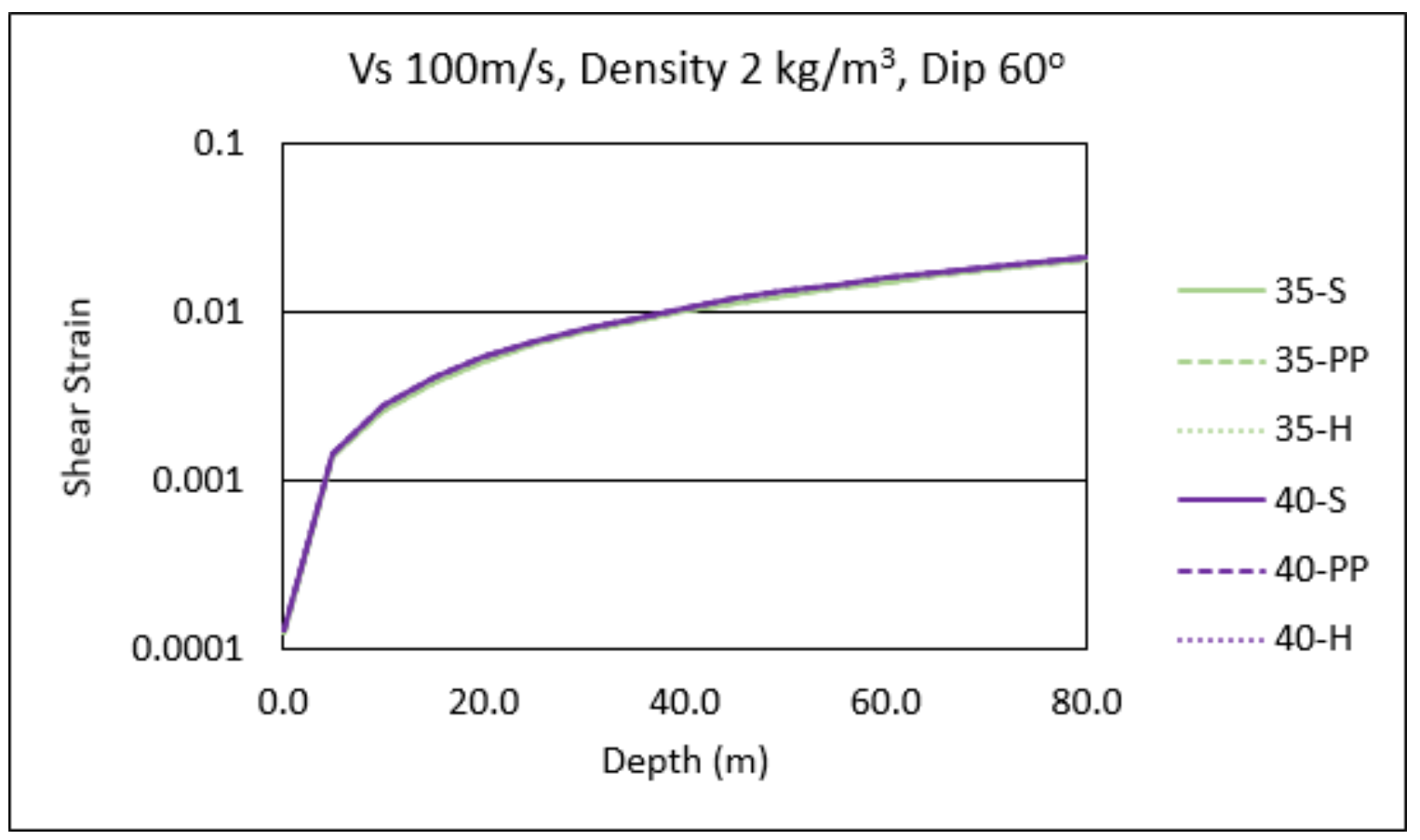

Figure 5.20: Failure Envelops for Softening $\backslash$ Hardening $100 \frac{\mathrm{m}}{\mathrm{s}^{2}} \mid 2 \frac{\mathrm{kg}}{\mathrm{m}^{3}}$

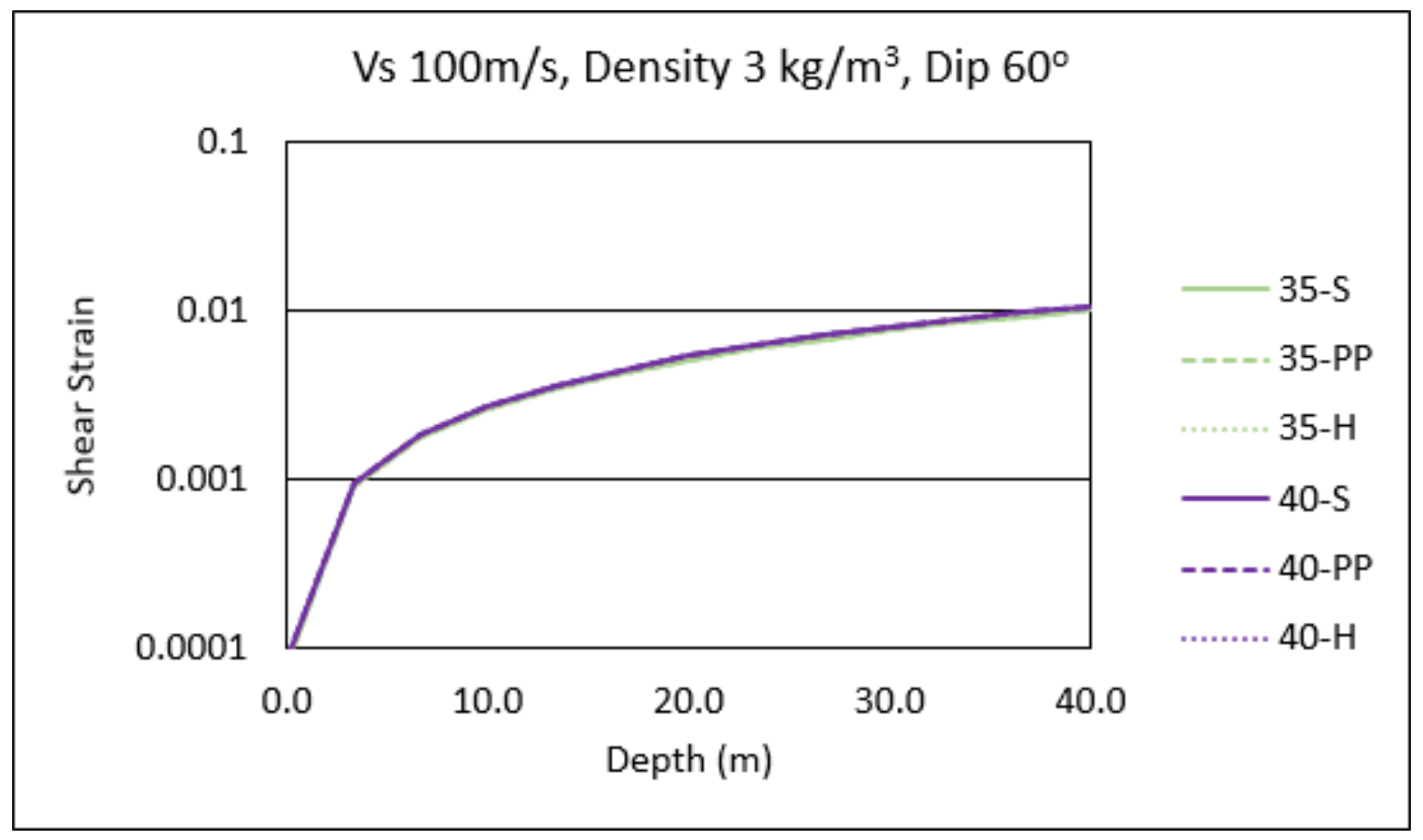

Figure 5.21: Failure Envelops for Softening $\backslash$ Hardening $100 \frac{\mathrm{m}}{\mathrm{s}^{2}} \mid 3 \frac{\mathrm{kg}}{\mathrm{m}^{3}}$ 


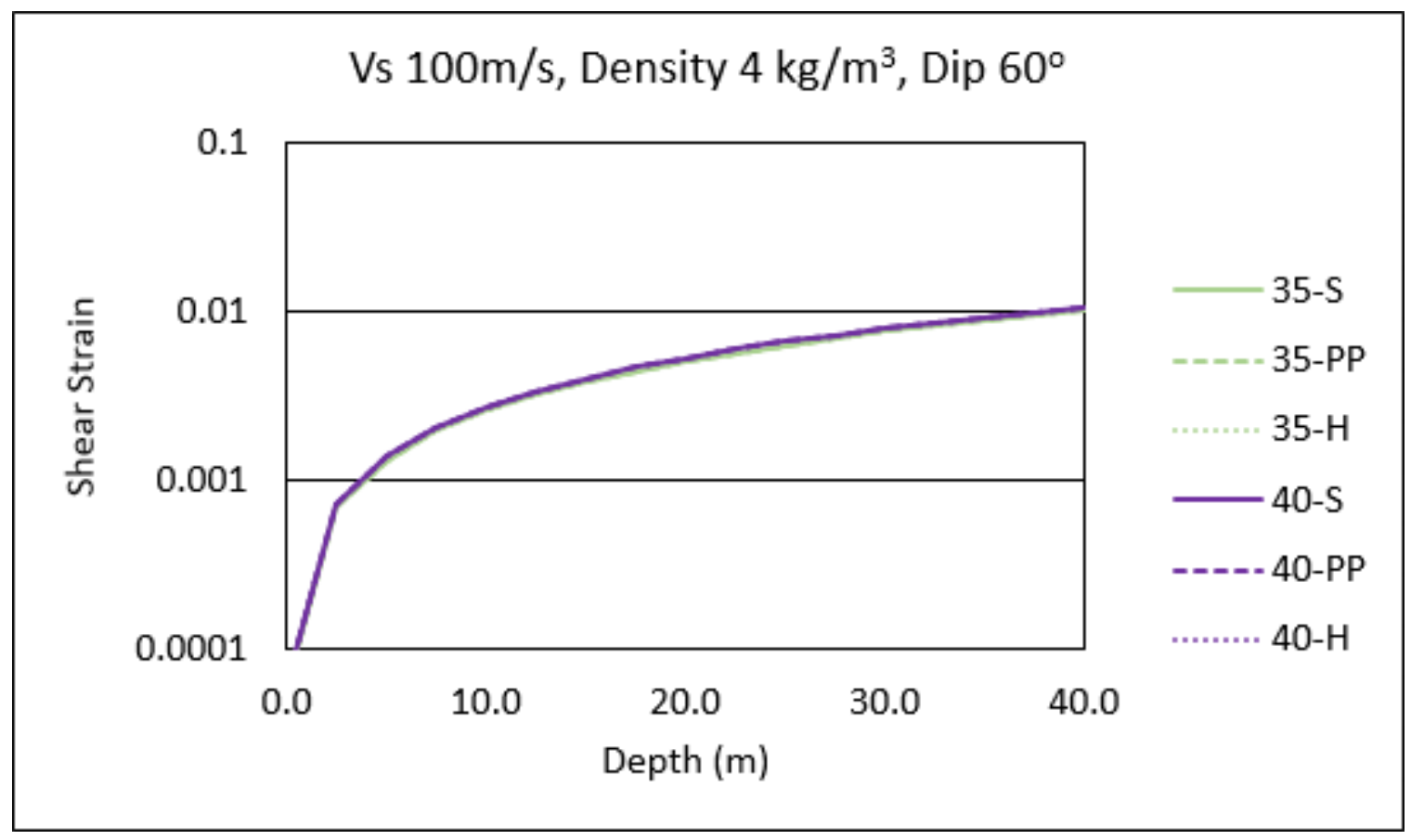

Figure 5.22: Failure Envelops for Softening $\backslash$ Hardening $100 \frac{\mathrm{m}}{\mathrm{s}^{2}} \mid 4 \frac{\mathrm{kg}}{\mathrm{m}^{3}}$

\subsubsection{Dip Angle}

A $60^{\circ}$ Dip Angle was used as the standard for the majority of the study because the results for similar boundary conditions had already been validated with physical testing by [4] [20] [11]. Dip Angles of $45^{\circ}$ and $30^{\circ}$ were also evaluated to investigate the robustness of the trends across different boundary conditions.

Shallower Dip Angles require more total Basal Displacement to achieve the same Normalized Basal Displacement. Figures 5.23 -5.25 show that for a given soil, the yield strain is near identical for varying dip angles. This trend holds for varying Initial Friction Angle, Density, or Post Failure Behavior.

As in Dip Angles of $60^{\circ}$, varying Shear Wave Velocity has a pronounced effect on the yield strain for other Dip Angles. Figure 5.26 shows yield strain varying for different Shear Wave Velocities and Dip Angles given an Initial Friction angle of $35^{\circ}$ and a Density of $2 \frac{\mathrm{kg}}{\mathrm{m}^{3}}$. 


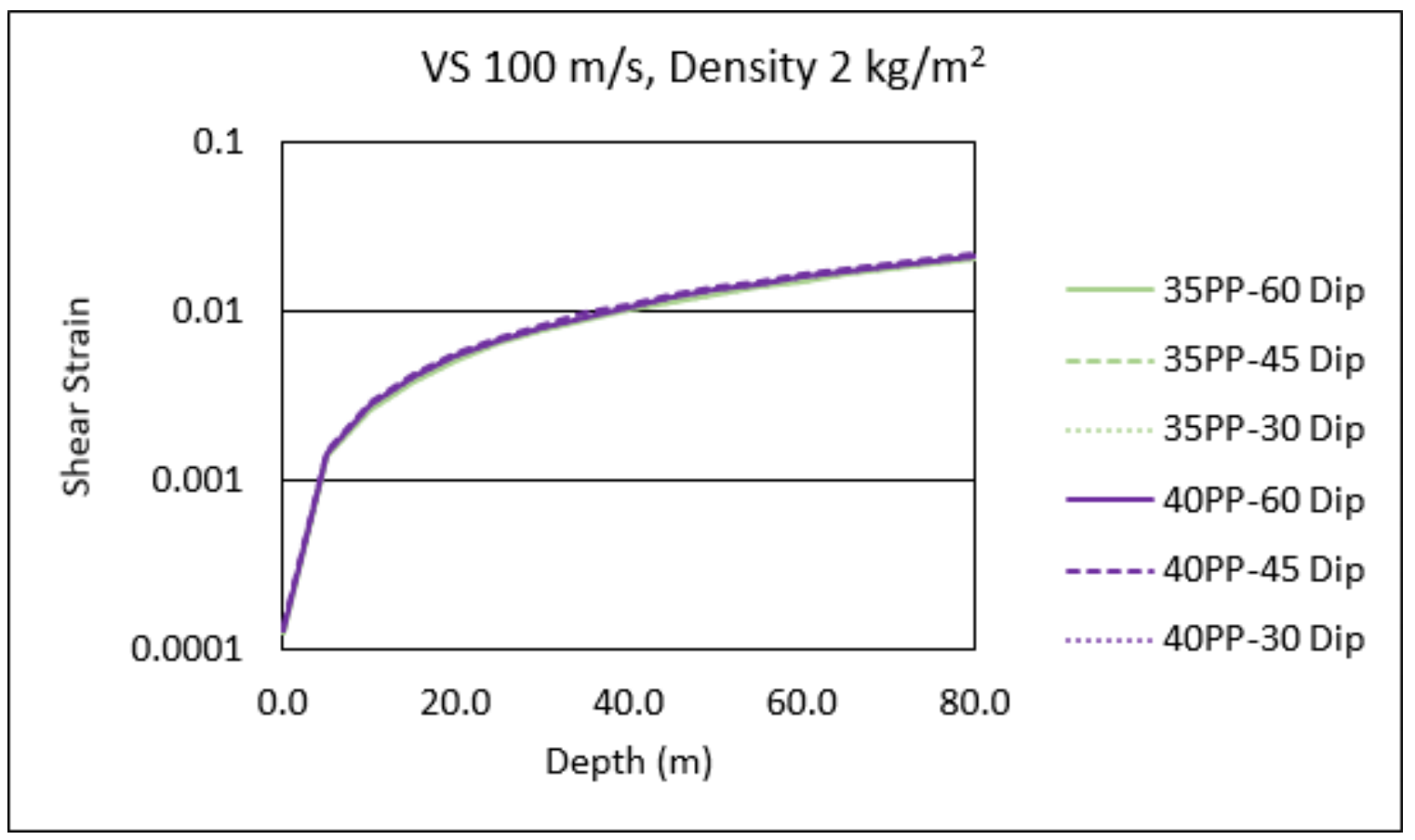

Figure 5.23: Failure Envelops for $35^{\circ}$ PP $100 \frac{\mathrm{m}}{\mathrm{s}^{2}}\left|2 \frac{\mathrm{kg}}{\mathrm{m}^{3}}\right| \mathrm{Dip} 60^{\circ}, 45^{\circ}, 30^{\circ}$

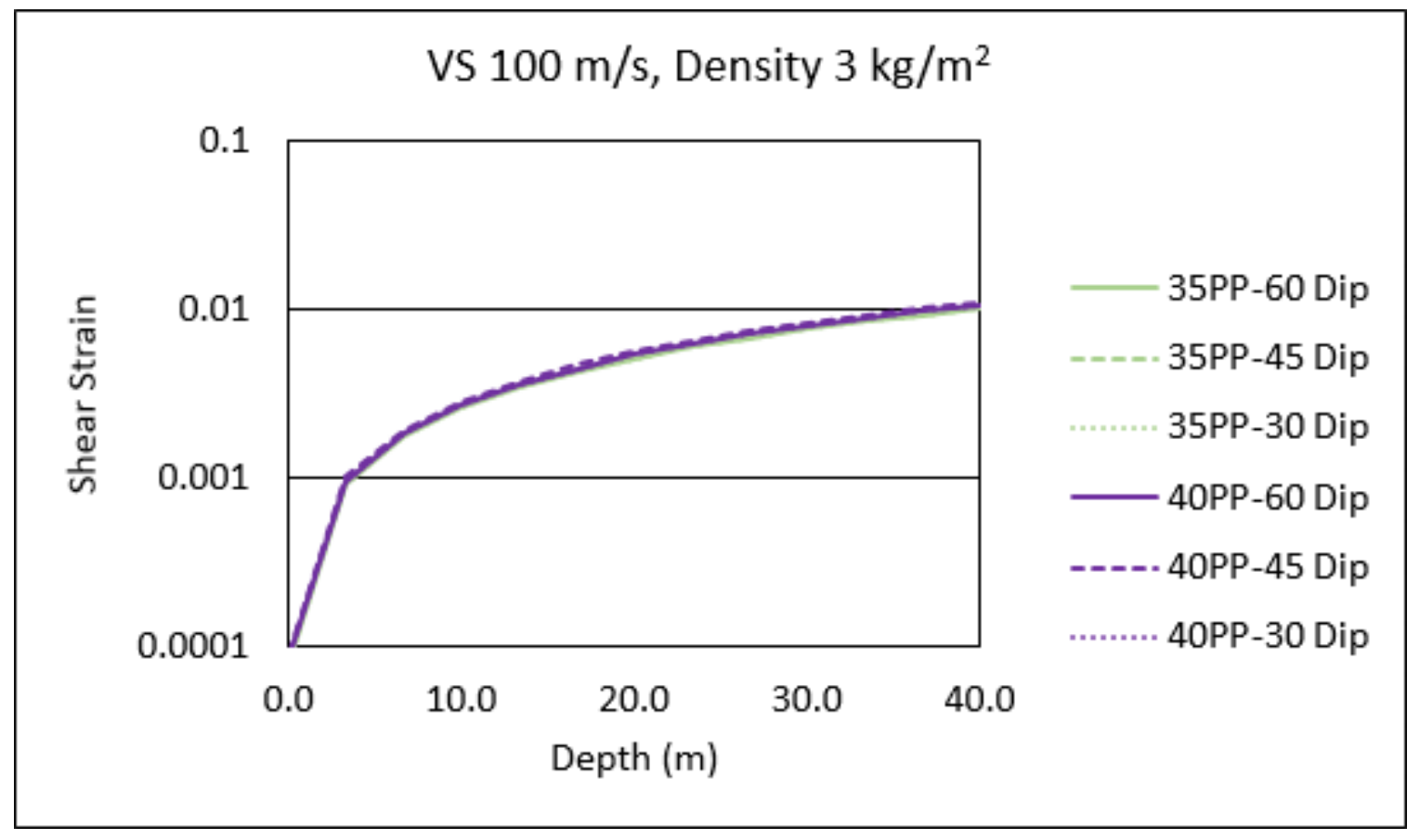

Figure 5.24: Failure Envelops for $35^{\circ}$ PP $100 \frac{\mathrm{m}}{\mathrm{s}^{2}}\left|3 \frac{\mathrm{kg}}{\mathrm{m}^{3}}\right| \mathrm{Dip} 60^{\circ}, 45^{\circ}, 30^{\circ}$ 


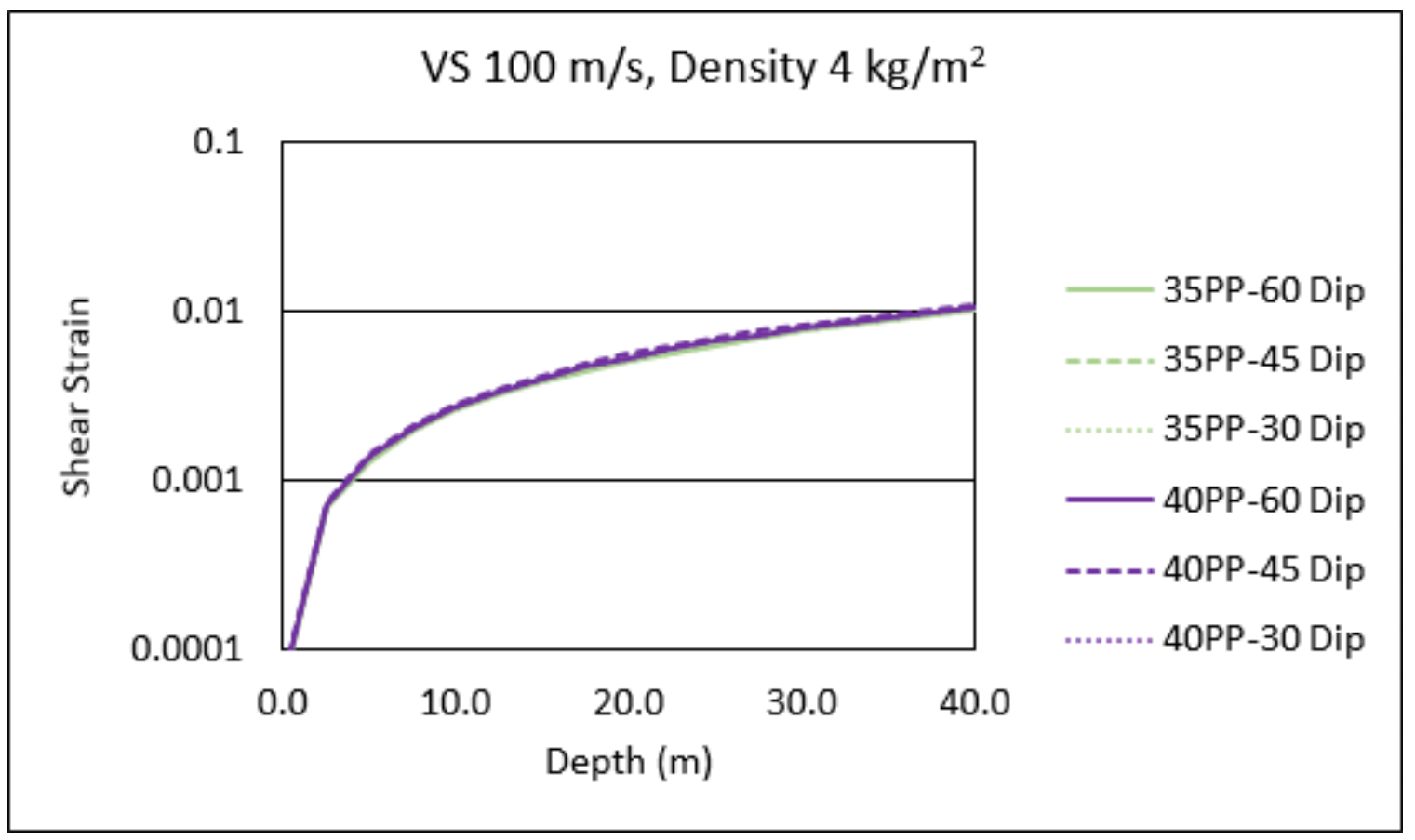

Figure 5.25: Failure Envelops for $35^{\circ}$ PP $100 \frac{\mathrm{m}}{\mathrm{s}^{2}}\left|4 \frac{\mathrm{kg}}{\mathrm{m}^{3}}\right| \mathrm{Dip} 60^{\circ}, 45^{\circ}, 30^{\circ}$

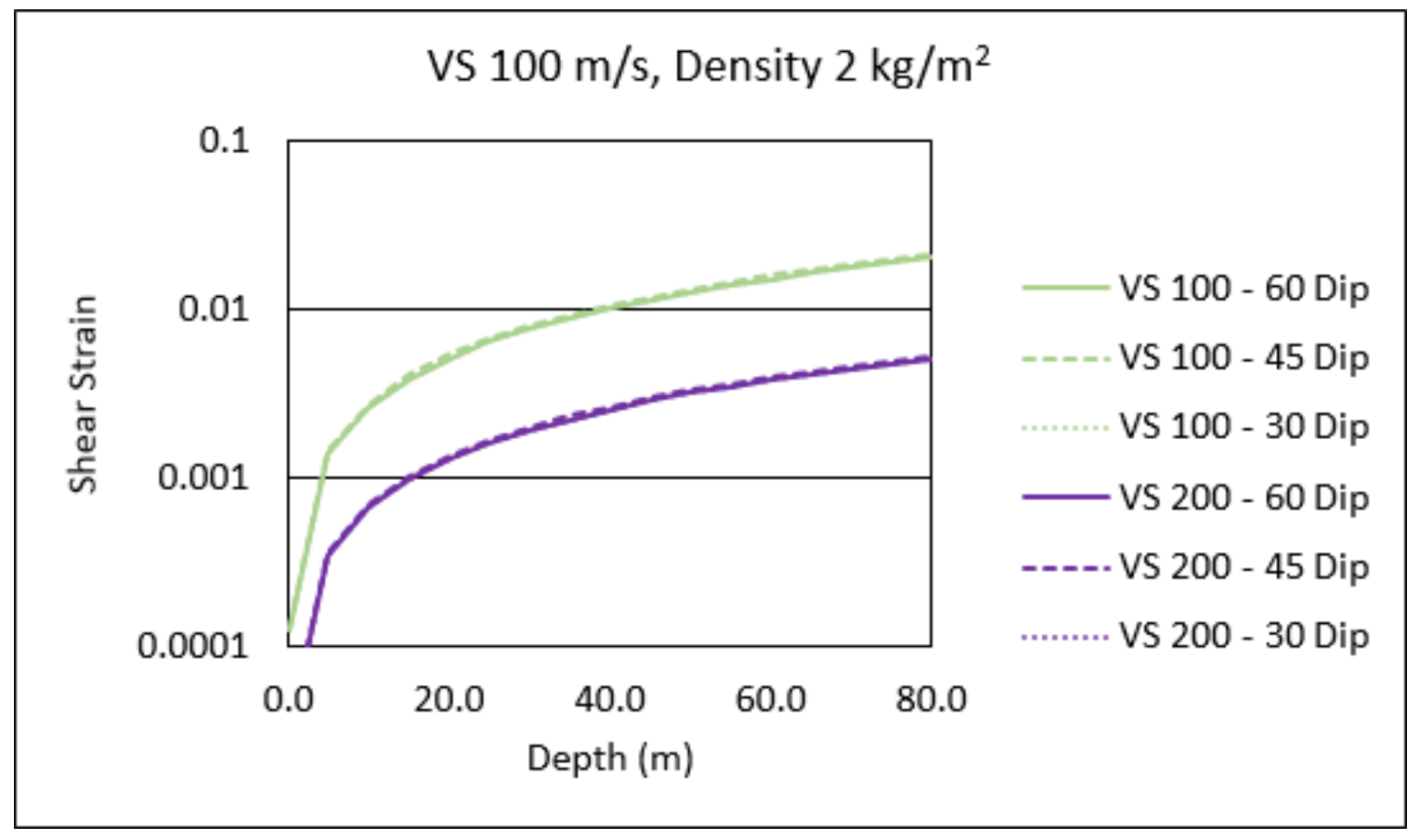

Figure 5.26: Failure Envelops for $35^{\circ}$ PP $100-200 \frac{\mathrm{m}}{\mathrm{s}^{2}}\left|4 \frac{\mathrm{kg}}{\mathrm{m}^{3}}\right|$ Dip $60^{\circ}, 45^{\circ}, 30^{\circ}$ 


\subsubsection{Shear Wave Velocity}

To investigate the role of increasing shear wave velocity, in part to support the conclusions of the empirical study conducted in [2], the elastic modulus of soil profiles were generated to achieve desired $V_{s 30}$ while keeping other elastic properties the same.

Figures $5.27-5.30$ show the results for soil profiles of given shear wave velocity for a fault angle of $60^{\circ}$.

Soils with higher shear wave velocities require less normalized basal offset to achieve surface rupture. The size of the yield surface is dependent on the friction angle and cohesion, even with different elastic moduli the yield surface remains constant. Increasing the elastic modulus to achieve a desired shear wave velocity also increases the shear modulus making a soil profile stiffer. For a given enforced shear strain, the stress in a stiffer soil would be higher accelerating the rate at which it hits yield.

The stress hardening/softening behavior of the soil also contributes to the required normalized basal displacement to achieve rupture, but it's effect is secondary to the influence of shear wave velocity. 


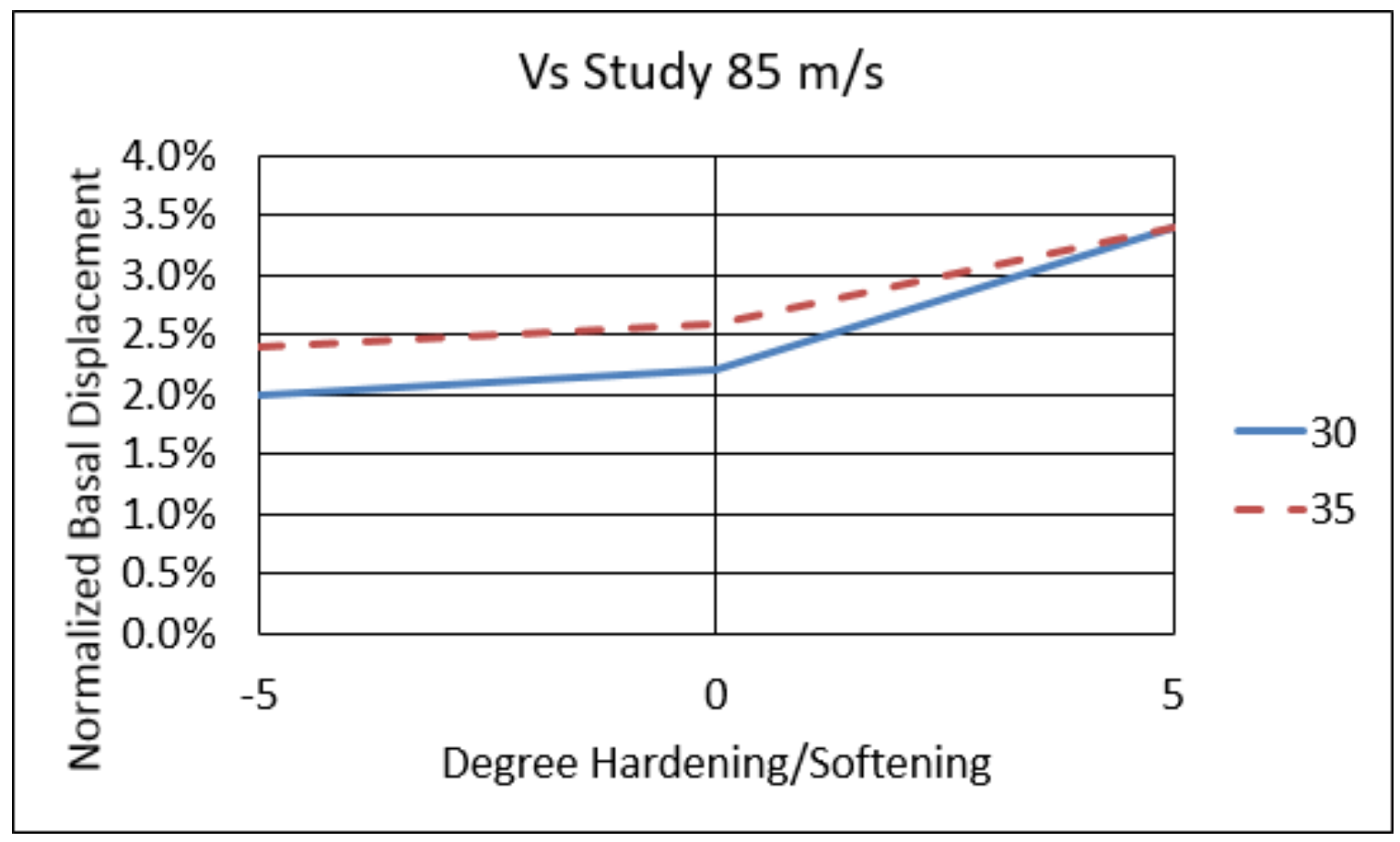

Figure 5.27: Test Results for Shear Wave Velocity Study $85 \frac{\mathrm{m}}{\mathrm{s}}$

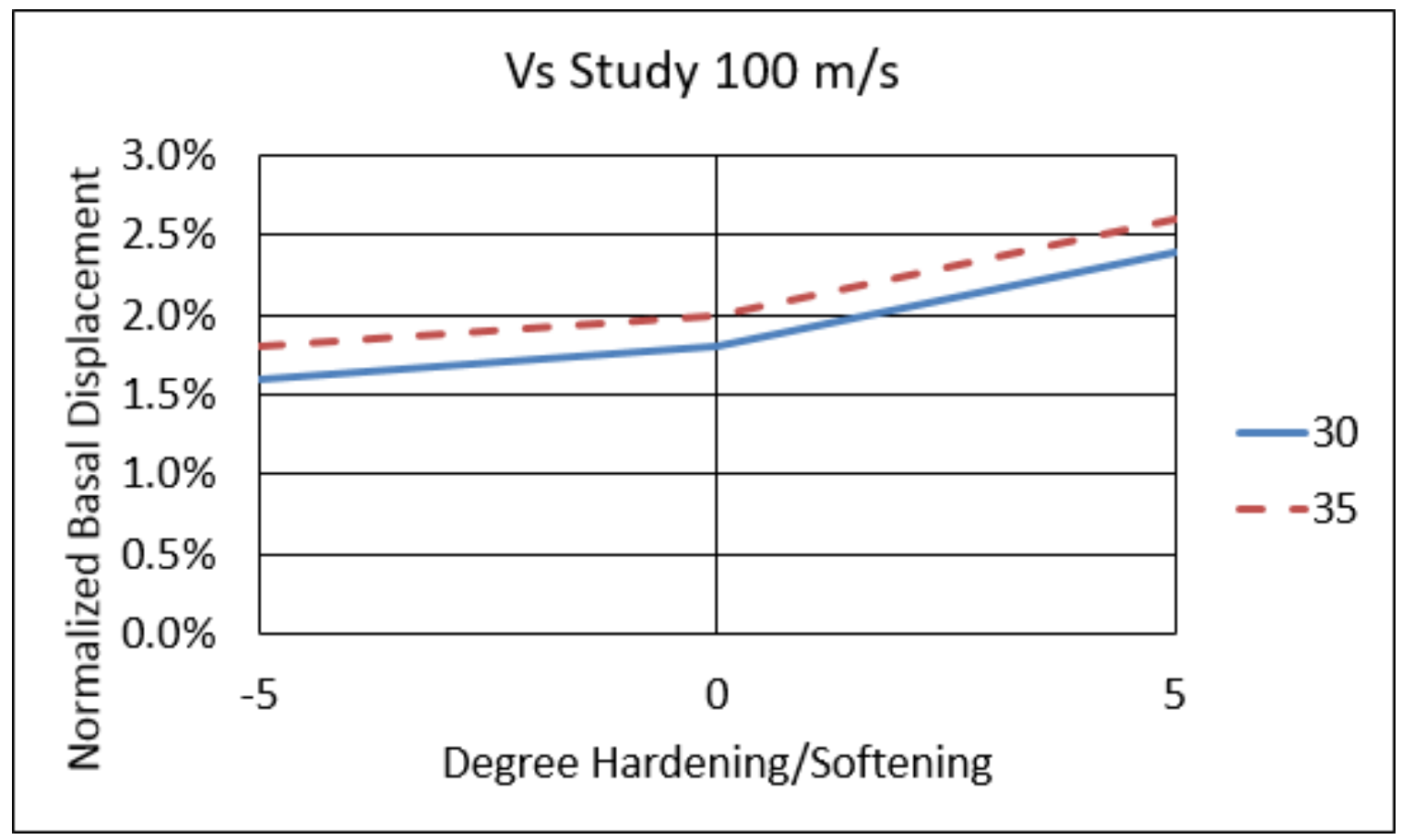

Figure 5.28: Test Results for Shear Wave Velocity Study $100 \frac{\mathrm{m}}{\mathrm{s}}$ 


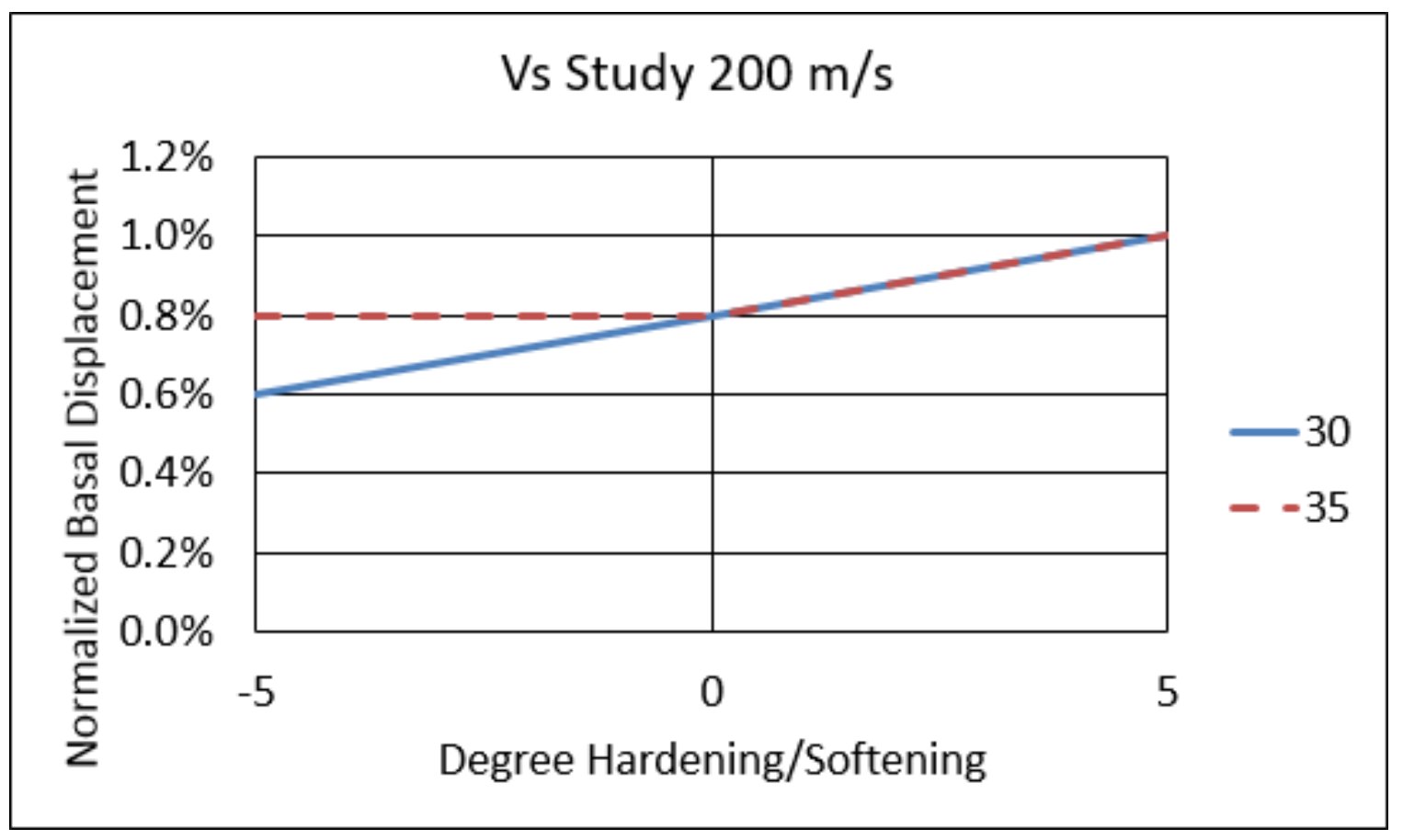

Figure 5.29: Test Results for Shear Wave Velocity Study $200 \frac{\mathrm{m}}{\mathrm{s}}$

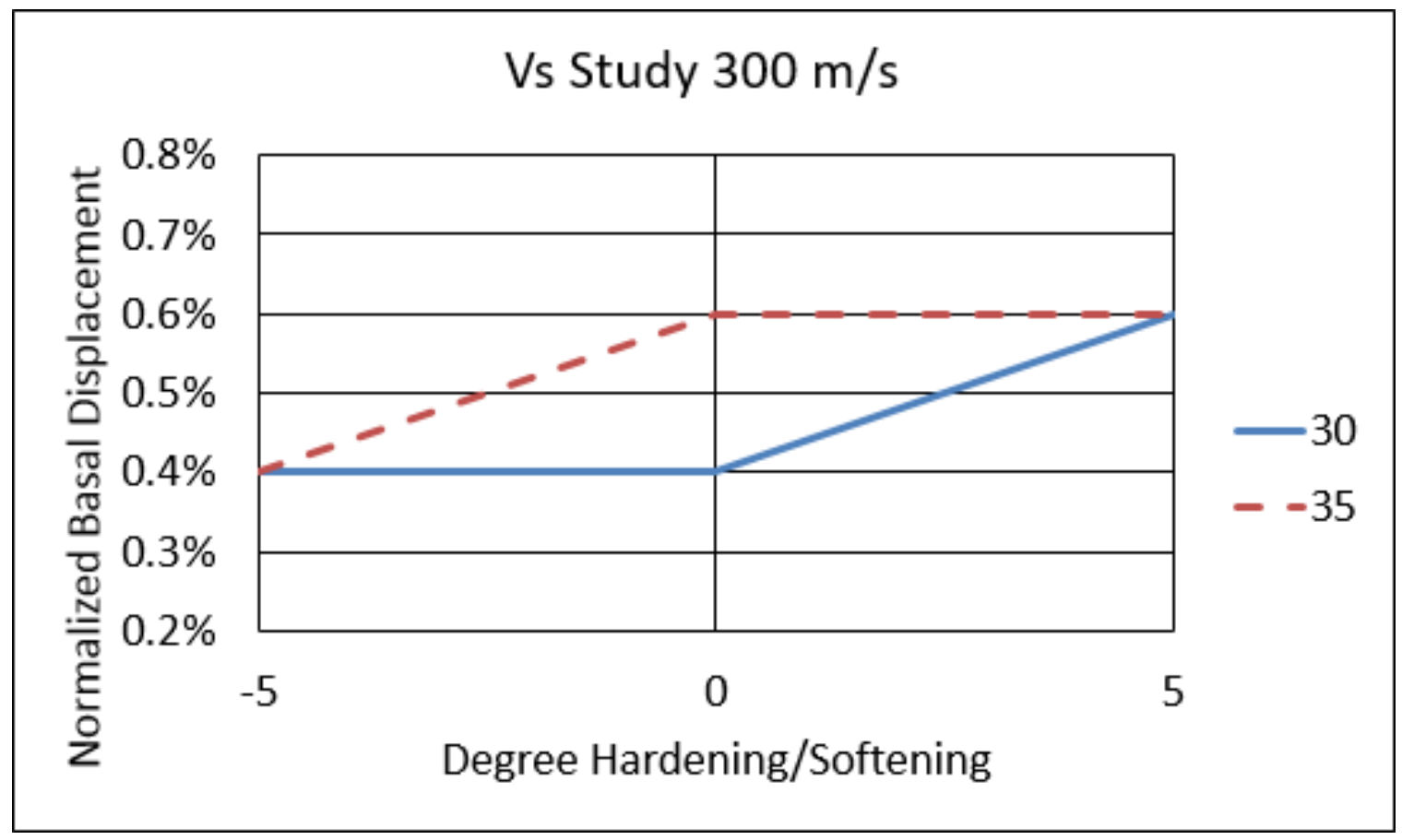

Figure 5.30: Test Results for Shear Wave Velocity Study $300 \frac{\mathrm{m}}{\mathrm{s}}$ 
The initial check was to evaluate the rate of rupture propagation for a soil with the same failure surface and post failure behavior but different shear wave velocities.

Using Equation (3) the Elastic Modulus was modified from the base soil properties of a Fontainebleau sand to generate the desired $V_{S}$. The results of the Numerical Study showed that increasing the Shear Wave Velocity decreased the required Normalized Basal Displacement to achieve rupture. The results of the Analytical model below support these results by showing that the yield strain for soils reduces appreciably with increasing Shear Wave Velocity.

Figures 5.31 -5.33 show the yield bands for a Perfectly Plastic soil with an Initial Friction Angle of $30^{\circ}$ with 3 different Shear Wave Velocities. The shape and width of the bands remains consistent regardless of the Shear Wave Velocity, the only difference is the max plastic strain and the amount of Normalized Basal Offset required to achieve ruptre.

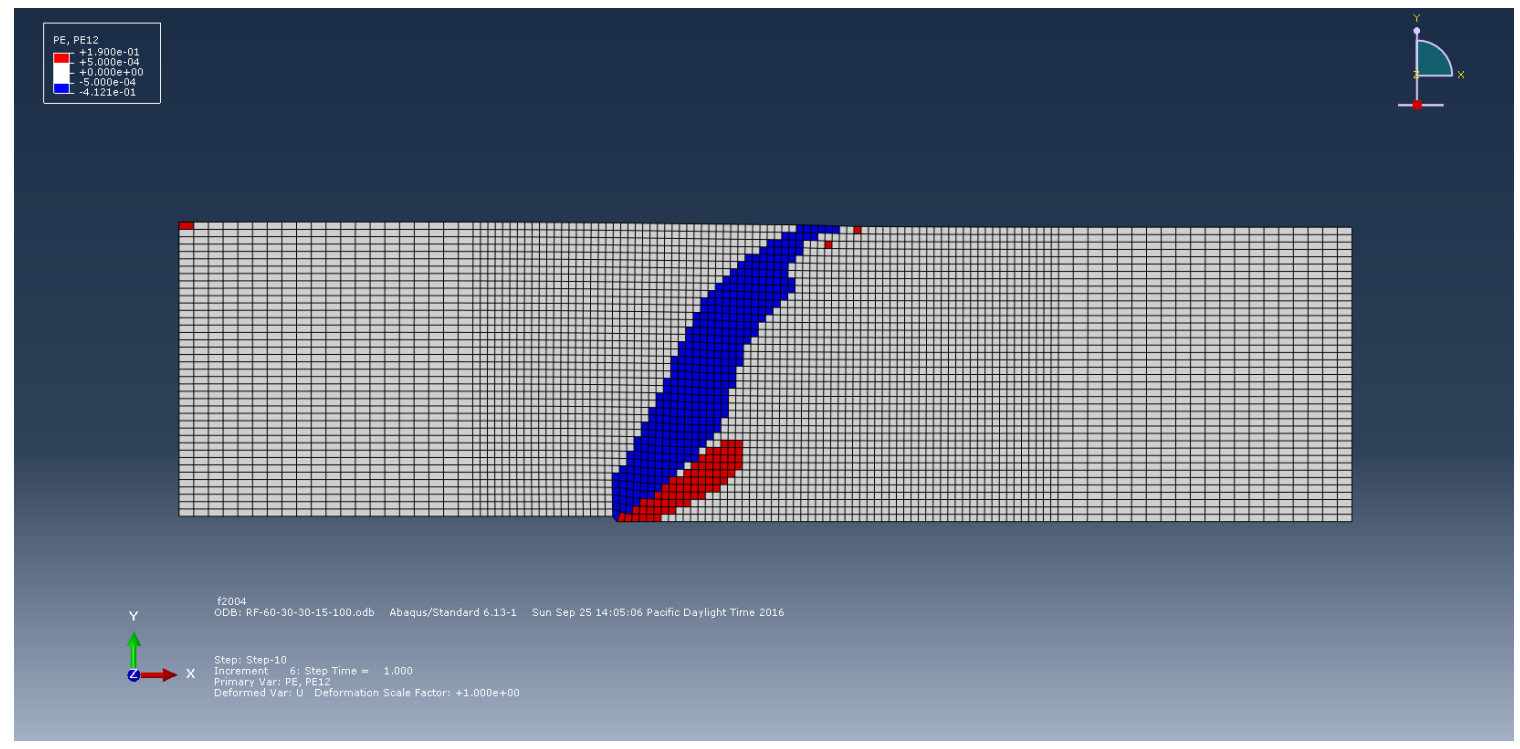

Figure 5.31: Shear Wave Velocity $100 \frac{\mathrm{m}}{\mathrm{s}^{2}}$ 


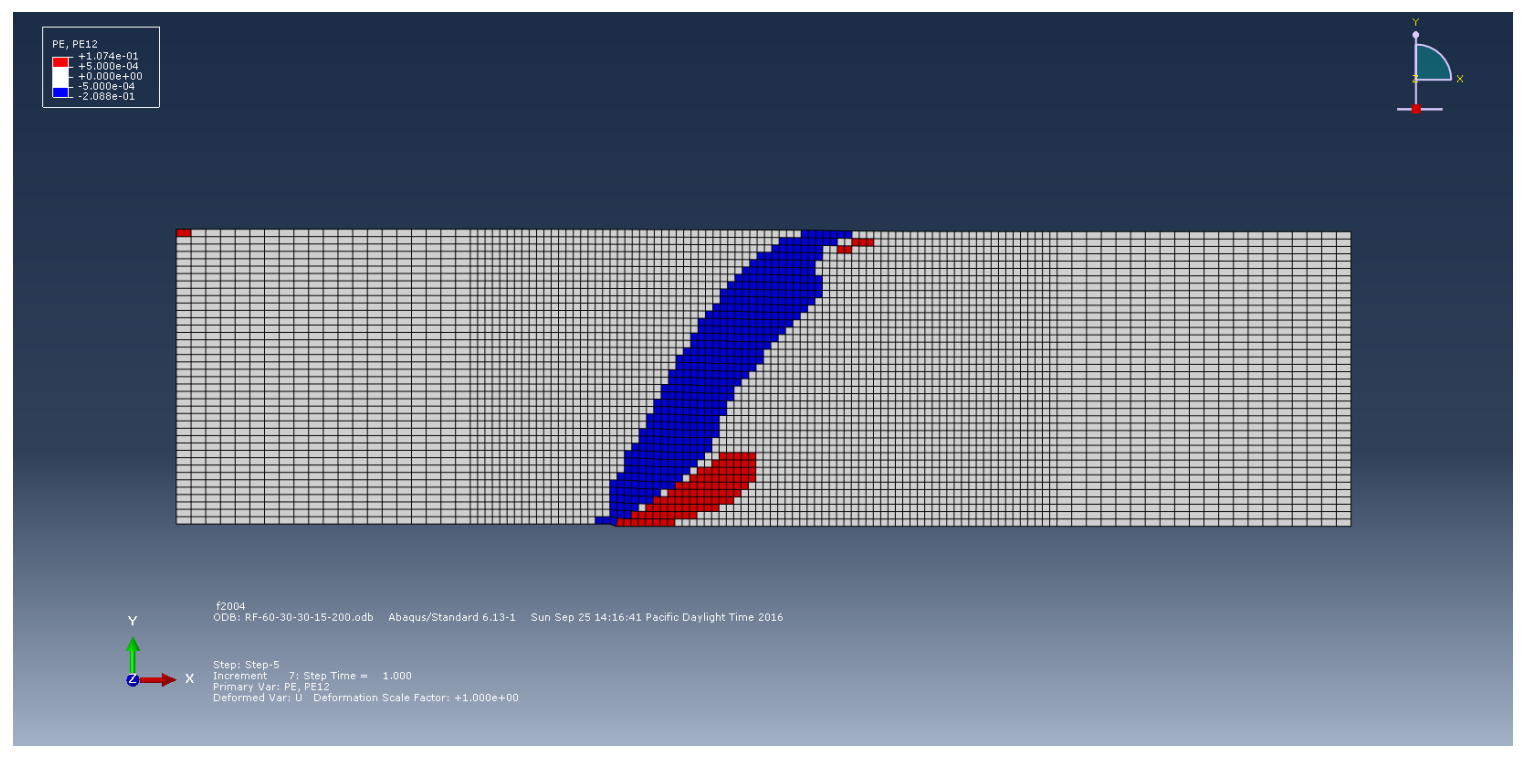

Figure 5.32: Shear Wave Velocity $200 \frac{\mathrm{m}}{\mathrm{s}^{2}}$

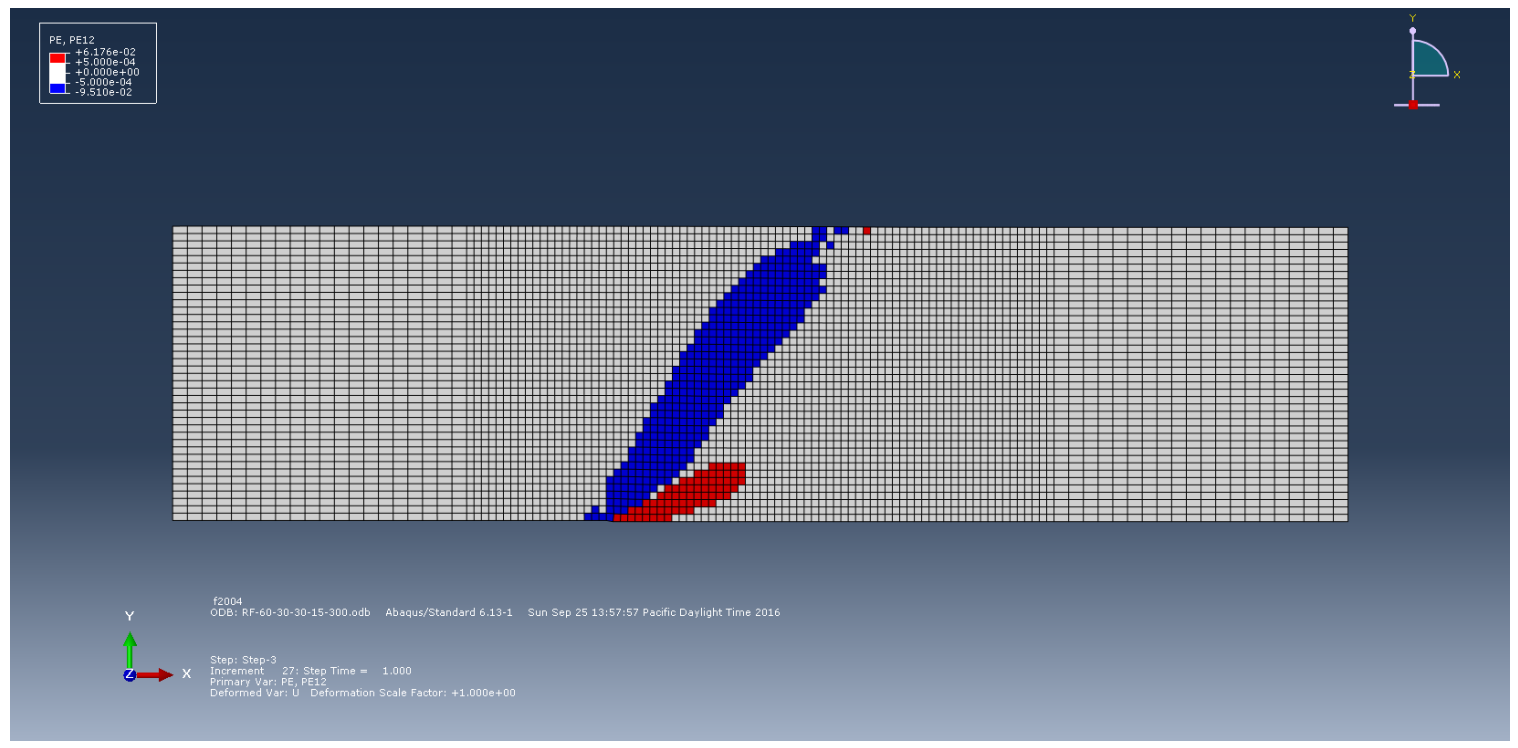

Figure 5.33: Shear Wave Velocity $300 \frac{\mathrm{m}}{\mathrm{s}^{2}}$ 
The Analytical Model's Shear Wave Velocity study results are consistent with the FEA results. Increasing Shear Wave Velocity has the biggest impact on the yield strain for the soils studied.

Figures $5.34-5.36$, show the yield strain for a given depth of soils with the same initial friction angle, $35^{\circ}$, and Density, $2 \frac{\mathrm{kg}}{\mathrm{m}^{3}}$, for 3 types of post failure behavior.

The trend of decreasing yield strain with increasing Shear Wave Velocity, holds regardless of the post failure behavior of the soil.

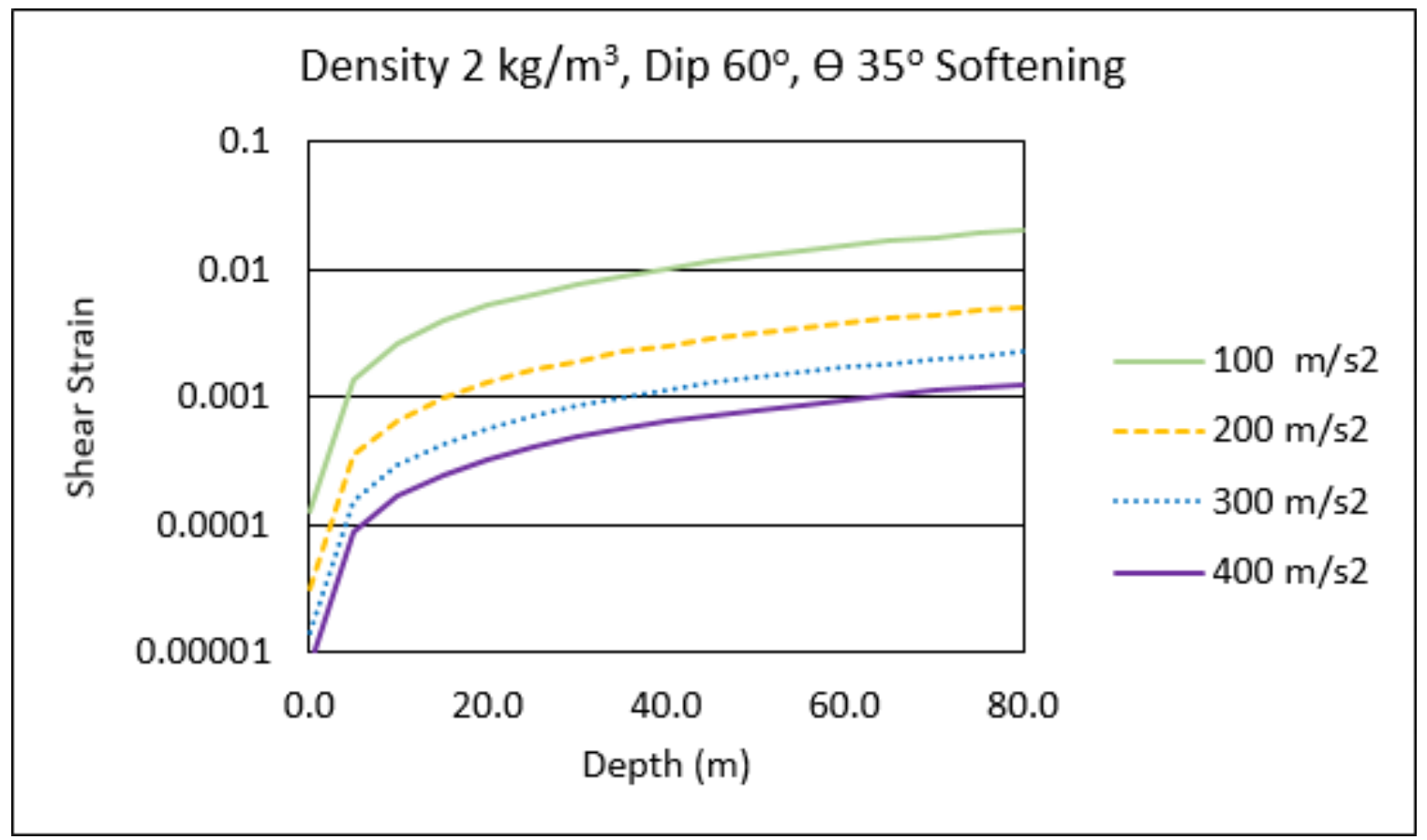

Figure 5.34: Failure Envelops for $35^{\circ}$ Softening $100-400 \frac{\mathrm{m}}{\mathrm{s}^{2}} \mid 2 \frac{\mathrm{kg}}{\mathrm{m}^{3}}$ 


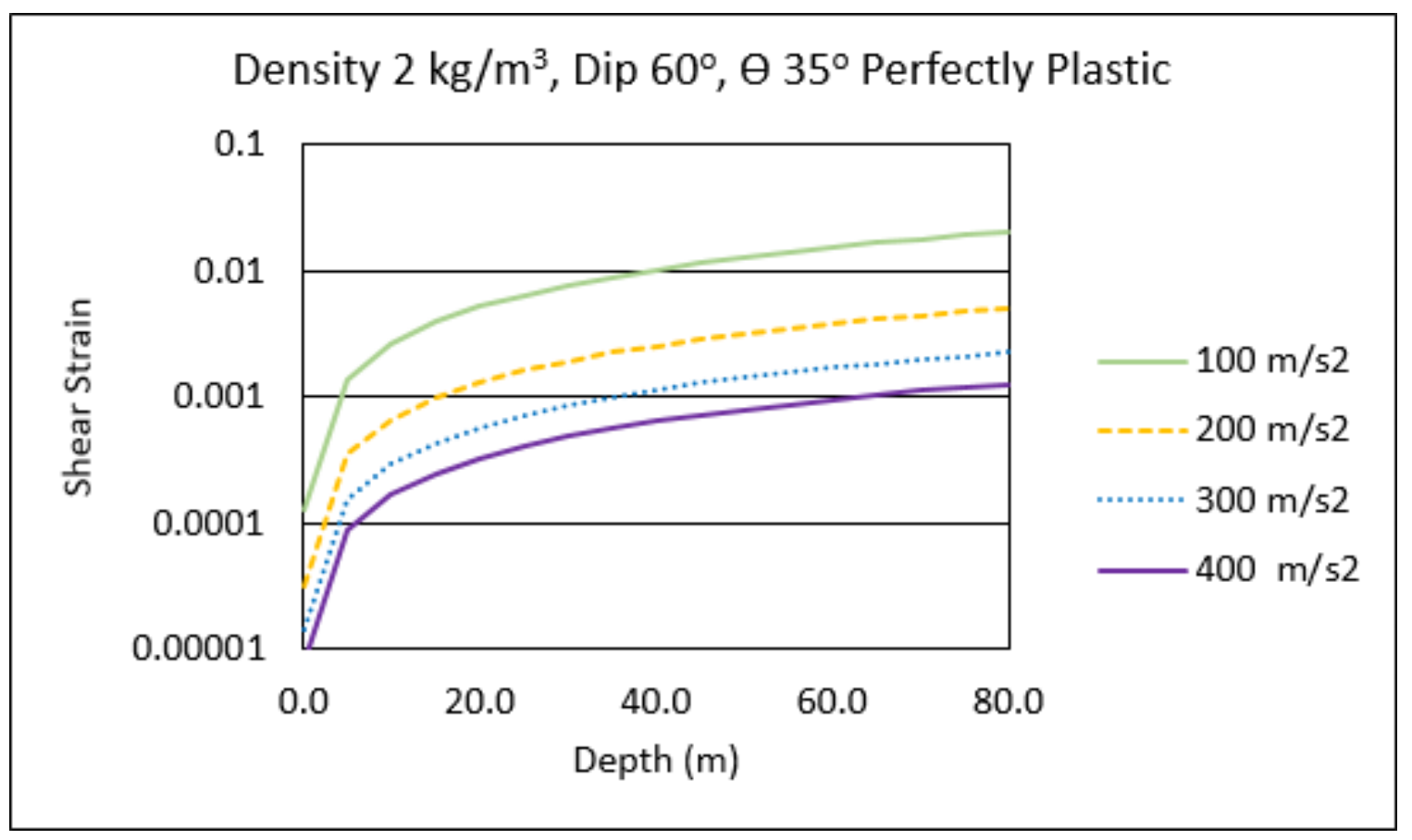

Figure 5.35: Failure Envelops for $35^{\circ}$ Perfectly Plastic $100-400 \frac{\mathrm{m}}{\mathrm{s}^{2}} \mid 2 \frac{\mathrm{kg}}{\mathrm{m}^{3}}$

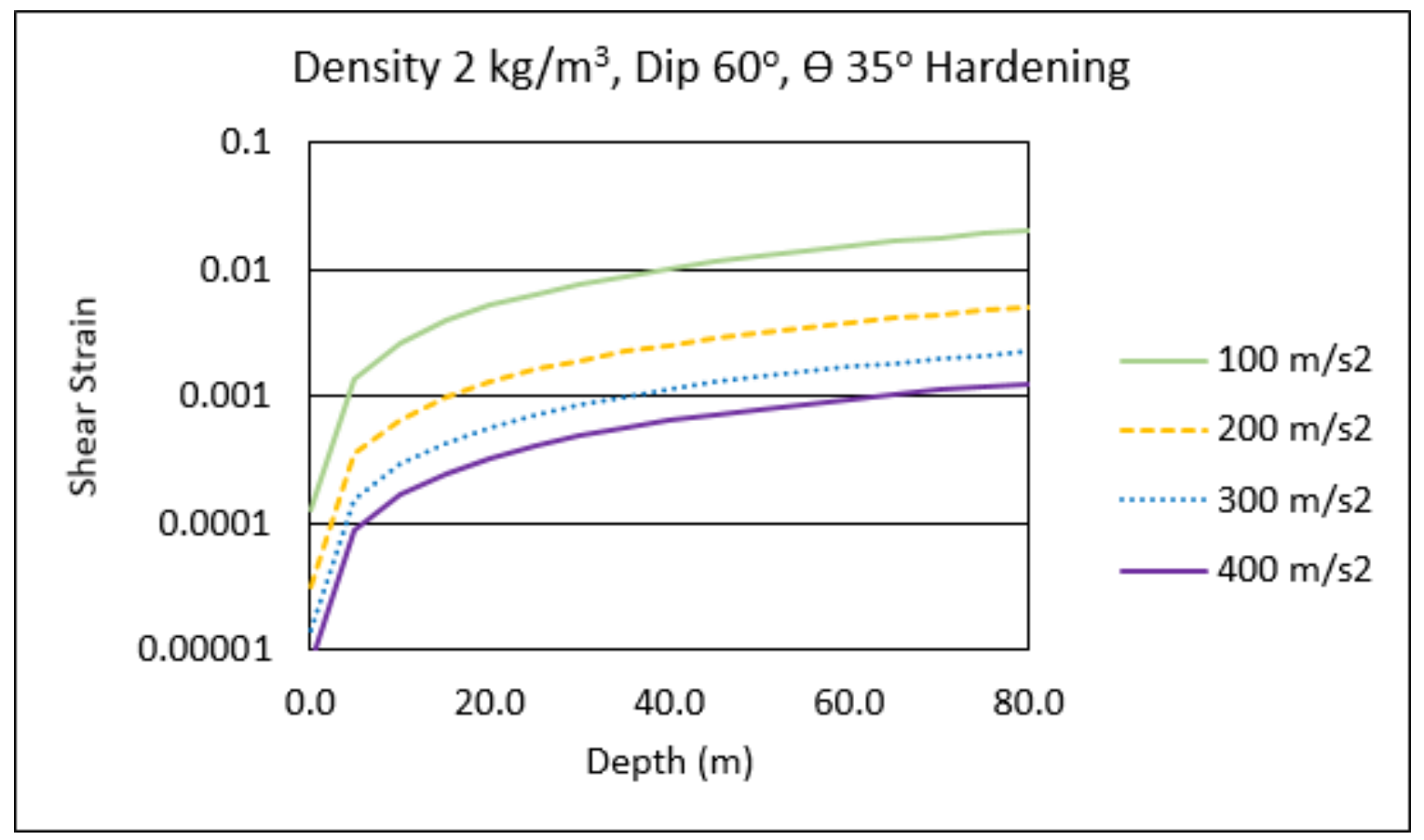

Figure 5.36: Failure Envelops for $35^{\circ}$ Hardening $100-400 \frac{\mathrm{m}}{\mathrm{s}^{2}} \mid 2 \frac{\mathrm{kg}}{\mathrm{m}^{3}}$ 


\subsubsection{Density}

From (3) it is evident that shear wave velocity is a function of both shear modulus and density. To examine the effect density had on the rate of rupture propagation a study was performed evaluating different densities on a soil with a set shear wave velocity.

Figures $5.37-5.39$ show the results for soil profiles for a shear wave velocity of $100 \frac{\mathrm{m}}{\mathrm{s}}$ and a fault angle of $60^{\circ}$.

For a given shear wave velocity modifying the density did not have a significant impact on the required normalized basal displacement to achieve rupture. The contribution of strain hardening/softening effects had a more significant impact on the required normalized basal displacement to achieve rupture than the change in density.

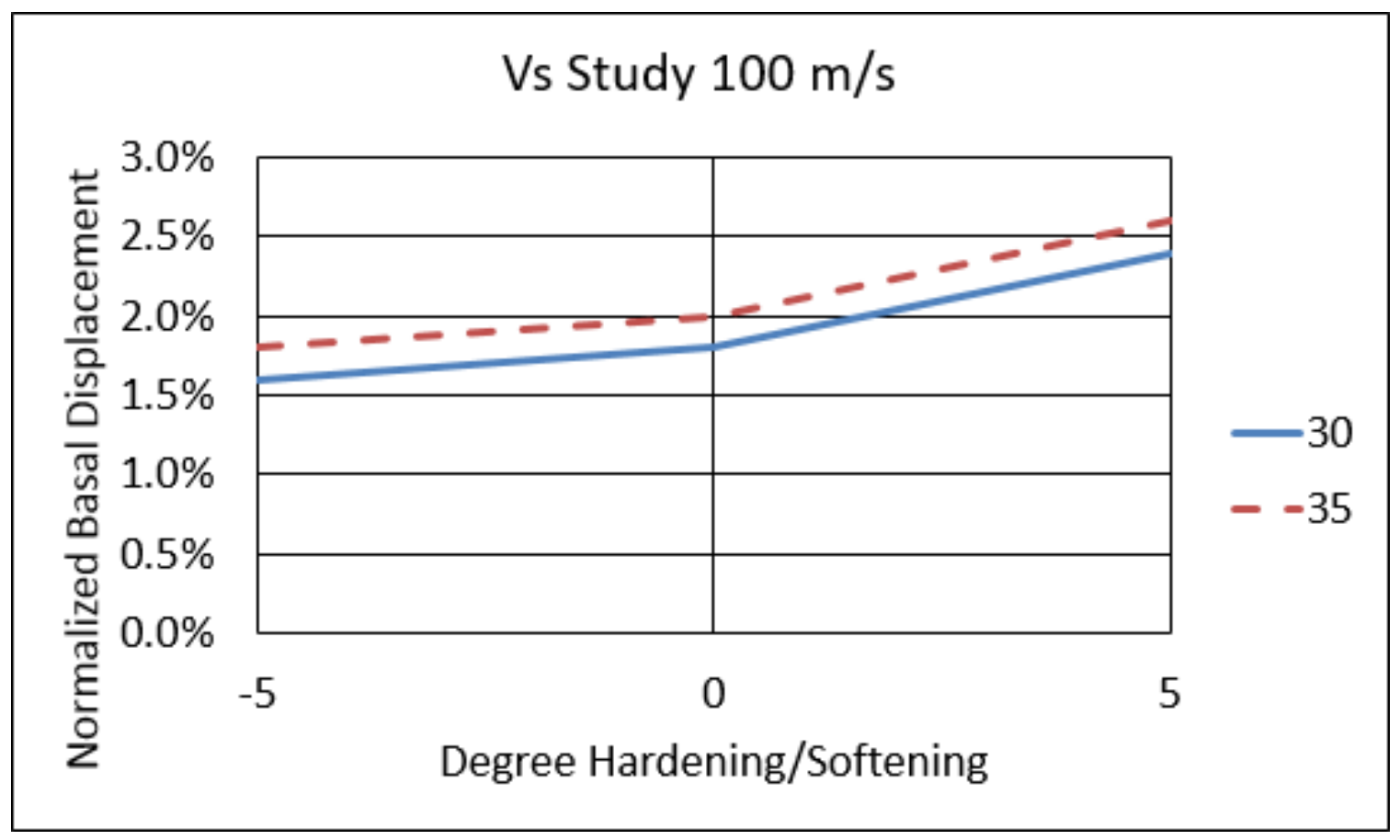

Figure 5.37: Test Results for Density Study $2 \frac{\mathrm{kg}}{\mathrm{m}^{3}}$ 


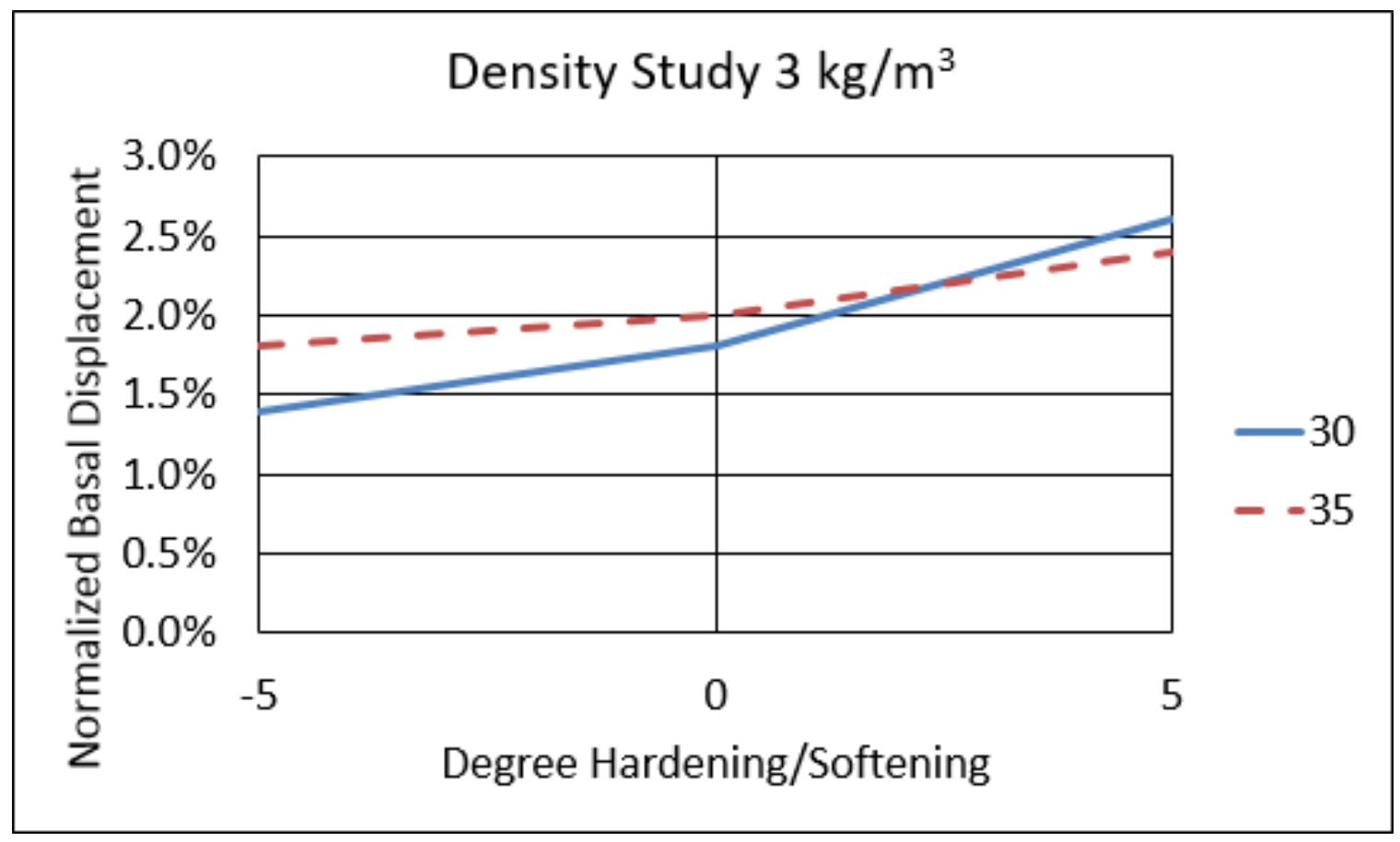

Figure 5.38: Test Results for Density Study $3 \frac{\mathrm{kg}}{\mathrm{m}^{3}}$

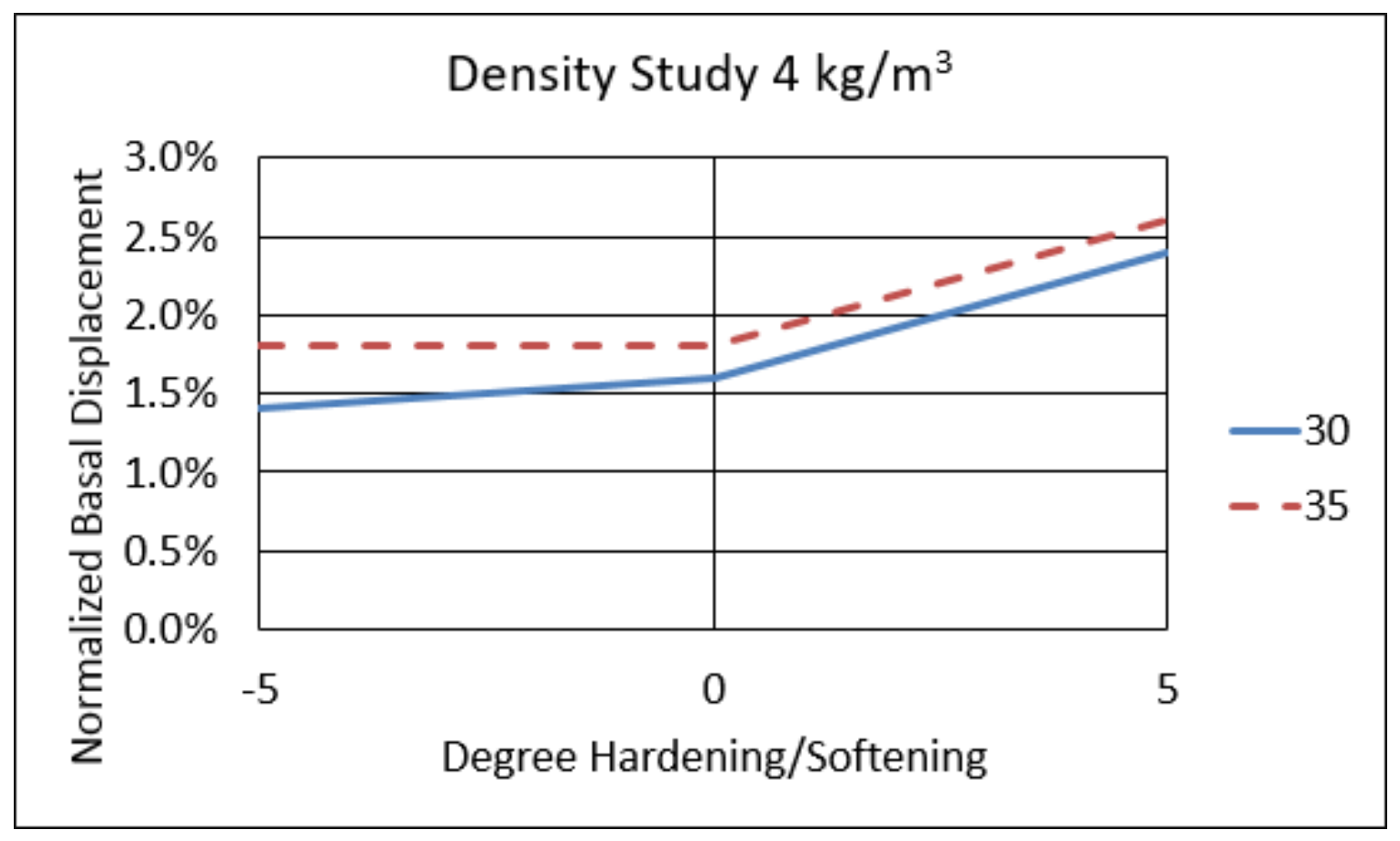

Figure 5.39: Test Results for Density Study $4 \frac{\mathrm{kg}}{\mathrm{m}^{3}}$ 


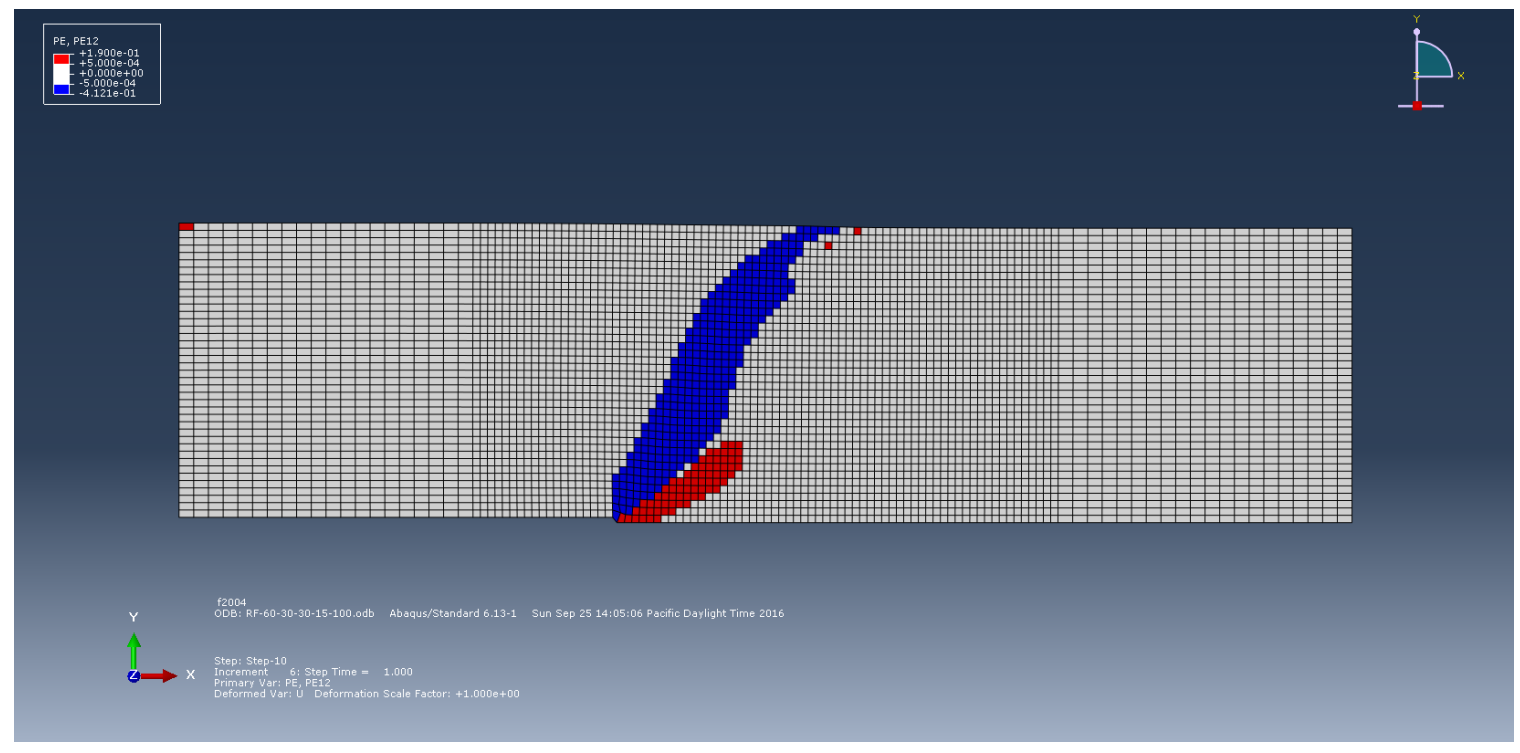

Figure 5.40: Friction Angle $30^{\circ}$, Density $2 \frac{\mathrm{kg}}{\mathrm{m}^{3}}$

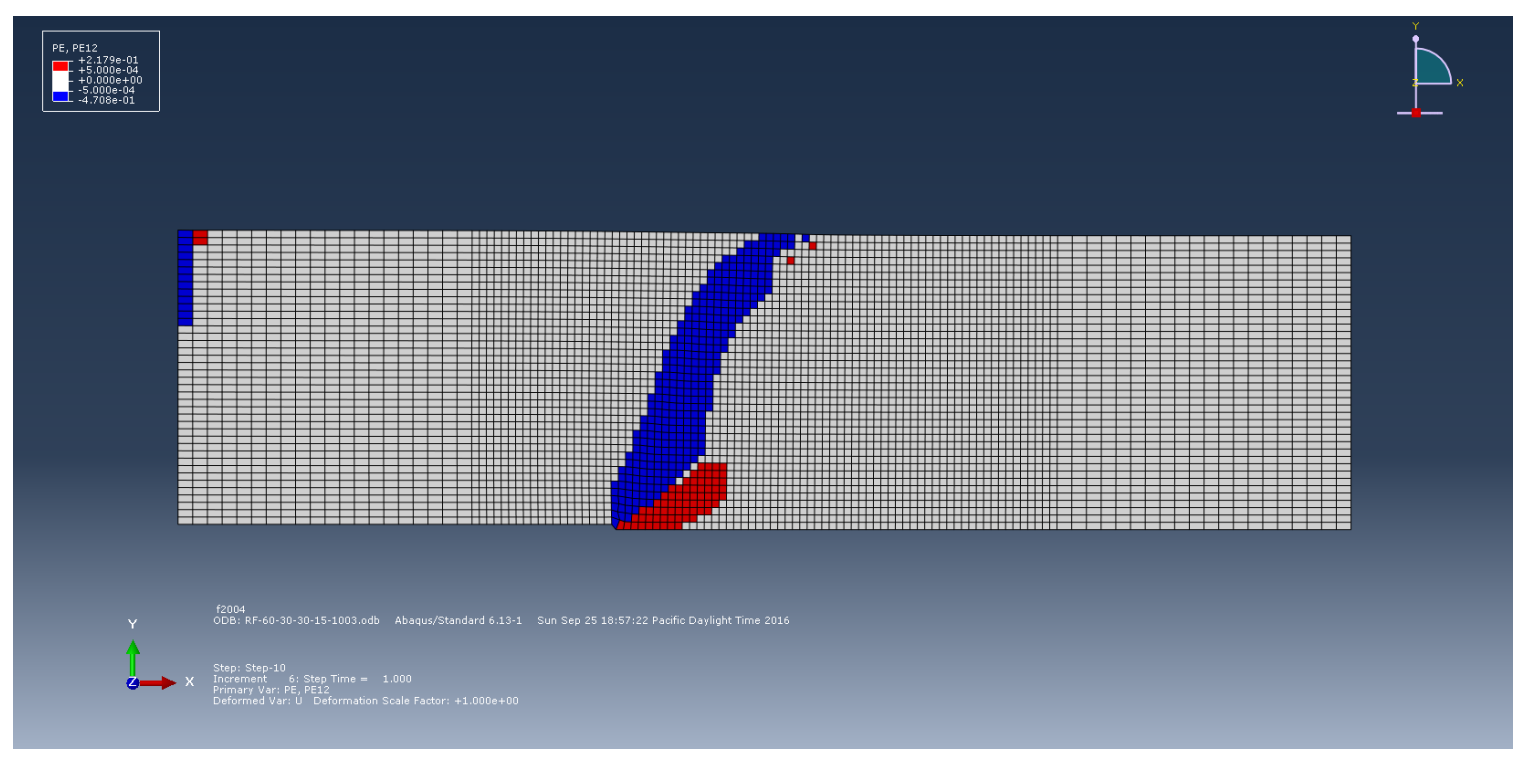

Figure 5.41: Friction Angle $30^{\circ}$, Density $3 \frac{\mathrm{kg}}{\mathrm{m}^{3}}$ 


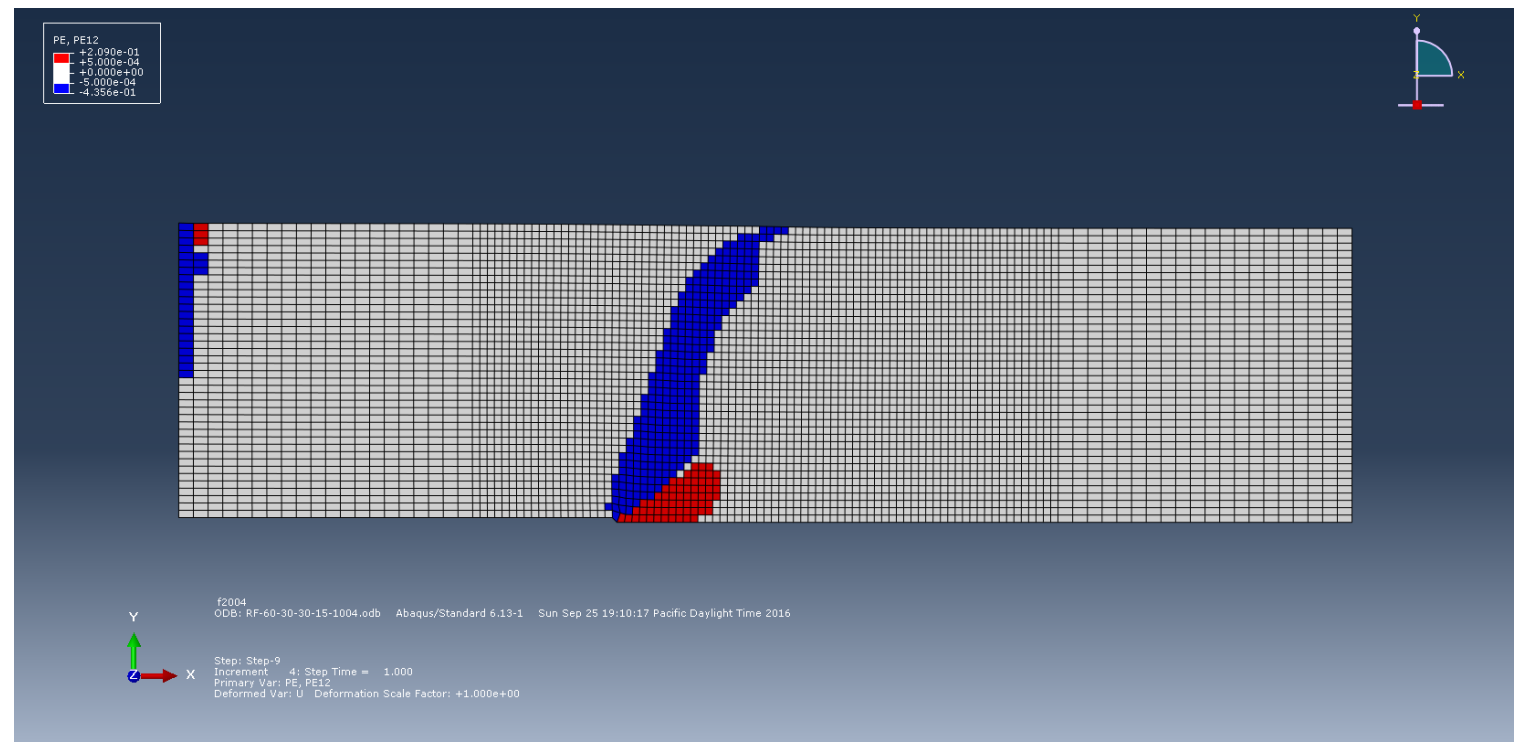

Figure 5.42: Friction Angle $30^{\circ}$, Density $4 \frac{\mathrm{kg}}{\mathrm{m}^{3}}$

Figures $5.43-5.45$ show that for a given soil, varying Density affects the near surface yield strain slightly. The yield strains converge by a depth of 10 meters for the soils studied.

Overburden stress is dependent on the density of the soil profile. Because Mohr-Coulomb relies on a deviatoric stress, near surface overburden of soils with smaller densities would generate a small deviatoric stress leading to a very small yield surface. The effect of overburden stress to the yield strain of soil decreases exponentially with depth as deviatoric stresses increase. 


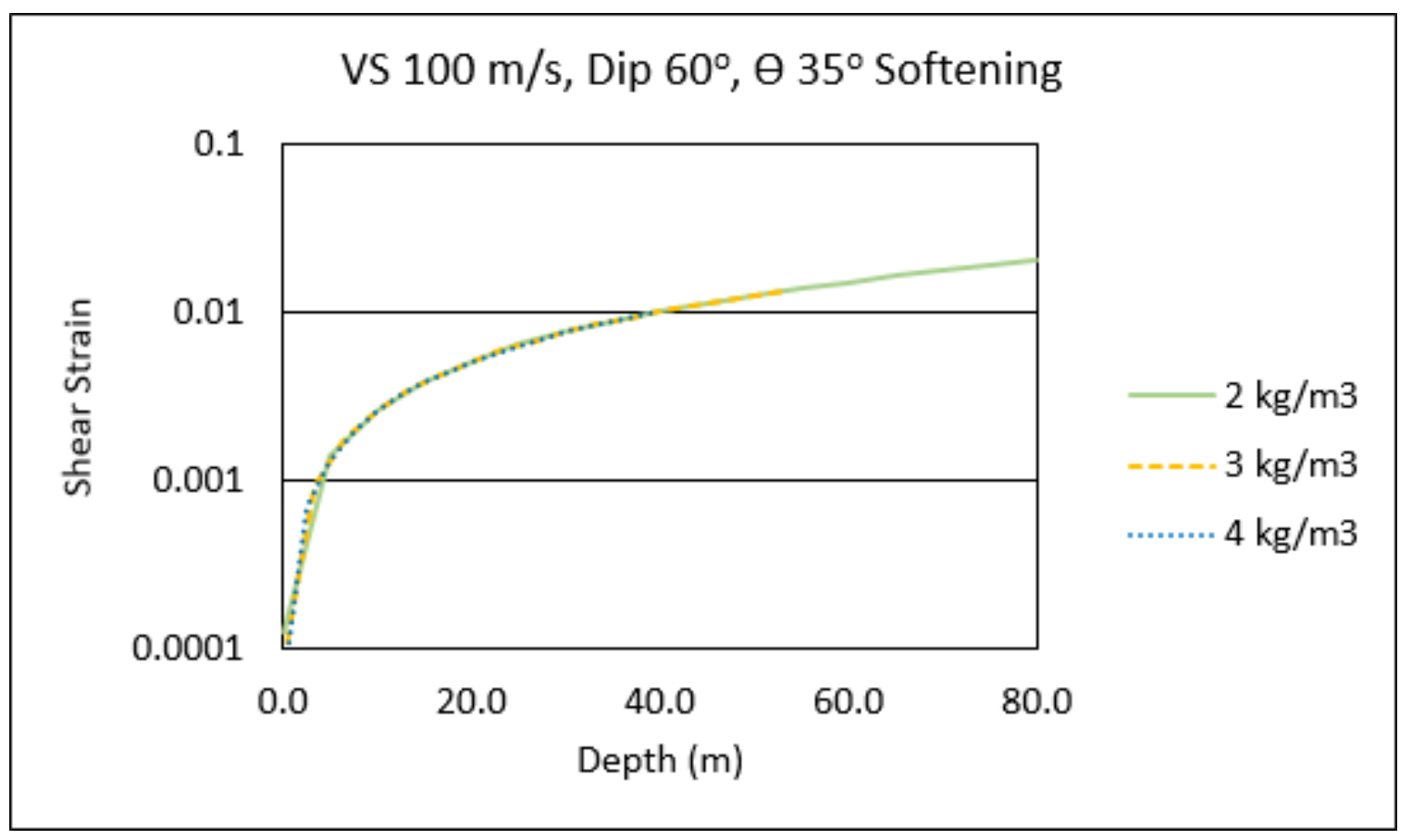

Figure 5.43: Failure Envelops for Softening $100 \frac{\mathrm{m}}{\mathrm{s}^{2}} \mid 2-4 \frac{\mathrm{kg}}{\mathrm{m}^{3}}$

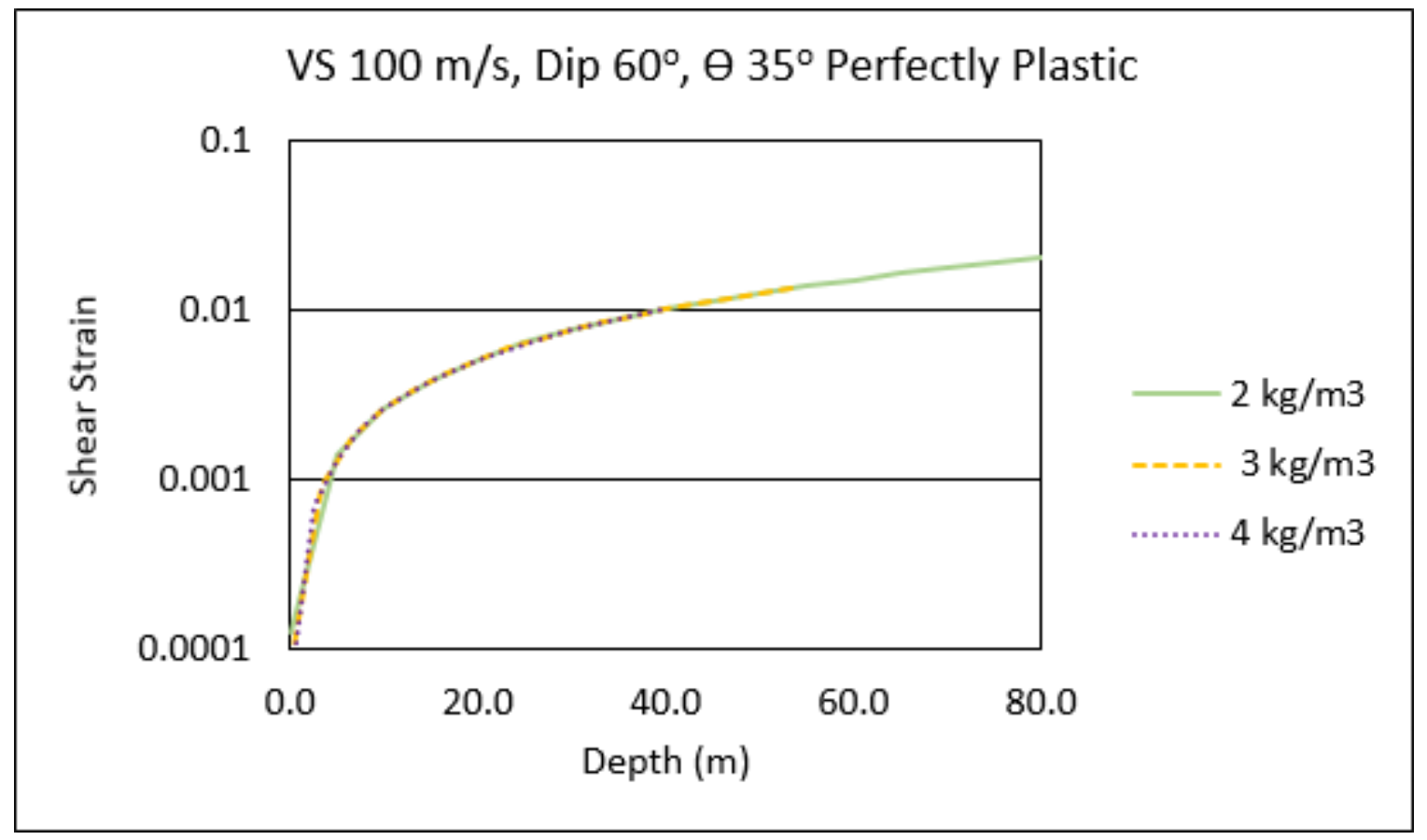

Figure 5.44: Failure Envelops for Perfectly Plastic $100 \frac{\mathrm{m}}{\mathrm{s}^{2}} \mid 2-4 \frac{\mathrm{kg}}{\mathrm{m}^{3}}$ 


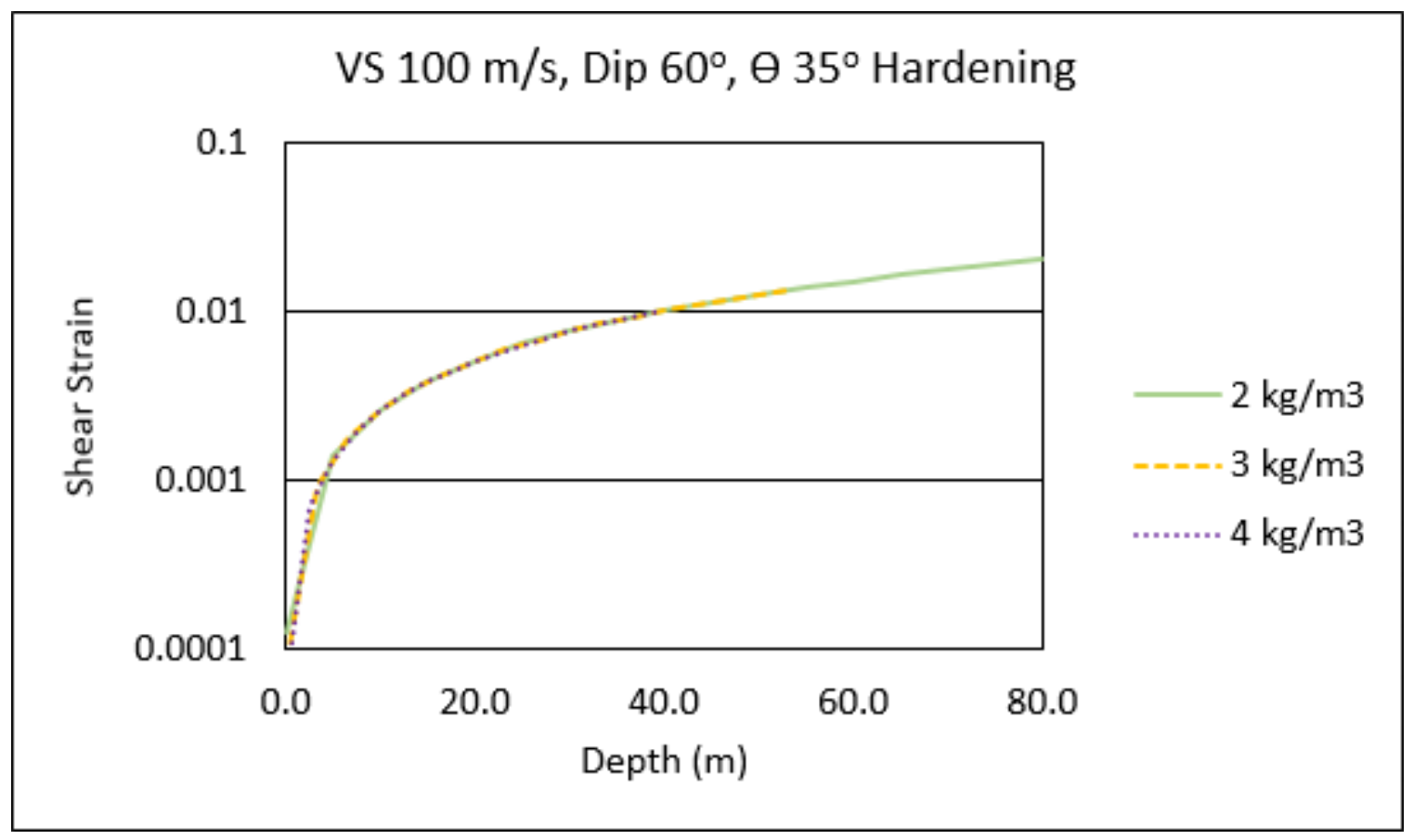

Figure 5.45: Failure Envelops for Hardening $100 \frac{\mathrm{m}}{\mathrm{s}^{2}} \mid 2-4 \frac{\mathrm{kg}}{\mathrm{m}^{3}}$ 


\section{CONCLUSION}

\subsection{Parameters Affecting Rupture Propagation}

Past empirical case studies [6] have evaluated field evidence of reverse rupture events and noted that the rupture plane is limited to a narrow band, with soils classified as brittle tending to have less normalized basal displacement required to achieve surface rupture than soils classified as ductile. This trend has been supported by numerical and fault box studies ( [4] [11] [7] [14] [10] [24]).

The case studies evaluated by [2] show an increased likelihood of fault rupture for a given earthquake magnitude of reverse events for soils with a higher shear wave velocity. Their study focused on a bulk parameter for soils in place of classical geotechnical parameters (e.g. $\theta$, $\rho, c$, etc.).

This study examined the soil material properties that affect the failure and post failure behavior of soil, as well as the elastic properties that affect shear wave velocity.

In soils, ductility relates to the materials ability to sustain large strains (relatively), without a significant drop in strength. The drop in strength is usually the result of a rupture or formation of a shear band of soil whose stiffness is much lower than that of the surrounding material.

The brittle/ductile behavior is therefore a property of the soil body under its current stress state and loading scheme and not the particular constitutive theory because the size of the yield surface in soils is also dependent on $I_{1}$.

Soils which strain soften post yield are classified brittle since they are unable to sustain additional load post yield, while soils which strain harden are classified as ductile since they are able to sustain additional load post yield. The results show, that like the previous studies have posited brittle soils require less normalized basal displacement to achieve surface rupture than ductile soils. 
Further, soils which strain soften have a narrower shear band; as the basal rock continues to displace, the soil along the rupture plane is more likely to continue yielding as the size of the yield surface continues to shrink and the un-yielded sections to the sides of the rupture plane have a larger yield surface and are more likely to remain elastic. Ductile soils are more likely to yield the material surrounding the rupture plane as the soil along the rupture plane will harden and have a yield surface larger than the surrounding soil, leading to a wider shear band.

When investigating the effect of shear wave velocity on fault rupture propagation, regardless of the parameters influencing shear wave velocity, increasing shear wave velocity increases the rate of rupture propagation. The range of Poisson's ratio and density of soil is fairly small compared to shear modulus, so increasing shear wave velocity implies increasing shear modulus. For earthquake fault rupture problems, this translates to a steeper stress/strain curve, so less basal displacement is required to achieve initial yield.

Although the post failure behavior (softening/hardening) affects the rate of rupture propagation and likelihood of rupture, the more significant contribution comes from the soil's elastic stiffness, which shear wave velocity serves as a suitable proxy for. Therefore, the numerical simulations of this study support the empirical studies of [2], which show a higher likelihood of surface fault rupture for soils with higher shear wave velocities.

\subsection{Future Work}

The numerical simulations in this study are limited by the existing validated constitutive models. More sophisticated simulation techniques such as discrete element methods [25] [26], multiscale methods [27], or simply more advanced elastic/plastic constitutive models for FEA such as [18], could be used to validate the results presented in this study as well as increase the potential for site specific simulation of earthquake rupture events. 


\section{REFERENCES}

[1] A. E. Alquist and P. V. Priolo, Alquist-Priolo State Special Studies Zone Act, 1972.

[2] R. E. S. Moss, K. V. Stanton and M. I. Buelna, "The impact of material stiffness on the likelihood of fault rupture propagating to the ground surface," Seismological Research Letters, vol. 84, pp. 485-488, 2013.

[3] M. Tolga Yilmaz and R. Paolucci, "Earthquake fault rupture shallow foundation interaction in undrained soils: a simplified analytical approach," Earthquake engineering I\& structural dynamics, vol. 36, pp. 101-118, 2007.

[4] I. Anastasopoulos, "Fault rupture--soil--foundation--structure interaction," 2005.

[5] J. D. Bray, R. B. Seed and H. B. Seed, "Analysis of earthquake fault rupture propagation through cohesive soil," Journal of Geotechnical Engineering, vol. 120, pp. 562-580, 1994.

[6] J. D. Bray, R. B. Seed, L. S. Cluff and H. B. Seed, "Earthquake fault rupture propagation through soil," Journal of Geotechnical Engineering, vol. 120, pp. 543-561, 1994.

[7] J. W. Lee and M. Hamada, "An experimental study on earthquake fault rupture propagation through a sandy soil deposit," Structural Engineering/Earthquake Engineering, vol. 22, pp. 1S--13S, 2005.

[8] D. A. Cole Jr and P. V. Lade, "Influence zones in alluvium over dip-slip faults," Journal of Geotechnical Engineering, vol. 110, pp. 599-615, 1984.

[9] P. V. Lade, "Elasto-plastic stress-strain theory for cohesionless soil with curved yield surfaces," International Journal of Solids and Structures, vol. 13, pp. 1019-1035, 1977.

[10] W. H. Roth, R. F. Scott and I. Austin, "Centrifuge modeling of fault propagation through alluvial soils," Geophysical Research Letters, vol. 8, pp. 561-564, 1981. 
[11] M. F. Bransby, M. C. R. Davies and A. E. Nahas, "Centrifuge modelling of normal fault-foundation interaction," Bulletin of Earthquake Engineering, vol. 6, pp. 585-605, 2008.

[12] D. M. Potts, G. T. Dounias and P. R. Vaughan, "Finite element analysis of the direct shear box test," Geotechnique, vol. 37, pp. 11-23, 1987.

[13] G. T. Dounias, D. M. Potts and P. R. Vaughan, "Finite element analysis of progressive failure: two case studies," Computers and Geotechnics, vol. 6, pp. 155-175, 1988.

[14] D. Loukidis, G. D. Bouckovalas and A. G. Papadimitriou, "Analysis of fault rupture propagation through uniform soil cover," Soil Dynamics and Earthquake Engineering, vol. 29, pp. 1389-1404, 2009.

[15] T. Schanz, P. A. Vermeer and P. G. Bonnier, "The hardening soil model: formulation and verification," Beyond 2000 in computational geotechnics, pp. 281-296, 1999.

[16] R. Guo and G. Li, "Elasto-plastic constitutive model for geotechnical materials with strainsoftening behaviour," Computers and Geosciences, vol. 34, pp. 14-23, 2008.

[17] C. S. Desai, S. Somasundaram and G. Frantziskonis, "A hierarchical approach for constitutive modelling of geologic materials," International Journal for Numerical and Analytical Methods in Geomechanics, vol. 10, pp. 225-257, 1986.

[18] M. Wang and J. Yang, "Three Dimensional Implementation of HISS Model in ABAQUS," in Constitutive Modeling of Geomaterials, Springer, 2013, pp. 771-781.

[19] X. Liu, X. H. Cheng, A. Scarpas and J. Blaauwendraad, "Numerical modelling of nonlinear response of soil. Part 1: Constitutive model," International journal of solids and structures, vol. 42, pp. 1849-1881, 2005.

[20] I. Anastasopoulos, G. Gazetas, M. F. Bransby, M. C. R. Davies and A. El Nahas, "Fault rupture propagation through sand: finite-element analysis and validation through centrifuge 
experiments," Journal of Geotechnical and Geoenvironmental Engineering, vol. 133, pp. 943-958, 2007.

[21] S. Dassault, "ABAQUS User's Theory Manuals - Release 6.13-1," Providence, RI, USA, 2013.

[22] H. B. Muhlhaus and I. Vardoulakis, "The thickness of shear bands in granular materials," Geotechnique, vol. 37, pp. 271-283, 1987.

[23] R. W. Ogden, Non-linear elastic deformations, Dover Publications, 1997.

[24] K. V. Stanton, "Investigation of Parameters Influencing Reverse Fault Rupture Propagation to the Ground Surface," 2013.

[25] J. M. B. T. C. C. R. K. a. C. G. Ting, "Ting, John M., et al. "Discrete numerical model for soil mechanics.," Journal of Geotechnical Engineering, vol. 115, no. 3, pp. 379-398, 1989.

[26] D. N. E. G. H. Y. M. \&. G. J. Zhao, "Three-dimensional discrete element simulation for granular materials," Engineering Computations, vol. 23, no. 7, pp. 749-770, 2006.

[27] T. M. a. J. D. F. Evans, "Evans, T. Matthew, and J. David Frost. "Multiscale investigation of shear bands in sand: physical and numerical experiments," International Journal for Numerical and Analytical Methods in Geomechanics, vol. 34, no. 15, pp. 1634-1650, 2010.

[28] D. Sheng, A. Gens, D. G. Fredlund and S. W. Sloan, "Unsaturated soils: from constitutive modelling to numerical algorithms," Computers and Geotechnics, vol. 35, pp. 810-824, 2008.

[29] R. D. Holtz and W. D. Kovacs, An introduction to geotechnical engineering, Pearson, 1981.

[30] J. D. Bray, R. B. Seed and H. B. Seed, The effects of tectonic movements on stresses and deformations in earth embankments, Earthquake Engineering Research Center, University of California, 1989. 